\title{
SHITHSONIAN
}

LIBRARIES 


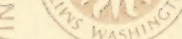

$\sum_{i=1} 1$ NinOSHN

ION NOILOLILSNI NVINOSHLIWS SJI Y

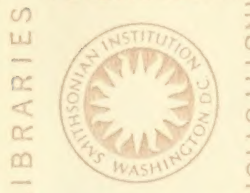

IIBRARIES

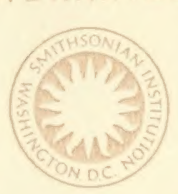

NOIINLILSNI

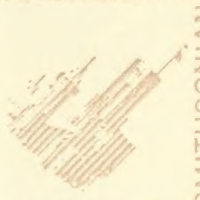

IIBRARIES

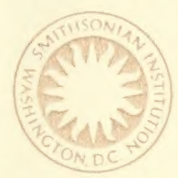

NOIIOHUSNI

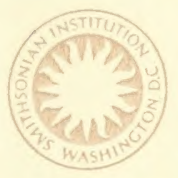

LBRARIES
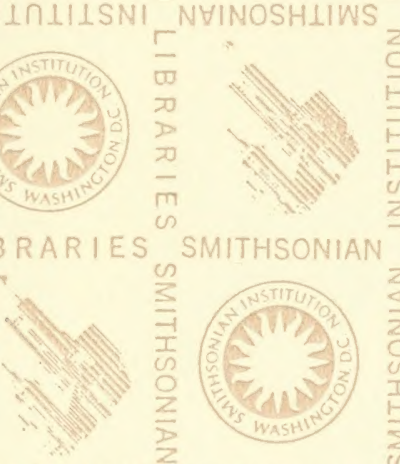

NOILOIIISNI
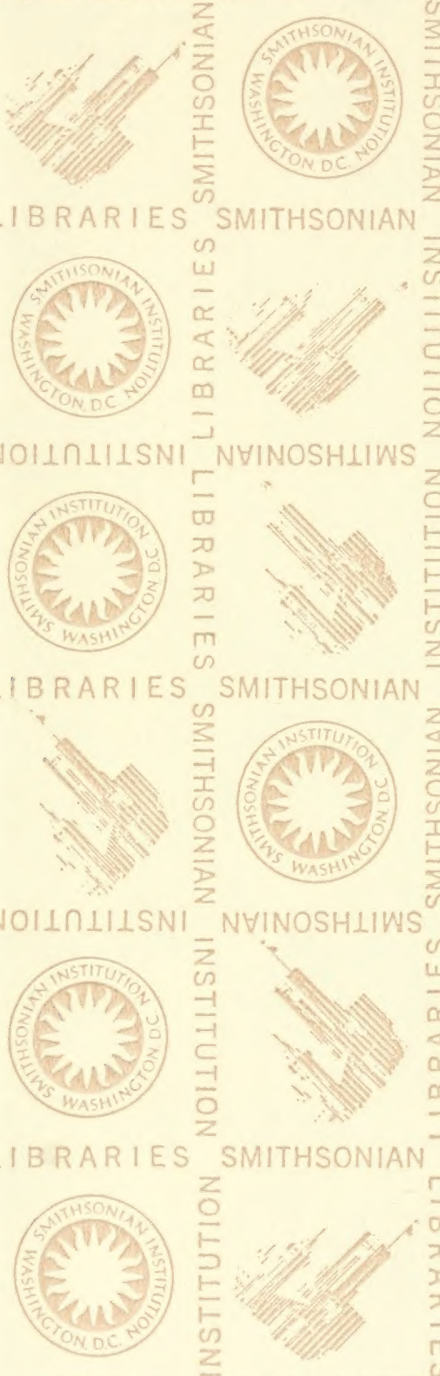

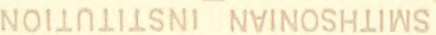

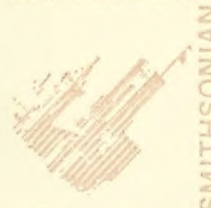

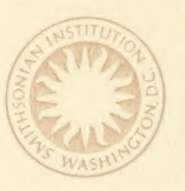
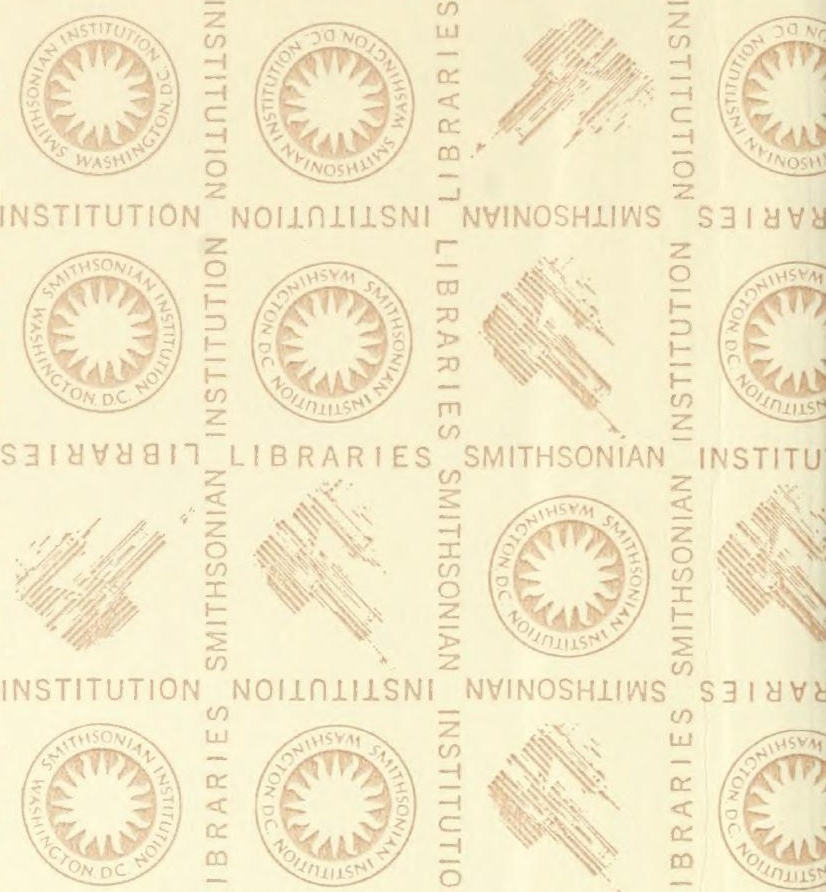

LIBRARIES

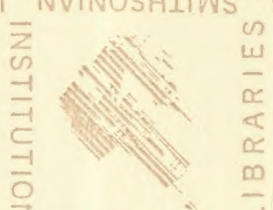

$\exists I \forall \forall \measuredangle$
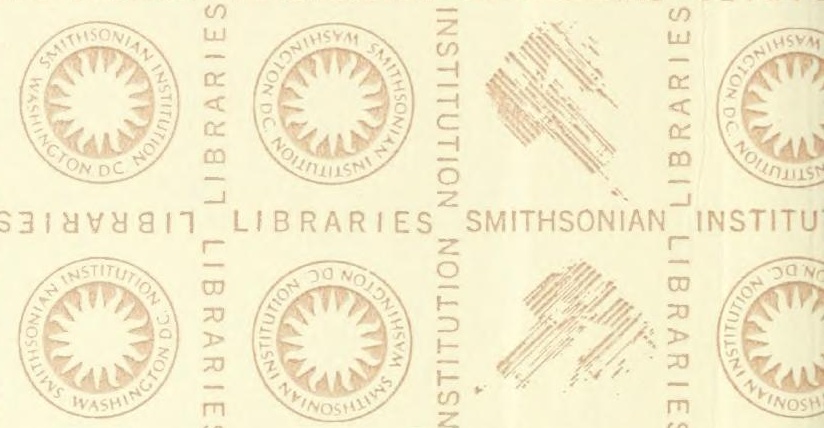

INSTITUTION NOIINIIISNI
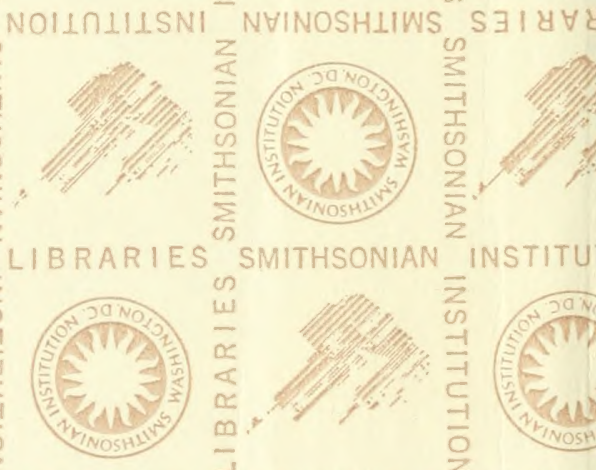

INSTITU
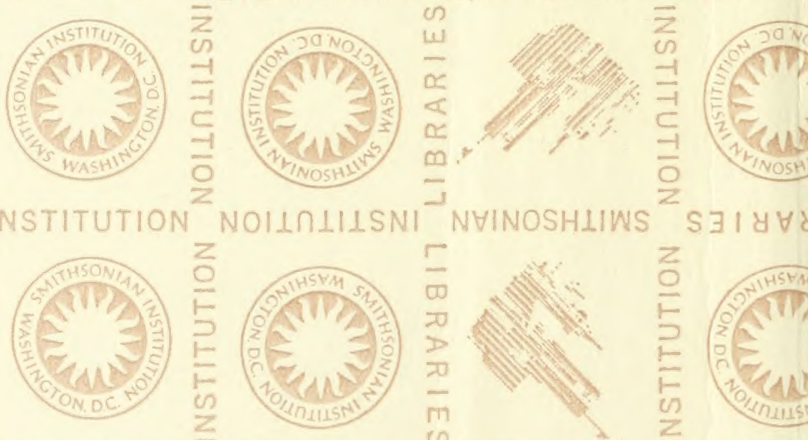
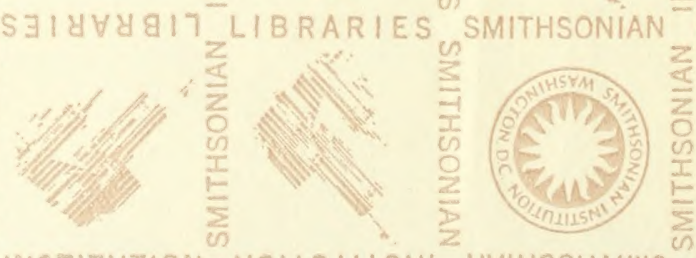





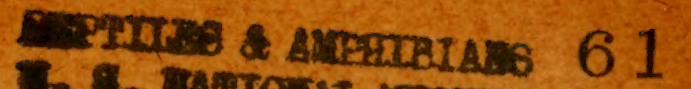

1919

Pephi

ANNALS OF THE NEW YORK ACADEMY OF SCIENCES

Vol. XXVIII, pp. $51-166$, pll. I-XIII

JAWES A. PETERS

Editor, RALPH W. TOWER

RECVD

CAT

BY

LEVERETT ALLEN ADAMS

A MEMOIR ON THE PHYLOGENY OF THE

JAW MUSCLES IN RECENT AND

FOSSIL VERTEBRATES

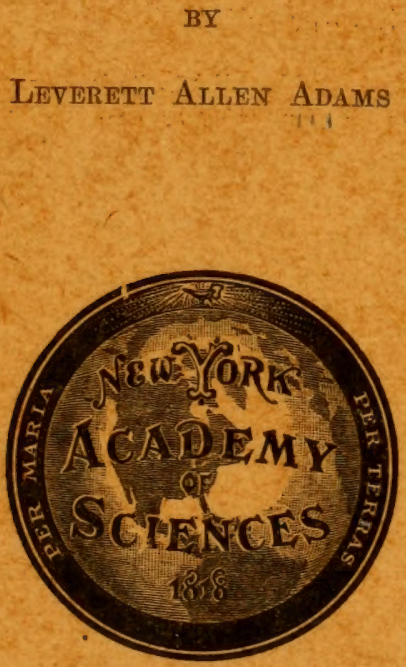

NEW YORK

PUBLISHED BY THE ACADEMY

15 JANUARY, 1919 


\section{THE NEW YORK ACADEMY OF SCIENCES}

(Lyceum of Natural History, 181\%-18\%6)

\section{- OfFICERS, 1919}

President-Ernest Ellsworth Smith, 50 East 41st Street Vice-Presidents-George B. Pegram, Frank H. Pike, Edmund 0. Hovey, Pliny E. Goddard Corresponding Secretary-Henry E. Crampton, American Museum Recording Secretary-RALPH W. Tower, American Museum Treasurer-Јонм TATLock, 37 Wall Street Librarian-RALPH W. Tower, American Museum Editor-RaLPH W. Tower, American Museum

\section{SECTION OF ASTRONOMY, PHYSICS AND CHEMISTRY}

Chairman-George B. Pegram, Columbia University Secretary-K. GeoRge FALK, Harriman Research Laboratory, the Roosevelt Hospital

\section{SECTION OF BIOLOGY}

Chairman-Frank H. Pike, College of Physicians and Surgeons Secretary-William K. Gregory, American Museum

\section{SECTION OF GEOLOGY AND MINERALOGY}

Chairman-Edmund 0. Hover, American Museum Secretary-Crrírles C. Mook, American Museum

$$
\text { SECTION OF ANTHROPOLOGY AND PSYCHOLOGY }
$$

Chairman-Pliny E. GodDard, American Museum Secretary-Robert H. Lowie, American Museum

The sessions of the Academy are held on Monday evenings at 8:15 o'clock from October to May, inclusive, at The American Museum of Natural History, 7\%th Street and Central.Park, West. 
[AnNals N. Y. ACAD. ScI., Vol. XXVIII, pp. 51-166, Pls. I-XIII.

15 January, 1919]

\title{
A MEMOIR ON THE PHYLOGENY OF THE JAW MUSCLES IN RECENT AND FOSSIL VERTEBRATES ${ }^{1}$
}

\author{
By Leverett Allen Adams
}

(Presented before the Academy, 8 March, 1915)

\section{CONTENTS}

Introduction . . . . . . . . . . .

Statement of the problem............................ 55

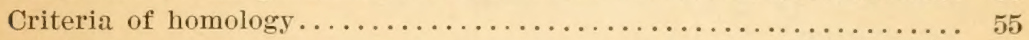

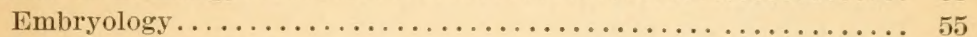

Nerve supply ............................... 56

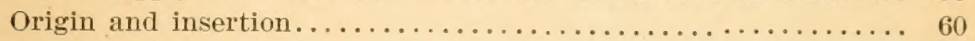

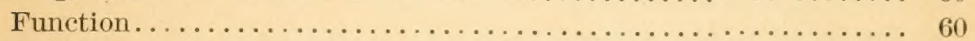

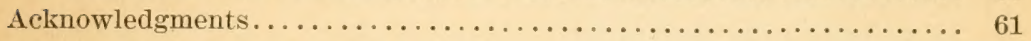

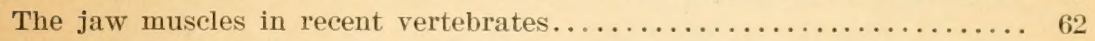

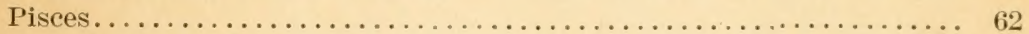

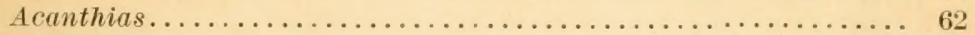

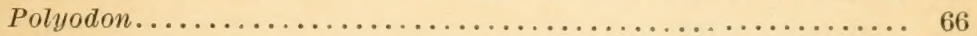

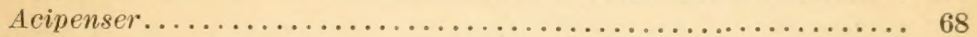

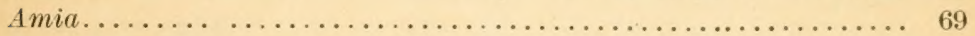

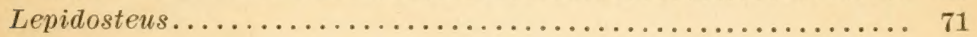

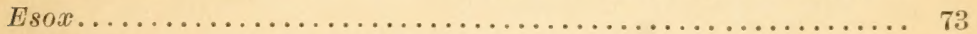

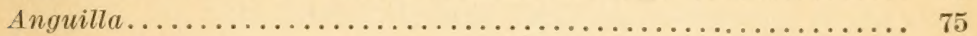

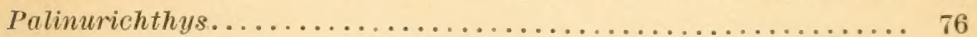

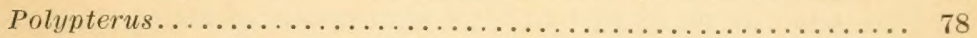

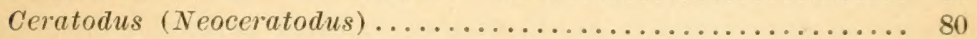

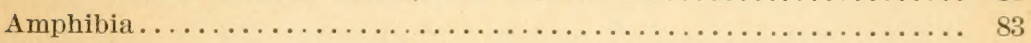

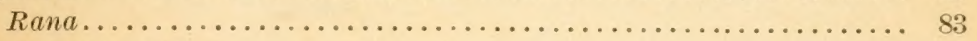

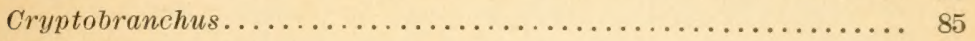

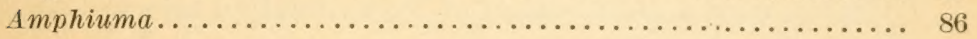

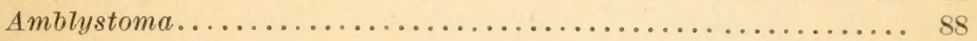

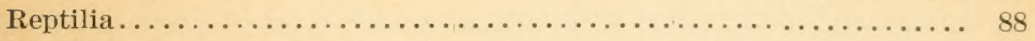

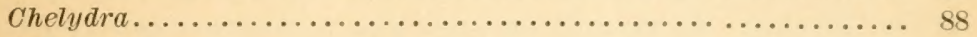

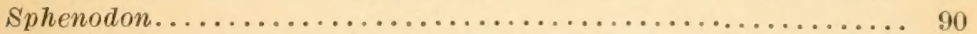

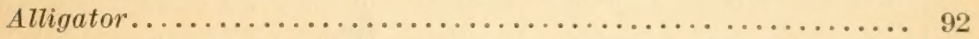

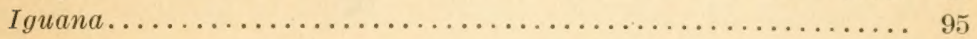

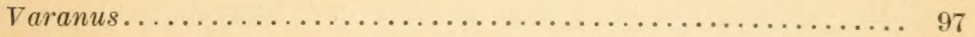

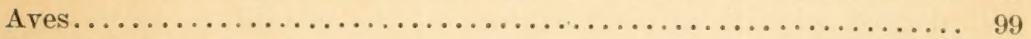

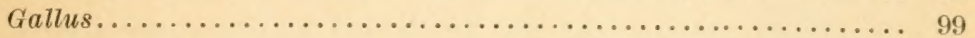

1 Studies in Comparative Osteology and Myology, No. 2, issued under the direction of Dr. William K. Gregory, Assistant Professor of Vertebrate Palæontology, Columbia University, and Research Associate, American Museum of Natural History. 
Mammalia ............................. 102

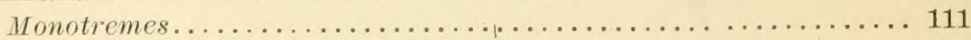

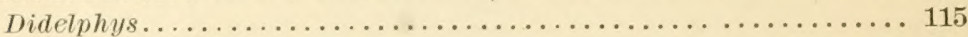

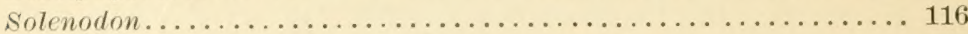

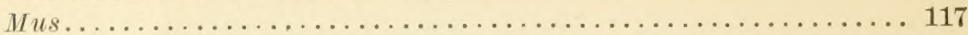

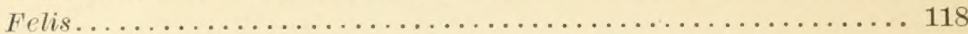

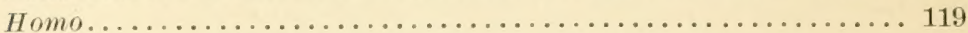

Reconstructions of the jaw museles in certain extinct vertebrates....... 120

Placodermi................................. 120

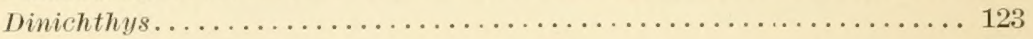

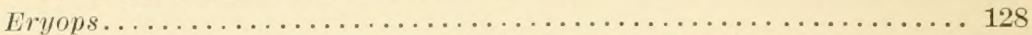

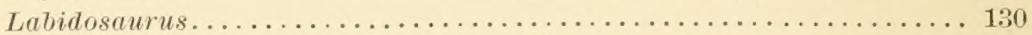

Tyrannosaurus............................... 132

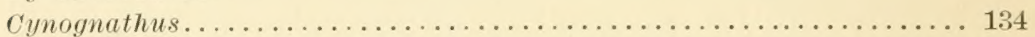

Homologies of the jaw muscles in vertebrates................ 137

Introduction. . . . . . . . . . . . . . . . . . . . . 137

Homology in the Pisces............................ 140

Homology in the Amphibia. . . . . . . . . . . . . . . . . . . 144

Homology in the Reptilia........................ 146

Homology in the Aves........................... 148

Homology in the Mammalia. . . . . . . . . . . . . . . . . . . . 149

General summary of homologies.................... 153

Relations of jaw muscles to the temporal fenestræ of reptiles...... 154

Tables I-V summarizing the homologies of the jaw-elements in Fishes,

Amphibia, Reptiles, Birds, Mammals and Vertebrates as a whole... 156 Bibliography .................................. 160

\section{INTRODUCTION}

This paper attempts first to trace the muscles of mastication from their origin in the primitive gnathostomes to their perfected development in the higher vertebrates and secondly to discover the co-adaptations of musculature and skull structure.

There has been a great neglect of the correlation between osteology and myology. Hundreds of monographs are at hand on both subjects, yet synthetic studies that deal with both and with their interrelationships are extremely rare. As muscle was no doubt in existence before bone, and as there is the closest relation between the two, we should naturally consider myology and osteology together instead of under separate heads.

Many monographs have been written on the myology of special forms, but usually with little consideration of the conditions to be found in related groups. Apart from the great work by Ruge on the seventh nerve, there have been few general surveys attempted. Ruge traced the facialis nerve and its musculature from the elasmobranchs to mammals, giving 
us one of the hest types of (onmparative work at present available. 'Toldt,

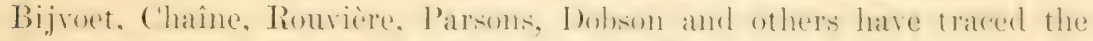
digastric muscle in the mammals, wiving homologies and trateing the muscle to its origin in the lower forms. 'The many writers on the muscles of special groups have used synonymous names and the nomenclature is far from clear at the present time. Many names for muscles are used in sperial cases that might well he changed to give a more miform sistem.

The influence of the musclature upon the crolution of the slieleton in rertehrates has also been neglected in most of the general workis on onmparative anatomy. Much has been written on the changes that have taken place in the shulls of the vertehrates, hut with ton little relerence to the muscles. The palæontologists and anatomists have traced the shiftings and (hanges of each bone in the skull so that the migrations of the hyomandibular and of the puatrate, for example, are known from the time when they appear as cartilages in the selachians to their final resting place in the mammalian ear. Thus during the last decade or two osteology has made great progress as an interpretative science. From the work done on the fosil forms the erolutionary histors of the skeleton is not neurly so obscure as it was a few decades ago. The structure of many of the fossil forms is being gradually worked out and some of the great vertebrate phylogenies are heing cleared up hy the rexent derelopments in palrentology and comparative anatomy. For example, the relatively (lose relationship between the reptiles and the amphibians is hecoming very clear, for the discovery of new Carboniferous forms has added much to our knowledge, so that more and more structures common to the two classes have been observed. The same applies to the relationship of reptiles and mammals. The recent discoveries in South Africa of a number of new cynodont reptiles have given much new light on the evolution of the mammals from the reptilian stock, so that great advances have been made in the early history of these relatively modern groups. Many morphological problems, such as the problem of the mammalian pterrgoid and its origin, of the ossicles of the ear, of the development of a new joint on the dentary, and its new articulation with the squamosal, have received illumination from the senthesis of palienntoleser and complatative

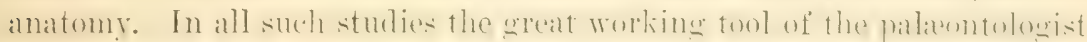
is comparative anatomy, as without it he is helpless to determine the relationships of the fossil forms, just as the student of modern forms is helpless if he attempts to work out the relationships of the morern fanmat without considering the maze of ancestral types that preceded them in the past. 'Thus the importance of the modern forms is demonstrated

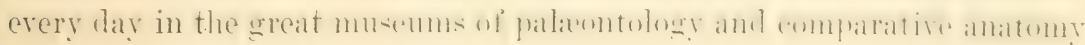


where many of the new discoveries are due to the synthesis of the study of present forms with those of the past, so that a department of palæontology should combine in its collections a complete series of the modern with the fossil forms, if correct interpretations are to be made of the fossil material.

The factor that has been most neglected has been the study of the myology along with the bony structure of the fossil forms. The bones of the skeleton should be studied not as independent elements, but as supports for the muscles that covered or were attached to them. The skull of an ophidian studied merely as an osteological specimen shows much in the way of specialization and peculiar development, but without the study of the motive power for which it furnishes the support the results are rather barren, as too much has been left out of consideration. It is like making a study of a complex series of levers without taking into consideration the forces that move them. A few papers and books do indeed consider the correlation of the bones and muscles in modern forms, especially man, such as Bardeleben (1903), Fick (190t-19101911), Strasser (1908). These studies on modern forms give the key for similar work on the fossils, as the principles of mechanics concerned hold throughout. Prof. W. K. Gregory (1912) has endeavored to correlate palientologry osteology and myology in his studies on the evolution of the limbs of recent and fossil ungulates. His discussion of the angle of insertion of the muscles upon the limb bones, in relation to power and spreed, hears upon the study of jaws and jaw muscles. Realizing the need of further studies of this kind, Dr. Gregory suggested that I should take up the prohlem of the evolution of the jaw muscles of rertebrates in relation to skull structure.

In this paper I have accordingly had before me the following aims: first, to follow the jaw muscles through a selected series of vertebrates ranging from shark to man and to express the essential facts in clear and semirliagrammatic drawings of uniform character and treatment, to facilitate comparison; second, to discover and summarize the homologous relations of the several jaw muscles throughout the series and thus attempt to clear up and harmonize the confusing synonymy due to varying systems of nomenclature founded on special types; third, to discover the adaptational relations between skull structure and musculature: fourth, to apply these principles to a reconstruction of the musculature in certain extinct vertebrates, especially those of great general phylogenetic importance in the different classes. 


\section{Statement of the Problem}

The problems of the musculature of the jaws and of the homology of these muscles throughout the rertebrates are of great potential importance in the future development of comparative anatomy. As the jaw muscles are concerned in all the movements of the skull and have developed with it, their influence in modifying the skull in the early history of the rertebrates is well worthy of detailed sturly. The jaw muscles also offer much of interest in their relation to the origin and evolution of the dentition and in the evolution of the mammalian sliull from the reptilian type. Such great themes as the origin of the mammalian auditory ossicles, the origin of the peculiar mammalian articulation of the mandible with the squamosal, the transformation of the reptilian jaw into the mammalian type, and the homology of certain skull bones in clifferent groups are also involved. The mechanical problems connected with the specialized jaw movements of some of the higher vertebrates are also interesting, especially in cases where the close relation of the jaw muscles and the specialized skull structures are readily discovered. The jaw muscles are also sometimes of value in testing relationships of closely relaterl groups, especially where specialization has not gone so far as to ohliterate all the primitive conditions, since with a few exceptions the arrangements of the jaw muscles are remarkably constant in fundamental characters in each of the vertebrate classes.

\section{Criteria of Homology}

The problem of homolugy in the muscular system is a most difficult one, as the muscles are rery unstahle elements, giren to shifting their positions, splitting up into fragments, and combining with other elements like themselves.

There are four tests that mar be applied to a muscle to determine its possible homology with a similar muscle in another animal: (1) embryologr, (2) nerve supply, (3) origin and insertion, (4) function. If all of these agree there is great prohability that the homology assumed is correct.

\section{EMBRYOLOGY}

Fimbrolngy is lelpful in determining origins and in giving a clew, at least, to the relations of the muscle. Keibel and Mall (1910) in their Iuman Embryolug show that primitire relationships are evident in cer- 
tain early stages of development. 'They describe the origin of the human jaw muscles that are imnervated by the fifth nerve as follows:

In the 7 mm. embryo the mandibular arch is filled with a closely packed mesenchyme, with only slight traces of condensation about the peripheral end of the mandibular nerve. In the $9 \mathrm{~mm}$. embryo, however, this condensation is clearly to be recognized. This peripheral mass, in which the $\mathrm{N}$. mandibularis ends, lies at about the middle of the arch. In a $11 \mathrm{~mm}$. embryo, this eggshaped pre-muscle mass has increased in size but still shows no indications of splitting into the various muscles. The pre-muscle is, from the beginning, closely associated with the condensed mesenchyme of the mandible, and with the differentiation of the proximal end of the mandible, the pre-muscle mass is partially split into a I-shaped mass, the handle representing the M. temporalis, the outer limb corresponding to the M. masseter, and the inner, deeper limb, separated from the outer by the proximal end of the mandible, representing the mass for the Nm. pterygoidei externus and internus.

'Thus it is seen that all these jaw muscles arise from the same group.

The relations of the jaw muscles to the body muscles as a whole are as follows: In the early stages of the vertebrate embryo the myotome is a hollow body with a splanchnic inner layer and an outer or somatic layer. This motome grows down until it almost meets its fellow on the opposite side, the two remaining separated from each other by a connective tissue septum, the linea alba of the fishes. The myotome is also divided by a longitudinal line of connective tissue that follows along the lateral line of the fishes and the urodeles and divides the myotome into a dorsal or epaxial epimere and a ventral or hypaxial hypomere. The muscles of the body are acombling divided into three sromp-appendicular, axial and viseral. The appendicular muscles take their origin from the axial, and both in turn are derived from the dorsal or epaxial (epimere) part of the myotome. The visceral muscles, including those of the head region, are derived from the ventral or hypaxial portion of the myotome (hypomeres). (Wilder, 1909, p. 190.) The visceral or hypaxial muscles of the head region are further divided into a dorsal and a ventral series according to their position as depressors or levators of the gill arches.

\section{NERYE SUPILY}

The primitive innervation of the myotomes in Amphioxus is shown by Goolrich (1909, p. 2). The myotomes are supplied by the ventral roots of the serial nerves, the dorsal roots passing between the myotomes to supply the skin and the sensory nerres. The dorsal and ventral roots wf the seral nerveremain separate. Rewarling the innervation of trpical rertebrates Goodrich $(1909, \mathrm{p} .3)$ says : 
It is important to notice that while the myotomes and the muscles derived from them (such as the limb muscles) receive their motor nerves exclusively from the ventral roots of the spinal nerves, the splanchnic muscles, the skin, the mucous membrane and their sense organs are supplied by the dorsal, ganglionated roots.

'The embryology of Petromyzon, Amphioxus and the fishes gire some very illuminating evidence of the evolution of the muscular and the nervous system in the early vertebrates, and from them we may get a better understanding of the muscles and serial nerves of the higher vertebrates. 'Thus a study of the embryology gives much aid in tracing the homology of the capitimandibularis muscle in the reptiles, where it is an undifferentiated mass, as in the embryo of man. Again the problem of the

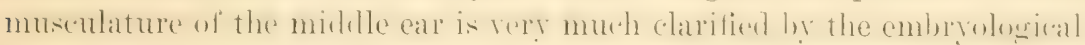
investigations of Gaupp, Versluys, Fuchs and other students of the ear, where the development gives an explanation of the origin of these elements.

As the nerves and muscles start out together very early in the life of the embryo, the nerve supply has always been taken as one of the best tests of homology. It is almost an axiom in comparative anatomy that a muscle is always followed by its nerve, and while in most cases this is true, it is occasionally not true. The stapedius muscle of the middle ear illustrates the constancy of the nerve supply. This muscle is followed from its position as a levator of the hyoid arch through many changes to its final resting place in the middle ear, with the innervation by the facialis remaining constant. The tensor tympani muscle also represents a slip of the reptilian pterego-mandibularis that has shifted to the mishle. ear. The facialis in its migration from the hyoid arch over the face gives another fine example of the constancy of the nerve supply to the muscle. In man the platysma, sphincter colli and facial muscles of the eye, nose and mouth have migrated from their original position on the side of the neck to the most anterior portion of the face. In this case the seventh nerve has orerlappent the territory of the trigeminus and the serial nerves anterior to it, while the muscles of the fifth nerve have remained in their original position. 'The pectoralis and latissimus dorsi muscles of man give another example of shifting muscles that carry their nerves with them. They shift from their original position to cover large areas of the trunk that were formerly innervated by the several serial nerves of the myotomes. In the external oblique of man and the rectus abdominis there is a fusion of the elements, their originally sepatrate condition hering shown by their nerve supply.

The digistrie is also a musele with a double nerve sulphly and is rery 
probably a muscle with a double origin, since it originally has two bellies, the anterior innervater by the fifth nerve and the posterior belly by the seventh.

In spite ol' some sereming contradictions, the nerves offer the best means of letermining homoloyies in the muscles. Wilder (1909, p. 196) says:

Were it possible to follow each motor nerve fiber from its origin to its connection with its muscle, it would probably serve as an absolute criterion for muscular homology, but there is a chance for error in the fact that an anatomical nerve is not a single fiber, but a bundle of them, and while each fiber is presumably constant in its supply, there is some rariation in the way in which they are put into bundles, so that no one can be sure that a given nerre is quite homologous with one in a like location in another animal.

Most anatomists agree with Wilder's statement of the case. We may suppose that these changes of the contents of the bundle are responsible for some of the examples of apparent non-homology that often occur in animals that are closely related. We may assume that in the original condition of the rertehrates the myotomes were placed in regular order and each mrotome was supplied with a serial nerve. With the gradual changes that took place in development the higher vertebrates disguised the metameric arrangement until only slight remnants of them remain in a few muscles like the obliquus externus of man. The myotomes are evident through the fishes and tailed amphibians, but are not so erident in the reptiles and mammals. The elements of certain of the myotomes usurped the position of the others and developed into the larger muscles of the trunk, carrying with them their original nerres, thereby destroving the primitive arrangement.

In a paper by D. J. Cunningham (1891) the problem of nerve and muscle is very carefully considered. He considers the nerve supply a good guide but not an infallible one. He says that a solution of the problem can only be obtained by approaching the question from two points of view : first, by studying the early connections which exist between the nervous and the muscular system in the embryo; second, by examining one or more groups of muscles, the homologies of which are undoubted, in a large series of animals or in a large number of indirichuals of the same species, and observing whether in every case the nerves of supply are the same.

In many cases the nerves are found fusing into a plexus. Cunningham's paper favors the view that the same ganglion cells are invariably connected with the same muscle fibers, but that the fibers may adopt a different path and thus reach their connection through another route. This seems incapable of proof, but it is a good working hypothesis. IIe 
mentions two cases worked out by Sir William Turner where the Iong buceal nerve proceeded from the superior instead of the inferior maxillary of the filth nerve. If also gives some observations of his own on Elephes, IIyrax, and Castor, where the intermal plantar nerve invales the territory of the external plantar and seizes upon muscles which usually do not belong to it. In the fox-bat the opposite occurs and the extermal plantar lays hold upon a muscle which under typical conditions is controlled by the internal plantar. This piracy of the nerve terminals finds its analogue in the eapture of branches of the carotid, as described by Tandler. This may well be considered a changing of the paths of the fibers and not a change of the ganglionated cells and of the musele fibers. In the case of certain muscles of doubtful homology in Ornithorlhynchus Ruge has shown a substitution of the nerve supply from a different plexus from that which supplies the supposedly homologous muscles in other mammals. He solves the problem by deciding that the muscles concerned are not homologous.

Gadlow gives some cases of truly homologous muscles being supplied in different types by a different plexus. He shows that, in Iguana, the ischio-femoral.muscle is supplied hy the ischiadic plexus; that in the Crocodile it is supplied by another nerve, the obturator; while in Tarmus it is supplied by both. In placental mammals the adductor magnus is innervated by two nerves, one from the obturator nerve and one from the sacral plexus. In marsupials the adductor magnus is supplied solely by the sacral plexus.

Cumningham offers the following possible explanations of these anomalies:

(1) Complete obliteration, and then complete reconstruction of both nerves and muscles, the muscle assuming its old origin and insertion.

(2) Retention of both nerve and muscle elements but the adoption of new and more convenient paths.

(3) A retention of the muscular elements but a substitution of new nerre elcments.

He rejects the first, does not give much consideration to the third and seems to agree with Fiirbringer "that the nerve supply is the most important and indispensable guide but is not infallible."

Goodrich (1909, p. 82) concludes that, "in a series of metameric myotomes and nerves each motor nerve remains, on the whole, faithful to its myotome throughout the vieissitudes of phylogenetio and ontogenetic modifications."

In the case of the jaw muscles experience shows the wreat importance of the nerve supply in determining the homologies of muscles. 


\section{ORIGIN AND INSERTION}

The orisin and insertion of the muscles must be taken into consideration in the letermination of their homologies, but as some of the skeletal "lements shilt and drop out in the rlifterent classes, this criterion must be used with care in cases where the animals compared are not closely related.

The known changes and disappearance of the bones of the skull as we pass from Palwozoic to modern vertebrates suggest that, if the supposed homology of a muscle is based on the origin and insertion, the history of the bone to which it is attached must he known and completely traced: for example, in tracing the changes that have talien place in the ranodeling of the ryodont skull, in its crolution into the mammalian type, there is difficulty in following the origin and the insertion of certain murcles, as the shifting of hones is so marked in the jaw region that some muscles have changed their origin and insertion and some have Aropped out and been replaced by slips from neighboring muscles. Although it seems reasonahle to infer that muscles became readapted. ret if there was a mechanical or other reason for the dropping out of a muscle we may assume that a new slip was separated from another muscle that filled the requirements of the new function. Great changes from the primitive reptilian type must have taken place in the line leading to Cynognathus, Gomphognathus and Sesamodon. The posterior end of the dentary increased in importance and the coronoid process of the dentary gradually orershadowed the posterior end of the mandible as an attachment for muscles, so that muscles formerly attached to the surangular and to other posterior bones of the jaw moved forward and acquired an attachment on the upgrowing coronoid process. Finally the reluced muscles of the movable ptergoid of the reptiles must have shifted, disappeared or possibly be left as remmants such as the pterygospinosus of the erlentates or the pteryou-tympanic that is sometimes found in man.

\section{FUNCTION}

The jaw muscles are on the whole remarkably stable throughout the vertebrates with minor adaptive changes. The larger muscle masses can be traced through the different classes, but some of the minor slips must be followed closely in their development through a number of forms if the homology is to be certain. The history of the changes of function can be traced from their innervation and their relation to their supports. 'Tlue facr that ther are derived from the visceral muscle system indicates 
that they arose as museles for contrating and dilating the gill openings, drawing in water antaining ford and oxyen, and finally that they were used in suapping at prey (Gregory, 1915). The preclatory habits of the primitive fishes were responsible, it is believed, for the change of the gill muscles into true jaw muscles. Even in mammals the muscles are still intimately related with the brambial arehes. with the tomene and even with the ear. The point of attachment and the function of a mus-

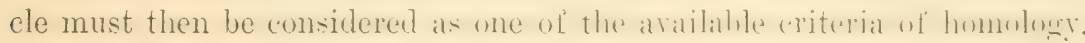
This should always be considered when the history of the boue to which the muscle is attacherl has heen thoroughly studied through a mumber of classes and when also its developmental history is certain.

Neomorphs have often arisen as slips from some of the muscles; muscles frequently have split up into slips that eventually have become separate and taken a part of the parent nerve with them as in the pterygoids of the mammals. We have numerous examples of this splitting: for example, the derivation of the anterior belly of the digastric of mammals from the mylohyoid, or the subdivision of the "adductor mass" into numerous slips in Amia. If this splitting is carried further and the slips separate. it hecomes arrespmolingly more liftienlt to trater their homology.

\section{Acknowledgatents}

This work has been carried on in the Department of Vertebrate Palæontology at the American Museum of Natural History, under the general direction of Professor W. K. Gregory, from whom the author has constantly received critical suggestions and helpful advice. I am also grateful to Professor R. C. Osburn for the loan of private material used in a part of the work on the teleosts; and to Mr. J. T. Nichols for other specimens of fish needed in the teleost series. To Dr. L. Hussakof my thanks are due for his placing at my disposal numerous specimens from the collection of Arthrodira in the Department of Ichthyology. Finally, in common with many other investigators, I am mindful of a larger debt to the American Museum of Natural History for liberty to use its extensive resources.

A series of 26 existing types of vertebrates has been dissected as follows: Elasmobranchii 1, Chondrostei 2, Holostei 1, Teleosti 3, Crossopterygii 1, Dipnoi 1, Urodela 3, Anura 1, Chelonia 1, Rhyncocephalia 1, Lacertilia 2, Crocodilia 1, Ares 1, Mammalia \%. In each case special attention has been paid to the innervation of the muscles as a guide to homologies. By means of these data, and of the principles that became apparent as the work proceeded, reconstructions of the jaw musculature 
Were attempoterl in the following series of extinct forms: Dinichthys (Arthrolira), Eryops (Temmospondyli), Lalidosaurus (Cotylosauria), Tyrannosaums (Theropoda), Cynognathus (Cynodontia).

\section{THE JAIT MUSCLES IN RECENT VERTEBRATES}

\section{Pisces}

\section{ACANTHIAS}

I'late I, Figs. 1, 2

The elasmolyanchs as primitive gnathostomes are far superior in rank to the presnathostome stage represented by the ostracoderms, for the first two visceral arches have already taken their places as the future supports wf the jaws and hyoid areh. For many geological ages the teeming multitules of pregnathostomes no doubt tried to derelop a perfected form of jaws, but up to the appearance of the elasmobranchs the attempts to develop something besides a suctorial mouth were hardly satisfactory.

Somewhere in early Palæozoic times the vertebrates acquired the cartilaginous jaws, for the acanthodians as far back as the upper Silurian had already developed the type of jaw that is to continue through the rest of the vertebrate series. The cartilages of the skull and body in the clasmobranch give a fairly firm and stable attachment for the muscles. The great arlvance has been in the change of function of the two anterior visceral arches. The first two arches of the visceral series have lost their function as supports for the gills, and form the cartilaginous structure that is to become the jaw and hyoid apparatus of the gnathostomes. The first arch has grown forward under the brain case and has attached itself to the ethmoid region at the anterior end and to the hyomandibular rewion posteriorly. The palato-quarlrate bar is continuous, forming a long bar extending from the anterior end to the posterior part of the side of the skull.

The teeth have already developed in the sharks. The denticle-covered skin has been drawn into the mouth and by growing together or enlarging the denticles have developed into fairly efficient teeth.

The jaw system in the shark is just the opposite of that in Dinichthys. The maxillary region is securely fastened to the skull, although it may be movalile. while the mantible is the movable agent with the articulation in the quatrate region of the palato-quadrate bar. This mandible in the shark is capable of movement only in one direction. There is no side movement in these forms as there is no muscular system to operate it. 
The adducting movement of the mandibles is accomplished by the great adductor muscles, while the opening of the jaw is left to the long muscles of the ventral region. The muscles of the elasmobranch head are very simple, showing traces of the segmental condition in many particulars and indicating the homolngy of the jaw muscles with the branchial muscles. They are attached to the cartilages and to the fascia of the skin, but the skin has not assumed the importance that it does in the higher forms where it has become ossified to form plates as in A mia. In the sharks the skin gives some support to the muscles but it is not of great importance.

One of the first to work on the jaw musculature of the elasmobranchs ${ }^{2}$ was Benjamin Vetter (18\%4). On page 406 he gives a system for the naming of the muscles of the head and branchial region that is still used. with some morlifications, in the literature of the subject. He regards the adductor mandibule as part of the series of "adductores arcumm risceralium (Mittlere Beuger der Bogen)"; these are small muscles on the inner sides of the branchial arches stretched between the lower end of the upper midtle segment and the upper end of the lower midnle segment (p. 445). He divided the musculature as follows:

Die muskulatur der Visceralbogen zerfällt nach Lage und Innerverirung in vier Gruppen oder Șstemen: (1) Oberflichliche Ringmuskulatur. (2) Obere Zwischenbogenmuskeln, (3) Mittlere Beuger der Bogen, (4) Ventrale Längsmuskulatur.

Tetter subdivides the muscles of the "Oberflächliche Ringmuskulatur" (Constrictor areuum visceralium) as follows:

Bei den Selachiern treten folgende Muskeln als gesonderte Differencirung dieses Systems auf: (1) Mr. constrictor superficialis, oberflachlicher Constrictor; (2) Mm. interbranchiales, Kiemenscheidewand Muskeln; (3) M. levator maxille sup., Heber des Oberkiefers; (4) M. trapezius, Heber und Vorwätszieher des Schulterguitels.

In the description of the jaw muscles of Acanthias the following muscles of the adductor or temporal group (innervated by $V_{3}$ ) are considered :

\section{MUSCLES OF THE ADDUCTOR OR TEMPORAL GROUP}

$\left(\right.$ INNERVATED $\left.B Y V_{3}\right)$

Adductor mandibulæ $(\mathrm{Adm}$.$) .$

Levator labialis superioris (L. l. s.).

Levator maxillæ superioris (L. m. s.).

Constrictor superficialis dorsalis $\left(\mathrm{C}_{1}\right.$ s. d. $)$.

2 The authors followed and compared in the study of the elasmobranchs were: Vetter (1874), Tiesing (1895), Marion (1905) and Drüner (1903). 
IIUSCIES OF THE DEPRESSOR OR DIGASTRIC GROUP

(INNERVATEL BY VII)

Constrictor 2 superficialis dorsalis $\left(\mathrm{C}_{2} \mathrm{md}\right.$, Ruge; $\mathrm{Csd}_{2}$, Marion).

Coracomandibularis (Co. m.).

Coracohyoideus (Co. hy.).

\section{MUSCLES OF THE ADDUCTOR OR TEMPORAL GROUP}

\section{$\left(\right.$ INVERTATED $\left.I 3 Y \quad V_{3}\right)$}

Adductor mandibulce (Adm.).-This is the large adductor muscle of the shark which closes the mandible against the maxillary or palatoquadrate bar. It lies on the skull, anterior to the hyomandibular, and fills the lower part of the space between this and the eye. It arises along the dorsal margin of the quadrate. A superficial layer arises on the postorbital process and some of the fibers come from the tendinous mass back of the eye. At the postero-rentral region a few of the fibers from $\mathrm{C}_{1} \mathrm{sr}^{\mathrm{r}}$ join with the adductor. The insertion is on the cartilage of the mandible along the whole length of the exterior surface and slightly on the upper edge of the inner surface. A tendon extends to the levator labii superioris (L. l. s.) somewhat as it does in the teleosts, where a tendon connects with the adductor from the premaxillary region of the skull. Marion (1905, p. 23) gives a similar muscle in Raia which he calls levator rostri.

In 4 canthias the adductor muscle is a large mass made up of fibers from several sources, as in the teleosts and ganoids. It is more divided and specialized in Paia than in the typical sharks. The typical ondition of this muscle in the lowest forms shows fibers from several sources, and this is suggestive of the subdivisions of the mucle in the higher forms, where the same mas in the amphibians and reptiles is divided to a creater or less extent, according to the form of the animal and the type of jaws. Tiesing (1895, pp. 8\%-90) discusses the adductors of the rarious elasmobranchs, showing this spliting of the muscle in some of them. especially Rlinobatus.

Levator labii superioris (L. I. s.) is a small muscle arising on the ventral portion of the skull, under the eyes and anterior to them, extending around the labial cartilages to meet and join with the adductor mandibulæ.

Vetter (18\% 4, p. 406) calls it Add. $\beta$ in Acanthias and places it with the "Oberflichliche Ringmuskulatur" (Comstrictor arcum visceralium). Marion (1905, p. 21) follows Tetter and places it with the similar constrictor, as a serial homologue of the MI. levator maxillæ superioris. Tiesing (1595, p. 84) gives the origin in Mustelus "von vorderer Wand 
der Augenhöhle unterhalb des Processus pratorbitalis." 'Tiesing (Irlem., 1. S(i) classes this muscle with the dorsal constrictors: "Nit der Erkenntnis dass es sich um die Versorgung durch den Ramus III trigemni handelt, verliert auch der M. Levator labii superioris die ihm von frïheren Autoren zuerkannte selbstindigheit und reiht sich dem system der levators resp. dorsalen Constrictors im Trigeminusgebiet an."

Levator maxilla superioris (L. m. s.).-This is one of the dorsal constrictors which arises on the skull, just anterior to the constrictor superficialis dorsalis $1\left(\mathrm{C}_{1} \mathrm{sd}\right)$. It is inserted on the dorsal surface of the palato-quadrate bar. 'This muscle is so closely associated with $\mathrm{C}_{1}$ sd in both origin and insertion that most writers have placerl them together. Vetter (18\%4) places it with the dorsal constrictors and Marion (1905) follows his determination. Vetter (18\%4, p. 408) gives the function of the two muscles as follows: "Der Levator maxillæ superioris und $\mathrm{C}_{1} \mathrm{sd}$ heben den Oberkiefer, der erstere dreht ihn dabei um sein Gelenk mit dem Schädel nach vorn, der letzere nach hinten."

Constrictor (1) superficialis dorsalis $\left(\mathrm{C}_{1} \mathrm{sd}\right)$. - This small muscle is just posterior to the levator maxillæ superioris and is closely associated with it. Both muscles represent a division of one of the dorsal series as mentioned in the discussion of the other muscles. Its origin is on the wall of the skull above the spiracle, from where it curves around the anterior border of the spiracle to the insertion on the palato-quadrate bar, just posterior to the insertion of the levator maxillæ superioris. 'This constrictor represents the dorsal part of the original dorsal constrictor $\left(\mathrm{C}_{1} \mathrm{sd}\right)$ and in some pre-elasmobranch stage was probably much larger.

MUUSLES OF THE DEPIRESSOR OR DIGASTRIC GROUP

(INVERVATED BY VII)

There is no true depressor attached to the mandible in the elasmobranchs that has any connection with the dorsal part of the skull. The

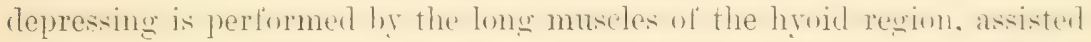
by the coraco-mandibularis and coraco-hyoideus. These are hyoid arch muscles and both are innervated by nerve VII as would be expected, as they belong to the region of the second superficial constrictor.

Constrictor (2) superficialis dorsalis $\left(\mathrm{C}_{2} \mathrm{sd}\right)$.- This is the large, undif-

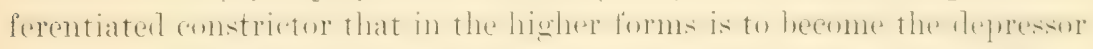
mandibula of the Amphibia, birds and reptiles; but in the Pisces it is a wide muscle arising from the posterior part of the shull and from the fascia of the back muscles. It is inserted in the quadrate region of the upper jaw onto the cerato-hyal cartilage and onto the tendinous bridge of the dorsal and rentral constrictors. 
Coraco-mandibularis (Co. m.).-This lies along the ventral medial line of the uncler part of the throat. It is an azygos muscle belonging to the long muscles of the ventral system. It arises on the fascia of the long muccles ("oraco-arcuales), extends forward as the most superficial of the rentral muscles, and is inserted on the mandibular cartilage, near the rmplysis. It is the true depressor muscle of the elasmobranchs and acts in depressing the jaw. Tiesing calls it a depressor, but it adds confusion to the nomenclature, and it should be regarded as a rentral muscle, used below the amphibians for this purpose.

Coraco-hyoideus (Co. hy.).-This also assists in the depression of the mandible. While it is not attached to the mandible, it is close to the coraco-mandibularis and assists in drawing down the mandible by pulling on the arch. It is a paired muscle, attached by fascia in its origin to the coraco-branchialis and coraco-arcualis communes. It is inserted on the underside of the hyoid arch near the median line.

\section{POLYODON}

\section{Plate I, Fig. 4}

The skull on the whole approaches the shark type. It consists largely of cartilage, the derm-bones being much reduced. The rostrum is enormously prolonged and flattened. The skull is extremely hyostylic, the long slender jaws being connected with the skull chiefly through the snall stmplectic and the long backwardly inclined hyomandibular. The muscles of the hyomandibular are large and well developed. As the fish feeds on small food particles, the jaws and their muscles are weak. The adductor muscle arises on the palato-quadrate bar, and passes over a pulley-like groove at its posterior end and is inserter into the mandibular fossa.

The jaw muscles of Polyodon, as described by Danforth (1913), resemble those of the sturgeon but are less reduced. They are also fundamentally similar to those of the elasmobranchs.

MUSCLES OF THE ADDUCTOR OR TEMPORAL GROUP

(INNERVATED BY $V_{3}$ )

Adductor mandibulæ 1 (Ad. m. ${ }^{1}$, adm. of Danforth).

Adductor mandibulæ 2 (Ad. m. ${ }^{2}$, adm. ${ }^{1}$ of Danforth).

Protractor hyomandibularis (P. hy.).

MUSCLES OF THE DEPRESSOR OR DIGASTRIC GROUP

(INNERVATED BY YII)

Retractor hyomandibularis et operculi (R. hy. et o.). 
$\left(\right.$ INNERVATLD $\left.B Y V_{3}\right)$

The adductor mandibulie is divided into two parts: a large anterior portion, and a smaller deep part. The large portion extends anteriorly along the palato-quadrate har, while the posterior, deep, portion is a short muscle from the quadrate region.

Adductor mandibula 1 (M. adm. of Danforth).-This is the larger section of the adductor which lies orer the palato-quadrate bar, curves around the quadrate and is inserted in the suprameckelian fossa. Its origin starts on the dorsal, anterior cun of the palato-quadrate and extends backward, overlapped slightly alome its rentral side be the maxilla; it curves downward under the maxilla at a sharp angle and is inserted into the suprameckelian fossa and also on the dentary. Its curve is very abrupt, so that its insertion is at right angles to the main mass of the muscle.

Adductor mandibula ¿ (M. adm. ${ }^{1}$ of Danforth). -Just posterior to the abrupt curve of the adductor mandibula 1 arises the adductor mandibulæ 2 on the posterior end of the palato-quadrate bar. It extends ventrally to be inserted on the dentary and in the suprameckelian fossa.

Danforth $(1913$, p. 116) mentions some speculations in regard to the adductor mandibulie 1 of Polyodon that are rather interesting and perfectly justified from the conditions. He says:

In Acipenser there is, in addition to the adductor mandibule, a strong constrictor (Cs of Vetter) which orerlies it. The latter arises from the antorbital process and extends around the lower jaw. The anterior part of the adductor in Polydon has a superficial resemblance to this muscle, but none of its fibers arise from any part of the cranium proper and I have been unable to find any indication that they ever pass over into the rentral constrictor, below the jaw. Consequently from the adult material alone, it cannot be stated with any certainty that the anterior adductor of P'olydon finds its homologue in the constrictor of Acipenser, although there is a possibility that such is the case.

From its position, it could be a part of the constrictor superficialis 1 of Tetter, as Danforth suggests. It is tempting to imagine that the old origin on the skull has been lost and that it slipped down to its present position. Several other forms have a muscle of this type and the embryology should show the truth or falsity of the assumption. This muscle protracts and closes the mouth.

Protractur hyomandibularis (P. hy.).-This muscle strongly suggests the similar muscle in Acipenser. It is a double-headed muscle that arises from the base of the skull at the posterior end of the roof of the mouth and from the post-orbital process, anterior to the spiracle. It 
extends to the hyomandibular and is inserted along its anterior margin, with a long insertion extending almost to the distal end of the bone. It protracts the hyomandibular, pulling the distal end outwards and forward. The homology of this muscle is interesting. Danforth (1913) says: "The partial division of this muscle is of some interest, since the homologies of the levator arcuus palatini and the dilator operculi in the teleosts are rather uncertain."

MUSCLES OF THE DEPRESSOR OR HIGASTRIC GROLP

(IXIERTATED BY YII)

Retractor hyomandibularis et operculi (levator and add. operculi?) (1. hy. et o.).- This is a large sheet of muscle that arises along the groove in the cranium, under the long pterotic. It may represent the levator operculi and the adductor operculi of 1 mia. The fibers spread out and are divided into small bundles and are attached to the posterior edge of the hyomandibular. Posteriorly they attach themselves to the whole dorsal border of the degenerate operculum. A few superficial fibers extend over this sheet from the anterior part of the origin to the operculum. These muscles raise the hyomandibular and operculum.

\section{ACIPENSER}

Plate I, Fig. 3

The dermal plates of the skull are superficial ossifications. The cartilaginous skull of this form is more degenerate than in Polyodon, as the mouth is reduced to a small sucking dise, while Polyodon has duck-like jaws. The adductor is shrunken to a small, short muscle, as there is very little demand for a strong muscular action. The opercular and hyomandibular region have large muscles, as there is much movement in these parts during the ingestion of food.

MUSCLES OF THE ADIUUCTOR OR TEMPORAL GROUP

$\left(\begin{array}{llll}T \\ \text { TERTATED BY }\end{array}\right.$

(1) Adductor mandibulæ (Ad. m.).

(2) Protractor hyomandibulæ (P.h.).

MUSCLES OF THE DEPRESSOR OR DIGASTRIC GROUP (INNERYATED BY VII)

(1) Retractor hyomandibularis (R. hy.).

(2) Levator opereuli (L。.). 
WUSCLES OF THE ADIOECTOR OR TEMTORAL GROUP

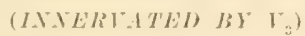

Adductor mandibute (Ad. m.).-This is a small muscle that arises on the upper side of the palato-quadrate region. It curves around and is inserted on the small Neckelian cartilage. It raises the mandible and presses it against the marginal cartilages of the maxillary region.

Protractor hyomandibularis (P. h.).-This is a large muscle in the sturgeon. It arises in the post-orbital region, extends ventro-posteriorly and is inserted on the hyomandibular. It is concerned in the action of the gill apparatus and in the sucking action.

\section{MUSCLES OF THE DEPRESSOR OR DIGASTIRIC GROET}

(IXYERTATEI) BY III)

Retractor hyomandibularis ( R. h.).- - It arises on the skull wall back of the spiracle and is inserted on the dorsal edge of the hyomandibular. It raises the gill apparatus.

Levator operculi (L. o.) (Vetter, 18\%4).-This arises along the side of the skull, just posterior to the origin of the retractor hyomandibularis. It is inserted on the operculum on the inner side. It pulls up the operculum.

A.MII

I'late II, Nigs, 1, 2

In the very primitive skull of A mia, the chondrocranium is but little ossified and the dermal plates are still on the surface and very much of the primitive ganoid pattern. The hyomandibular and preopercular are sunken deeper into the skin, so that the adductor is of the teleost type, with its origin on the anterior face of the preopercular. The cartilaginons palato-quadrate and the Meckelian cartilage are incased in their dermal bones, and good teeth have dereloped, so there is need of good muscular derelopment for the jaws. The quadrate, preoperculum and the cartilaginous skull make a good insertion for the splendid muscular system found in this group. The insinking of the preoperculum gires the adductor plenty of room for development and full advantage has been taken of this opportunity. ${ }^{3}$

MUSCLES OF THE ADIUECTOR OR TEMPOR.LI GROTP

(IXIERTATED IBY $\left.V_{3}\right)$

Levator maxillie superioris ( $\mathrm{L}$. m. s.).

${ }^{3}$ This study on Amia follows the work of Allis (1S97) and McMurich (18S5). 
Levator arcus palatini (L. a. p.).

Adductor mandibulæ (Ad. m.).

Protractor hyomandibularis (P. h.).

Dilator opereuli (D.o.).

IUSCLES OF THE DEPRESSOR OR DIGASTRIC GROUP

(INNERIATED BY VII)

Adductor hyomandibularis (Ad.h.).

Adductor opereuli (Ad. o.).

Levator operculi (L。.).

MUSCLES OF THE ADDUCTOR OR TEMPORAL GROUP

(INNERVATED BY $V_{3}$ )

Levator maxilla superioris (L. m. s.).-This is derived from the muscle of the same name in the selachians. It arises on the hyomandibular and along the side of the cartilaginous part of the skull; part of it is anterior to the eves. It is attached to the adductor muscle and to the dermis, between the maxilla and the palatine arch.

Levator arcus palatini (L.a.p.).-Arises on the post-orbital process and is inserted on the metapterygoid and the hyomandibular.

Adductor mandibula (Ad.m.).-There is a great change here from the condition of the selachians. The adductor mass is now attached to the bony elements of the mandible and is differentiated into three parts, the second of which is again divided into two.

(a) Pars superficialis (Ad. m. ${ }^{1}$ ).

(b) Pars temporalis lateralis $\left(\mathrm{Ad}, \mathrm{m} .^{2}\right)$.

(c) Pars temporalis medialis (Ad. $\mathrm{m}^{3}$ ).

(d) Pars intramandibularis $\left(\mathrm{Ad} . \mathrm{m}_{\circ}{ }^{4}\right)$.

(a) Pars superficialis ( $\mathrm{A}$ (l. $\mathrm{m}^{1} \cdot \mathrm{A}^{2}$ Allis) arises from the post-orbital process and the under surface and outer edge of the pterotic, and from the nuter lace of the preoperculum, hromandibular, quadrate, and symplectic. It is inserted on the coronoid and extends into the suprameckelian fossi. A tendon from this part extends to the inner side of the mixillat as in the selachians. This tendon represents a muscle of the selachians (levator labii superioris) that is lost in $A$ mia, the tendon only remaining.

(b) Pars temporalis lateralis $\left(\mathrm{Ad} . \mathrm{m}^{2}, \mathrm{~A}^{3}\right)$. The deep portion arises Prom the hyomandibular, quadrate, and the outer part of the metapterygoid. It joins Ad. m. ${ }^{1}$ near its insertion on the jaw. It is partly subdivided into the two parts $\mathrm{Ad} . \mathrm{m}^{2}{ }^{2}$ and $\mathrm{Ad} . \mathrm{m}^{3}$ 
(c) Pars temporalis metialis $\left(.1 \mathrm{r} . \mathrm{m}^{3}{ }^{3}\right)$ is the inner slip of the medial layer pars temporalis lateralis.

(d) Pars intramandibularis (Ad. m. ${ }^{4}$, A $\omega$ Vetter) is the part of the adductor mass that extends torwarel into the hollow ramus of the jaw as in the teleosts. It arises from the fascia on the other two parts of the adductor and fills the hollow ramus, heing attached to the splenial and the dentary.

Protractor hyomandibularis.-This muscle is not present in Amia as a separate muscle, but its function is taken by the posterior part of the levator arcus palatini, this has a small insertion on the underside of the hyomandibular, thus acting as a protractor of that element.

Dilator opercuti (D. o.).-Whis arises on the pterotic, extends through the usual fossa in the hyomandibular and is inserted on the anterior, inner face of the operculum by a tendon. The path of this muscle over the hyomandibular, just ahove the preoperculum is well marked, as it is in all fishes. This muscle raries and puls the opereular region ontwards.

\section{MIUSCLES OF THE DEPRESSOR OR DIGASTRIC GROUP}

(INNEIRVATED BY TYII)

These muscles of the facialis group represent the $\mathrm{C}_{2}$ sd of Vetter, that is the dorsal part of the "second constrictor" pertaining to the hroid arch $\left(\mathrm{C}_{2} \mathrm{sd}\right)$.

Adductor hyomandibularis (Ad. h.).-This arises from the otic region and is inserted on the inner face of the hromandilubar, along the posterior edge to the articulation for the opereulum. It pulls the hrommdibular dorsally.

Adductor operculi (Ad. o.).

Levator operculi (L. o.).-These two muscles of the operculum both arise on the pterotic and pariotal, the arlductor operculi heing the anterior slip. They extend down to the opereulum and spread out on its immer face. They raise the operculum.

\section{LEPIDOSTEUS}

I'late II, Fig. 3

Lepidosteus has a well dereloped skull with a great elongation of the mandible and maxilla. The great forward prolongation of the quartrate and mandible gives what is demanded for a catcher of fish, namely; a quick snap. The enormous adductor with its temporal and masseter slips must serve to close the jaw with a very quick snap, so that the numerous sharp pointed teeth get a hold on the slippery prey. These 
muscles are inserted at a very oblique angle and the leverage is such as to give a very rapid morement with comparatively slight porrer.

MUECLES OF THE ADDUCTOR OR TEMPORAL GROUP

(IXYERTATED IBI $\mathrm{V}_{3}$ )

Adductor mandibulæ (Ad.m.). (Divided into three parts.)

Protractor hyomandibularis (P.h.).

MUNCLES OF THE DEPRESSOR OR MIGASTRIC GROUP

(IXYERT ITED BY III)

Adductor operculi (A. o.).

Levator operculi (L. o.).

JUSCLES OF THE ADDUCTOR OR TEMPORAL GROUP

$\left(I X Y E R T^{\top} \perp T E D \quad B Y Y_{3}\right)$

Adtuctor mandibule (Ad.m.).-This muscle is divided into three parts: Adductor 1 (to preoperculum), adductor 2 (along the roof of the skull), adductor 3 (to quadrate). Adductor 1 takes its origin in a fan-shaped mass along the outer face of the operculum. It extends anteriorily, becoming tendinous at the posterior border of the eyes, and is inserted in the space above the Neckelian cartilage. Adductor 2 is a long muscle arising along the entire face of the cartilaginous region of the skull, from the preorbital region to the hyomandibular. It extends along the roof, dorsal to the eyes and to the anterior edge of the mandible. The two pair almost meet in the median line, as only a thin cartilaginous plate separates them. It is inserted in the Meckelian fossa with the other parts of the adductor mass. Adductor 3 is a short portion of the adductor that arises on the tiny quadrate, spreads out in a thin sheet and is inserted on the coronoid process of the mandible. It is a very small muscle, lying under adductor 1.

Protractor hyomandibularis. - This muscle is between the dorsal and the rentral parts of the adductor mandibula. It arises on the orbitosphenoid with a small tendon at its anterior end and a fleshy attachment to the side of the skull as it extends posteriorly to its insertion on the hromandibular. It resembles a homologous muscle found in Acipenser, and Vetter calls it by the same name.

ULACLES OF THE DEPRESNOR OR DIGASTRIO GROLP

(IXYKRI:ATED ISI III)

Adductor operculi ( 1.0.$)$.- This is a small muscle that arises on the hromandibular and curves around to be inserted on the inner face of 
the operculum, near its anterior edge. It pulls the operculum forward and is homologous with the muscle of the same name in A mia.

Levator operculi (L. o.).-This arises on the occipital region of the skull, spreads out in a fan-like insertion on the upper, inner face of the operculum. It raises the operculum. Both of these muscles are probably the homologues of $\mathrm{Csd}_{2}$ of Vetter and the $\mathrm{C}_{2}$ md of linge.

\section{ESOX}

Plate III, Figs. 1, 2

In Esox, as in other teleosts, the dermal bones have sunk into the skin so that the adductor region is free on the outside. 'The preoperculum, metapterygoid, quadrate, and post-frontal legions gire the adductors a good surface for insertion. The teleost mandible becomes enlarged and the articulation with the quadrate is greatly improved in its mechanics. As the maxilla are rednced and have lost the power to meet the mandibles, their teeth have disappeared and the mandibles are inclined inwards to meet the teeth of the palatines.

The following description is based partly on that by Vetter (18\%8):

\section{IUSCLES OF THE ADDUCTOR OR TEMPORAL GROLP}

$$
\left(\text { (INIERTATED BY } \mathrm{V}_{3}\right)
$$

Adductor mandibule + (Add. (") of Vetter).

Arlductor mandibulie 1 (Superficial).

Adductor mandibulie $2+3$ (To symplectic, ete. Deep.).

Levator areus palatini (Vetter).

MUSCLES OF THE DEIRESSOR OR DIGASTRIC GROUP

(INYERIATED BY III)

Adductor hyomandibularis (Vetter).

Dilator operculi (Tetter).

Levator operculi (Vetter).

Adductor operculi (Vetter).

For homologies see Table 1, p. 156.

WUSCLES OF TIIE ADIUCCTOR OR TEMIORAL GROLP

(INIERTATED BY $\mathrm{V}_{3}$ )

The muscles of Esox have been worked out by Vetter (18\%8, p. 49.4). His names are used for the most part in the present description, although the nomenclature of the adductor mandibula is changed, as explained in the notes. The adductor has three distinct parts. 
Adductor mandibula \& (Add. w of Vetter, 18\%8, p. 494).-This large muscle mass fills the supramechelian fossa and is attached to the side of the lossa and to the cartilage. It is homologous with that found in Amia ( d. m. $^{4}$ ) and in several other forms where the Meckelian fossa is large.

Adductor mandibula 1 (Vetter, 18\%8, p. 494). - This is the outer sheet of the adductor, which completely covers the rest of the muscle. It takes its origin from the edge of the frontals, from the postorbitals to the articulation of the hyomandibular, along the face of the hyomandihular and the anterior face of the preoperculum; the lower part arises from the symplectic and the postero-ventral portion of the quadrate. It ends at the mandilsle with a short, wide tendon and joins with the rest of the adductor mass, to be inserted in the mandible, in the coronoid region and in the suprameckelian fossa.

Adductor mandibule 2.- This is underneath the superficial adductor (Adil. . $^{1}$ ). It arises on the metapteryoid, preopereulum, quadrate, and has a slight origin on the hyomandibular and operculum. This complex muscle becomes tendinous at the anterior end and extends to the jaw medial to the superficial adductor. It extends into the suprameckelian fossa to join the rest of the adductor.

Adductor mandibule 3.-The deepest portion of the adductor mass. Its tendon joins that of Ad. m. ${ }^{2}$.

Levator arcus palatini (L. a. p.) (Vetter).-This is found along the upper part of the post-frontal region, after the adductor mandihule 1 is removed. It arises on the pterotic and alisphenoid and is inserted on the metapterygoid and hromandibular. It pulls up on the palatine region and closes the gills.

MUSCLES OF THE DEPRESSOR OR DIGASTRIC GROUP

(INIERYATED BY VII)

Adductor hyomandibularis (Ad. hy.) (Vetter, 18\%8, p. 502).-A small muscle hetween the hyomandibular and the skull that arises on the skull wall in the otic region and is inserted on the inner side of the hromandibular. It adducts the hyomandibular, as its name indicates.

Dilator operculi (D. o.).-This muscle is not to be seen until the adductor mandibule 1 is lifted off. It extends from the pterotic to the opereulum. It arises on the pterotic and hyomandibular and extends orer the hyomandibular and under the tip of the preoperculum to be inserted on the upper, inner face of the operculum. It opens the opercular cavity.

Levator operculi (L. o.).-This muscle is just posterior to the dilator operculi. It arises on the posterior end of the pterotic with a slight 
attachment to the hyomandibular. It is inserted on the upper edge of the operculum where it spreads out in a lan-shaped mass. It raires the operculum.

Adductor opercuti (A. o.).-This is a short muscle that arises on the posterior limb of the pterotic and in the epiotic groove. It is inserted under the levator operculi on its anterior edge and is also attached to the opercular process of the hyomandibular and to the origin of the adductor mandibule 2 (Vetter). It closes the operculum and pulls it dorsally.

\section{ANGUILLA}

Plate II, Figs. 4, 5

The peculiar reduction of the maxillæ and premaxillæ in the Apodes has made the mandibles incline inwards to meet the teeth on the palatines. The extreme is reached in the Murænidæ, where the maxillæ and premaxilla are lost and the palatines and ptergoils aswme their function. The eels have a reduced pterygoid region and the maxilla and premaxilla are small or lost, the vomers and palatines being supplied with teeth, and functioning as the maxillary elements. The mandihle is changed in position so that it is inside of the palatines when it is closed.

The muscular development of Anguilla is remarkably like that of certain reptiles. The dipnoans and Apodes are about the only examples among the fishes that show the adductor muscles extending up to the median line of the skull and meeting there, separated only by fascia. The condition in Apodes is mique in this respect, for the muscles are free to extend to the median line and have their movements entirely unhampered by any covering of bone. Thus the adductor muscle resembles the capiti-mandibularis of the reptiles and compares favorably with the temporalis muscle of some mammals in shape and development. Although the alductors meet on the median line their fibers do not mix. as they are separated by fascia.

The hyomandibular is large and well muscled.

MUSCLES OF THE ADDUCTOR OR TEMPORAL GROUP

(INNERVATED BY $\mathrm{V}_{3}$ )

Adductor mandibulæ.

Dilator operculi.

MUSCLES OF THE DEPRESSOR OR DIGASTRIC GROUP

(INNERTATED BY TII)

Levator operculi. 
IVECLES OF THE ADIOUCTOR OR TEMTORAL GROUP

(IXIERTATED BY $\left.V_{3}\right)$

Adductor mandibula.-This muscle completely covers the skull posteriorly, covering the dorsal, median line to a depth of three or four millimeters. It is in two layers, a superficial (Add. 1) and a deep (Add. 3 ). 'The superficial layer arises on the frontal, parietal, pterotic, and hyomandibular, and is inserted on the coronoid region of the mandible. The origin of this muscle is far different from that of the usual teleost muscle, which takes origin from the preoperculum. It has spread over the skull and arises much as in the reptiles. The great development of the hyomandibular and the reduction of the opercular bones is the probable cause of the change of origin.

The deep layer (Add. 3) arises on the parasphenoid, sphenotic, hyomandibular, and quadrate. It joins the outer layer and is inserted on the mandible.

Dilator operculi (D. o.).- This muscle is covered by the adductor. It arises on the sphenotic and hyomandibular and is inserted on the upper portion of the anterior border of the operculum. It raises the operculum and pulls it forward.

MUSCLES OF THE DEPRESSOR OR DIGASTHIC GROUP

(INDERTATED BY III)

Levator operculi (I. o.).-This arises on the posterior part of the pterotic and spreads out in a fan-shaped sheet on the outside of the operculum. It raises the operculum. 'This muscle is on the inside of the operculum in most teleosts but in the Apodes it creeps to the outside. The reduction of the opercular bones probably has something to do with this change.

\section{PALINURICITHYS}

Plate II I, Figs. 3, 4, 5

The skull is fundamentally similar to that of the perch but is short antero-posteriorly and with large orbits.

The principal muscles of the jaws are as follows:

UUSCLES OF THE ADDUCTOR OR TEIIPORAT GROUP

$\left(\right.$ IXIERTATED BY $\left.\mathrm{V}_{3}\right)$

Adductor mandibule (1 and 2).

Levator arcus palatini (L. a. p.). 
Protractor hyomandibularis (P. h.).

Dilator operculi (I). o.).

IUSCLES OF THE DEIRESSOR OR DIGASTRIC GROUP

(IXIERIATED BY VII)

Levator operculi (L. o.).

IIUSCLES OF THE ADDUCTOR OR TEIPORAL GROUP

$\left(\right.$ IIIERTATED BY $\mathrm{T}_{3}$ )

The adductor is divided into two layers and a third is present as the intramandibular slip. There is a comnection by a rudimentary tendon with one of the anterior levator maxilla muscles that arises at the anterior of the premaxilla and joins the adductor near its tendon. The main adductor arises along the anterior face of the preoperculum, following down along this bone to its tendon near the mandible. The deeper layer arises on the quadrate and metapterygoid region, joining the rest of the adductor and ending in a crescent-shaped tendon near the coronoid region of the mandible. 'This connects with the muscle in the mandible ( $\left.\mathrm{Adm}^{4}\right)$ which is the Adl. $\omega$ of Vetter. 'This consists of a mass of fibers attached to the dentary, with all of the fibers conrerging to a central tendon, which is connected with the tendon of the main adductor.

Levator arcus palatini (L. a. p.).- Then the eve is remover this muscle is seen with its fibers extending ventrally to be attached to the palatines and pterygoids. It arises on the parasphenoid and most of the short fibers are inserted with a fleshy attachment to the palatine and a few to the pterygoids. It raises the palatine region.

Protractor hyomandibularis (P. h.).- This muscle arises on the sphenotic and extends under the dorsal end of the adductor, to be inserted on the outer face of the hyomandibular. It draws the hyomandibular and opercular apparatus forward.

Dilator operculi (D. o.).--It arises on the sphenotic under the protractor hyomandibularis and extends posteriorly to be inserted on the anterior, dorsal portion of the operculum. It pulls the operculum forward and raises it slightly.

MUSCLES OF THE DEPRESSOR OR DIGISTRIC GROTP

(INIERTATED BY III)

Levator operculi (L. o.).- - It arises on the posterior end of the pterotic and extends downward to its insertion on the inside of the upper, inmer face of the operculum. It raises the operculum and pulls it slightly forward. 


\section{POI,Y PTERUS}

Plate IV, Figs. 1, 2

The condition of the skull in Polypterus is extremely primitive, as all the dermal elements are on the surface. The skull is broken up into small elements so that the comparison with the Devonian Rhipidistii, such as Osteolepis, is easily made. The elements may not be exactly the same, but they represent the breaking up of the hard dermal shell to allow the necessary movement occasioned by the muscular development. It might be possible to account for all of the breaks by making a phylogenetic study of the muscles in the fossil forms. In this connection Gregory (1915, p. 32\%) offers the following very interesting and suggestive hypothesis:

It may be stated as a general hypothesis that in the dermocranium of the primitive fishes the position and arrangement of the sutures and the subsequent pattern of the osseus elements are the evolutionary resultants of the various symmetrically balanced stresses induced by the action of the underlying muscles of the eyes, jaws, branchial arches and pectoral limbs, in composition with the position and size of the olfactory, optic and auditory capsules. It is at least a fact that sutures and articulations define loci of greatest mobility, centers of ossification define loci of least mobility. Differential growth of one region of the skull, as in the rapid elongation of the snout, also results in more or less rearrangement of the sutures and osseus elements.

An examination of the skull of Polypterus shows that Dr. Gregory's hypothesis works out well, as most of the breaks in the skull might be explained by the stress of the muscles actually present. The adductor mandibulæ would tend to make the break over the frontal and parietal region, as this is at right angles to the pull. The pull of the masseter would cause the break in front of the preoperculum by its pull against the squamosal and quadrate elements. The spiracle and its muscle might account for the broken condition in that region with its many small plates. The breaks in the region in front of the orbits are more difficult to account for, but in the sharks and some of the other fishes there is a l'ator maxilla which might have caused the breaking up in this region.

The jaw muscles of Polypterus have been figured and described by Pollard (1892).

MUSCLES OF THE ADDUCTOR OR TEIIPORAL GROUP

$\left(\right.$ INNERVATED $\left.B Y V_{3}\right)$

Adductor mandibulæe ( (l. m.).

Protractor hyomandibularis (P. h.).

I.evator maxilla superioris (L. m. s.). 
IIUSCLES OF THE DEPRESSOR OR DIGASTRIC GROUP

(INNERYATED BY VII)

Adductor hyomandibularis (Ad.h.).

Adductor branchialis (Pollard).

The differences in the musculature of the shark and of Polypterus are due to the fact that the latter has a bony skull roof and requires a different form of musculature.

IIUSCLES OF THE ADDUCTOR OR TEMPORAL GROUP $\left(\begin{array}{lll}\text { INVERVATED } B Y \mathrm{~V}_{3} \\ )\end{array}\right.$

Adductor mandibula.-This muscle is somewhat more complex than the adductor of the selachians, where the mass is rather compact. It may be divided into a temporal $\left(A d \mathrm{~m}^{2}\right)$, masseter $\left(\mathrm{Adm}^{1}\right)$ and pterygoid portions $\left(\mathrm{Adm}^{3}\right)$.

(a) The masseter $\left(\mathrm{Adm}^{1}\right)$ is the largest part of the adductor and stretches across the face of the mass, so that the pull is almost along the line of the skull base. It is covered by the preopercular plate, so that it, as well as the rest of the adductor, is not seen from the outside. The muscle slip arises along the back part of the skull where the preoperculum joins the hyomandibular and qualrate. 'These bones hound a triangular resion at the posterior part of the skull where the masseter slip arises. It is attached to the preoperculum along the inner face, where it overlaps the hyomandibular and extends to the quarlate. The insertion is on the coronoid process of the mandible.

(b) The temporal portion $\left(\mathrm{Ad \textrm {m } ^ { 2 }}\right)$ of the adductor, as well as the pterygoid slip, are at right angles to the masseter portion, so that the combined pull of the three parts is at an angle of about $45^{\circ}$ to the top of the skull as a base line. This slip arises on several bones of the dorsal part of the skull, on the postorbital and frontal. The attachment to the frontal (after Pollard, 1892, p. 391) is "to its under surface between its projecting edge and its articulation with the orbito-sphenoid, extending even above the eye." The insertion of the temporal portion is in the suprameckelian fossa. This part is anterior to the pterygoid slip and overlies it somewhat. It is at right angles to the masseter.

(c) The pterygoid slip $\left(\mathrm{Adm}^{3}\right)$ arises behind the temporal and beneath it, on the orbitosphenoid and parasphenoid, and its insertion is on the mandible along with the temporal. This mass of muscle represents a part of the capiti-mandibularis of reptiles and the adductor of the selachians.

Protractor hyomandihularis (P. h.).-Two muscles connected with the adductor group assist in the movement of the operculum, the protractor 
hyomandibularis and the levator maxille superioris. 'They are closely associated with each other and by their retraction pull the operculum ontward and help in moving the water in the gill chamber. The protractor arises on the postfrontal and is inserted on the operculum and hyomandibular where the two bones meet. A small slip of this muscle, according to Pollard, is attached to the bones around the spiracle and assist in regulating its closing and opening.

Levator maxilla superioris (L. m. s.) Add. $\beta$ Vetter.-This muscle is closely connected with the protractor. It arises on the postfrontal and is attached to the metapterygoid and quadrate and to the lower edge of the hyomandibular.

JUSCLES OF THE DEPRESSOR OR IOGASTRIC GROUP (IXIERYATED BY VII)

Adductor hyomandibularis (Ad. h.).-This is the retractor hyomandibularis of Pollard. It arises in the otic region on the proötic and along the ridge of the postero-external process. The anterior part of the muscle is called the retractor. 'The insertion is on the hyomandibular, above the posterior articulation of this bone with the operculum. It is attached to the anterior part of this articulation and on the imner side of the bone.

Adductor branchiatis (Ad. br.) (Pollard).-There is a small muscle at the angle of the jaw that, according to Pollard (1892, p. 389), may represent the adductor arcus branchialis of the selachians. It is in the ligaments that connect the hyomandibular, quadrate and stylohyal.

\section{NEOCERATODUS}

Plate IV, Figs. 3,4

The wide massive skull of Ceratodus (Neoceratodus) is correlated with the peculiar derelopment of the splenial, romerine and palatine teeth. The cartilaginous skull is covered by the superficial derm bones and with a great space reserved at the posterior region for the accommodation of the large adductor mandibulie. The opercular region is rectuced and the hyomandibular is restigial or absent. Günther (18\%1, p. 52t) saw this little restige of both the hyomandibular and the symplectic but did not recognize them as such. Huxley (18\%6, pp. 3-1) says:

It is obvious that this little cartilage is the homologue of the hyomandibular element of the hyoidean areh of other fishes, the small conical process being the rudimentary symplectic, and, therefore, that it is itself the dorsal element of the hyoglean arch, attached in its normal position, as its relations to the seventh nerve show. (Huxley's observation on Giinther's work. Giunther, 1571. 1. 5:24.) 
This small cartilage, then, represents the hyomandibular and the symplectic of the teleosts. It is in the correct position for these bones and there is little doubt of the homology. With its rechetion there has been quite a change in the opercular region, as the opercular bones are reduced and changed together with the preopercular. Giinther thought that a small bit of cartilage on the anterior edge of the opercular was the vestige of the preopereulum. Goodrich (1909, pp. 23\%-238) says:

It is in the connection of the skull with the visceral arches that the dijnoi have diverged most conspicuously from the other fishes. The modern generia are completely autostylic. 'The pterygo-quadrate bar is firmly fused to the cranium in front and behind. The spiracle disappears and the hyoid arch is well developed, with a medial basihyal, paired hypohyals and latre ossified ceratohyals. But the hyomandibular takes no share in the support of the jaws. It disappears, indeed, entirely in the Dipneumones where the ceratohyals alone remain, and, as Huxley showed, is represented in Coratodus by a minute restigial cartilage, overlying the hyomandibular branch of the seventh nerve.

The skull of Ceratochs has a continuous dermal temporal roof as in the stegocephalians. Parts of the skull resemble the cartilaginous structure in the urodele embryo, especially in the region of the arches, but here the resemblance stops.

In the arrangement of the jaw muscles this dipnoan is very simple. 'The skull consists of a massive cartilaginous part with a covering of dermal bones which gives

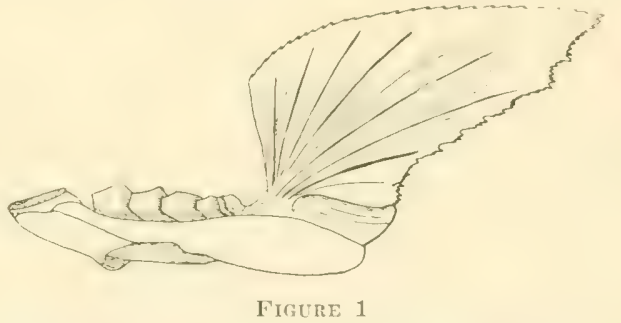

Mandible of Neoceratorlus forsteri with the tendinous fascia of the adductor mandibula muscle the head its large size. The space between the cartilage surrounding the brain and the dermal bone is filled with the enormous temporal muscle which supplies the motive power for the great crushing apparatus. 'The general aspect of the head is amphibian-like to an extent found in no other fish but the eels. There is a space along the mid-clorsal region of the cartilaginous skull that is covered with the temporal muscle and with the muscles of the neck region. In Polypterus and Amia the muscles of the skull top make no approach to this extension in the dorsal region, but in the eels the temporal muscles extend up and the muscles of the two sides meet in a reptilian way. The musculature of Veoceratodus, in fact, represents a highly specialized dipnoan type, retaining rery little of the primitive fish type. The loss of the hyomandibular causes the loss of several muscles common to the elasmobranchs and the teleosts. 
IIUSCLES OF THE ADDUCTOR OR TEMPORAL GROUP (INNERVATED BY $V_{3}$ )

Adductor mandibulæ (Ad. m.).

MUSCLES OF THE DEPRESSOR OR DIGASTRIC GROUP

(INNERVATED BY VII)

Levator operculi (L. o.).

MUSCLES OF THE ADDUCTOR OR TEMPORAL GROUP $\left(\right.$ INNERVATED $\left.B Y V_{3}\right)$

Adductor mandibula. - The adductor muscles of Neoceratodus are the largest found in fishes. The adductor is divided into two slips-a masseter $\left(A d m^{1}\right)$ and a temporal $\left(A d m^{2}\right)$-which give the cutting and crushing power to the powerful dental plates.

(a) The masseter slip $\left(\mathrm{Adm} \cdot{ }^{1}\right)$ is quite small and much shorter than the temporal portion of the adductor. It arises in the quadrate region and extends forward to he inserted hehind and below the insertion of the rest of the adductor. It also has a small tendinous sheet, but it is small in comparison with the sheet of the main adductor.

(b) The temporal slip $\left(\mathrm{Adm}^{2}\right)$ is the larger of the two muscles. It arises along the cartilaginous brain case, extending from a point anterior to the eyes to the posterior part of the brain capsule and extending well down on the sides. It is also attached to the bones of the roof of the skull, where they cover it. In dissection the muscle is seen to be broken up into small bumdles that are attarherl to the side walls of the skull. In the median line the cartilaginous skull does not extend to the roof of the skull in the region of the adductor muscles, so that the muscles fill this gap. They nearly meet in the midline, being separated only by some tendons of the long neck muscles and by fascia. This part of the addurtor is dividerl by a great tendinous sheet to which the fibers from both sides join. It is very heavy and thick, thus giving great power. It is inserted on the coronoid region in the Meckelian cartilage region.

\section{MUSCLES OF THE DEPRESSOR OR DIGASTRIC GROUP}

(INNERVATED BY VII)

Leiator operculi.-The levator is the only other muscle in the upper part of the skull. It arises on the posterior face of the lower part of the artilaninom capsule and is inserted on the inner side of the opereular region.

The mandibles are depressed by the long ventral muscles that are attarchel to the mandihles close to the symplysis and by the hyoid muscles. 
The loss of the hyomandibular and the degeneration of the opereular bones has caused the loss of the usual muscles of this region of teleosts.

\section{AMPHIBIA}

RANA

Plate $\mathrm{V}$, Figs. 1, 2

The fundamental resemblance in the skull of Anura to some of the fossil Imphibia, for example, such as (acops and E'ryops, is quite striking. These are incleed so much like the Anura that in studying them for restoration of the muscles it was found that the musculature demanded was invariably of the anuran type. Cacops in side view shows a type of covered skull that has opened out to a certain extent in the temporal region, while remaining whlid in the doral region. Some of the morlern Anura, $i$. e., Pipa americana, show something of the covered condition found in the stegocephalians. giving some likenesses to the fosil forms. although this resemblance may well be secondary. Eryops, also, is very much like the Anura in the palatal region, although the dorsal part of the skull appears to be quite different, because of the complete covering of dermal bones which it has retained from its early fish ancestors.

The frog skull represents a fenestrated condition of the roofed skull, with the palatal, postorbital and temporal region cleared of their bony covering. There is a light musculature in the jaw region to meet the conditions of the weak mandibles. It has been suggested (Gregory, 191\%) that this similarity of the Anura and the stegocephalians is more genetie than convergent and that our Anura may indeed represent certain remuants of stegorephalians in which the roof of the skiull berame fenestrated.

The jaw muscles in the frog, on account of the great open palatal region, are all on the posterior part of the skull, as there is no place for the muscles at the front part of the skull. The jaw muscles of the Anura are given the mammalian names by Ecker and Wientersheim (1896-190t, pp. 133-136).

MUSCLES OF THE ADIUCTOR OR TEUPORAL GROUP

$\left(\right.$ INNERVATED BY $\mathrm{T}_{3}$ )

Capiti-mandibularis superficialis.

(a) Pars major (Nasseter major of E. and W.).

(b) Pars minor (Masseter minor of E. and W.).

Capiti-mandibularis profundus (Pterygoideus of E. and W.).

Pterygoideus anterior (Temporalis of E. and W.). 


\section{MUSCLES OF THE DEPRESSOR OR DIGASTRIC GROUP} (INNERVATED BY VII)

Depressor mandibulx (E. and W.).

MUSCLES OF THE ADDUCTOR OR TEMPORAL GROUP $\left(\right.$ INNERVATED $B Y V_{3}$ )

(apili-mundibularis suprerficialis.-This muscle is divided into two parts by Ecker and Wiedersheim and called by them masseter major and masioter minor. It seems to be a muscle representing the superficial part of the capiti-mandibularis mass and may represent the two portions, as it is divided in the reptiles in this paper.

(a) Pars major.-This arises by two heads, one from the zygomatic process of the squamosal and the other from the lower quadrant of the tympanic annulus. It is inserted on the upper edge and outer sirle of the mandible and serves to tighten the ear-drum, thus acting as a tensor tympani.

(b) Pars minor.-This is smaller than the major and posterior to it. It is double-headed also, arising from the anterior horder of the posterior arm of the squamosal and from the lateral knoh of the quadratojugal. It is inserted on the mandible, posterior to the major. It is much shorter than the major.

Capiti-mandibularis profundus (Pterygoideus of E. and W.).-This is posterior to the eye and is covered by the pterygoideus anterior (temporalis of $\mathrm{E}$. and $\mathrm{W}$. .). It originates on the fronto-parietal and proötic and is inserted on the coronoid process, just posterior to the insertion of the pterygoideus anterior (Temporalis).

Pterygoideus anterior (Temporal of E. and W.).-This is a large muscle that fills most of the space hetween the proötic and the eres. It curves arome the annulus of the ear. covering the capiti-mandibularis profundus and going under the pars major of the capiti-mandibularis superficialis. It is a double-headed muscle. one head arising on the ridge between the proötic and the fronto-parietal, while the second head, arising on the anterior edge of the posterior limb of the squamosal, joins the first and is inserted on the coronoid process of the mandible. I call it pterygoideus anterior hecause it appears to be homologous with a muscle of the same name in the Reptilia.

MUSCLES OF THE DEPRESSOR OR DIGASTRIC GROUP

$(I N N E R V A T E D \quad B Y \quad V I I)$

Demeser mandibula (Ecker and Wiedersheim). - The depressor of the jaw is a large muscle that covers the posterior part of the skull, orerlap- 
ping the other muscles of that region. It is ilouble-headerl, arising on the posterior upper limb of the squamosal and from the lower part of the annulus trmpanicus and from the dorsal fascia. The anterior head arises on the posterior limb of the squamosal and from the lower part of the tympanic annulus. It joins with the posterion portion and is inserted on the angular. The hearl that arises on the horsal fascia springs from the region of the upper part of the scapula and extends down to join the anterior or cephalic portion of the muscle. The anterior hear tightens the ear-drum and lowers the jaw.

\section{CRYPTOBRANCHUS}

Plate V, Figs. 3, 4

The skull of Cryptobranchus (using this name in a broad sense to include the American and Japanese forms) is much depressed and widened. The squamosal is far up on the skull, maling a shoulder and groove around which the temporal muscles ride, so that their path is well fixed. The pterygoids are flattened out to fill the region posterior to the palate and to supply good origins for the muscles.

\section{MUSCLES OF THE ADDUCTOR OR TEMPORAL GROUP}

$\left(I N N E R V A T E D \quad B Y \quad V_{3}\right)$

Capiti-mandibularis superficialis (C.m.s.).

= Masseter (Osawa).

$=$ Petro-tympanicus (Hoffmann).

Capiti-mandibularis profundus (C.m. p.).

= "Temporalis" (Osawa).

Pterygoideus posterior.

= Pterygoideus (Hoffmann and Osawa).

Pterygoideus anterior.

= Temporalis of Osawa.

$=$ Fronto-parieto-maxillaris of Hoffmann.

MUSCLES OF THE DEPRESSOR OR DIGASTRIC GROUP

(INNERVATED BY VII)

Depressor mandibulæ (D. m. ${ }^{1}, \mathrm{D}, \mathrm{m}^{2}{ }^{2}$ ).

= Digastric of Humphrey.

= Cephalo-dorso-maxillaris of Hoffmann. 


\section{MUSCLES OF THE ADDUCTOR OR TEMPORAL GROUP}

$\left(\right.$ INNERVATED BY $\left.V_{3}\right)$

Capiti-mandibularis superficialis (C.m.s.).-This muscle covers the lower part of the temporal muscles. Its fibers extend posteriorly as they do in most urodeles. It arises on the whole outer face of the squamosal and extends over the pterygoid bone to be inserted on the posterior half of the exterior face of the mandible.

Capiti-mandibularis profundus (C.m.p.).-This is the posterior slip of the muscle called "temporal" by Osawa. It is a thin muscle that arises on the third neck vertebra, extends forward to join the pterygoideus anterior and is inserted on the inner side of the mandible.

Pterygoideus posterior.-Very small in this form.

Pterygoideus anterior (Pt. a.). - This is the anterior part of the temporal muscle of Osawa. It arises on the pre-frontal and fronto-parietal, extends under the eye and converges rapidly to a narrow tendon, and is inserted on the coronoid process and in the fossa. This muscle is a part of the muscle usually called a temporal muscle. but it is comsidered as the homologue of the muscle found in the reptiles alled pteryoideus anterior in this paper.

WUSCLES OF THE DEPRESSOR OR DIGASTRIC GROUP

(INNERVATED BY YII)

Depressor mandibute (D. m. ${ }^{1}, \mathrm{D} . \mathrm{m} .{ }^{2}$ ). - This is a double-headed muscle, as it is in all of the amphibians. It arises on the dorsal and posterior part of the squamosal, with a second part arising from the dorsal fascia. The anterior part arises from the otic region and from the posterior, upper face of the squamosal. Both parts are imserted on the upper and outer face of the angular bone of the mandible.

\section{ATIPHIUMI}

Plate Y, Fig. 5

The skull is elongated and there is a prominent sagittal crest so that a deep fossa is formed for the muscles of the upper part of the skull. The skull roof is open so that the muscles have free play, as in most urodeles. The pulley arrangement of the dorsal muscles gives a rery definite action to the jaws and is probably correlated with the backward extension of the capiti-mandibularis profundus, which is attached to the vertebra of the neck. 
MUSCLES OF TIIE ADDUCTOR OR TEMPORAL GROUP

(INXERVATED BY $V_{3}$ )

Capiti-mandibularis superficialis.

= Masseter.

$=$ Petro-tympano-maxillaris of Hoffmann.

Capiti-mandibularis profundus.

$=$ Posterior head of the temporal of others.

$=$ Fronto-parietal maxillaris (Post part) of Hoftmann.

Pterygoideus posterior.

= Pterygoideus.

$=$ Pterygo-maxillaris of Hoffmann.

Pterygoideus anterior.

$=$ Anterior slip of the temporal of others.

= Anterior part Fronto-parieto-maxillaris of Hofimann.

WUSCLES OF 'THE DEPRESSOR OR DIGASTRIC GROUP'

(INIERTATED BY TII)

Depressor mandibulæ.

MUSCLFS OF THE ADDUCTOR OR TEMPORAL GROUP

(INIEIRYATED BY $\left.V_{3}\right)$

Capiti-mandibularis superficialis (C.m. s.).- This is the outer or masseteric slip of the temporal mass, which covers over the other temporal muscles. It has a double head; the anterior arising on the large, outer face of the squamosal, while the posterior head arises on the rentral part of the same face. It is inserted on the outer face of the mandible on the posterior half.

Capiti-mandibularis profundus (C.m. p.).- This posterior part of the temporal mass arises from the fourth cervical vertehra, extends around over the groove on the skull, and, becoming tendinous, joins with the anterior part of the muscle called ptergenideus anterior in this paper. It is inserted on the coronoid region and in the fossa.

Pterygoideus posterior (Pt. n.).-This is a large muscle in Amphiuma, arising on the pterygoid under the apriti-mandibularis superticialis. It is inserted on the coronoid process. prosterior to the insertion of the other temporal muscles.

Plerygoideus anterior (Pt. a.). - This is the anterior part of the muscle usmally called the temporal. It arises along the groove on the frontoparietal and from the orhito-sphenoid. It extends downward, maldly

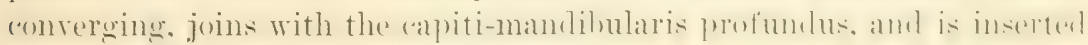
in the coronoid region of the mandible. 
MUSCLES OF THE DEPRESSOR OR DIGASTRIC GROUP

(INNERVATED BY VII)

Lepressor mandibula (D. m.).-This is a double-headed muscle, as in most urodeles. The anterior portion arises on the posterior face of the squamosal, the posterior from the dorsal fascia. They are inserted on the outer, dorsal face of the posterior end of the mandible.

\section{AMBLYSTOMA}

Plate V, Figs. 6, 7

The remaining urodeles are very similar in musculature, at least in the three forms studied in this paper. About the only difference is the separation of the lower, inner part of the temporal mass to form a separate pterygoideus posterior.

MUSCLES OF THE ADDUCTOR OR TEIPORAL GROUP

$$
\left(\text { INNERVATED BY } V_{3}\right)
$$

Capiti-mandibularis superficialis (C.m. s.).

$=$ Masseter.

Capiti-mandibularis profundus (C. m. p.).

$=$ Posterior slip of the temporal.

Pterygoideus posterior (Pt. p.).

$=$ Pterygoideus.

Pterygoideus anterior (Pt.a.).

$=$ Anterior head of the temporal.

IIUSCLES OF THE DEPRESSOR OR DIGASTRIC GROUP (YYIERVATED BY VII)

Depressor mandibularis (D. m.).

\section{REPTILIA}

\section{CHELYDRA}

Plate VI, Figs. 1, 2

The primitive chelonian Proyanochelys is the earliest known representative of the Chelonia. Unfortunately it is known only by the cast of the interior of the shell. Although the skull is mnknown it was probably of the heavily roofed type, something like that of the existing Chelone. Wratson (1914, pp. 1011-1020) describes the Permian genus Eunotosaurus as a probable ancestor of the Chelonia. It is quite probable that the ancestral chelonians were like the cotylosaurs with the temporal region 
of the skull covered and that there never has been a representative of this group with any fenestration of the lizard type. They have adopted a different scheme for the opening of the temporal muscle region by the posterior excision of the temporal rouf, leaving the muscles of the hear more or less bare. Except posteriorly, the roof is complete in C'hetone and there is a progressive reduction of the roof in the modern forms through Chelydra ant Triomle. until finally the opening is omplote in Cistudo, where even the jugal has lost its hold on the quarlrate. These forms thus give a morphological series. The reluction of the temporal roof is analogous to the fenestration of the skull in other orders of reptiles, where the temporal roof is perforated dorsally and laterally.

The great occipital rest indicates a corresponting tempral muscle in Chelonia, where the muscle extends hehind the condyle and lack orer the vertebre of the neck. The quick snap of the jaws of Chelydre and Trionyx is due to the extension of the occipital crest which gives the temporal muscle a long origin and an ohlique angle of insertion. The great separation of the squamosal from the prietal causes the depressor mandibula to slip down from its usual origin on the parietal to the outwardly projecting squamosal.

The turtle with its monimostylic skull has very simple jaw muscles, only three muscles being differentiated.

MUSCLES OF THE ADDUCTOR OR TEMPORAL GROUP

$\left(\begin{array}{llll}\text { INYERVATED } & B Y V_{3}\end{array}\right)$

Capiti-mandibularis (C.m.).

= M. Occipito-squamoso-maxillaris, Hoffmann (1890).

= Schläfenmuskeln, Wiedemann.

= Temporalis, Bojanus, Stannius, Cuvier, Owen.

Pterygoideus anterior (Pt. a.).

= Pterygo-maxillaris, Hoffmann.

= M. Pterygoideus, Bojanus, Owen.

= Flügelmuskel, Wiedemann.

$=$ Pterygoideus internus, Stannius.

MUSCLES OF THE DEPRESAOR OR DIGASTRIC GROUP

(INNERTATEI) BY III)

Depressor mandibulæe (D.m.).

= Digastricus maxillæ, Bojanus.

= Squamoso-maxillaris, Hoffmann.

= Masseter (apertor oris), Wiedemann.

= Apertor oris, Owen.

= Senker des unterkiefers, Stannius. 


\section{MUSCIES OF THE ADDUCTOR OR 'TEMIPORAL GROUP'}

$\left(\right.$ INVERVATED $\left.B Y V_{3}\right)$

Capiti-mandibularis (C.m.).-This represents the large capiti-mandihularis of the other reptiles and the adductor mandibularis of fishes, or at least a part of it. It is peculiar in the turtles in that they have developed a great occipital spine that supports this muscle. It arises on the following lones: proitic, quarlrate, parietal, squamosal, occipital spine, opisthotic. It is inserted on the posterior part of the mandible.

Pterygoideus anterior (Pt. a.).- This is the large ptergoid muscle of reptiles with a monimostrlic skull. It covers the floor of the pterygoid and palatine region and has a firn hold on the edge of the palatal racuities. It arises on the pterrgoids and palatines, extending almost under the eves, from the parietal, pterygoid, proötic and quadrate. It is inserted on the inner face of the prearticular. It does not wrap around the mandible on the outside as it does in most reptiles.

\section{MUSCIES OF THE DEPRESSOR OR DIGASTRIC GROUP}

(INIERYATED BY VII)

Depressor mandibuloe (D. m.).-The backward growth of the squamosal has captured this muscle so that it now is attached to it, instead of to the parietal, as in most reptiles. In Chelydra the whole origin is on the large and prominent syumosil. which may he explained hy the assumption that the growth of the squamosal pushed hack on the depressor mandihula (parieto-mandihularis), and that, wratually, the attarhment on the squamosal became more important, and finally the origin on the parietal was lost, as a result of the shifting of the bones of the skull. The depressor mandibulite is attached alomg the upper, posterior face of the squamosal and is inserted on the monder surface of the articular.

There is much in the condition of the skull in turtles to suggest the cotylosaurs, and I assume that the muscular system must have been similar.

\section{SPHENODON}

Plate VI, Figs. 3,4

The supratemporal fenestra of Sphenoiton gives exit to the temporal portion of the capiti-mandibularis on top of the skull, while the lateral temporal fenestra permits the masseter portion to expand freely in mastication. Owing to the fixed or monimostylic condition of the quadrate, there is very little movement either of the fore part of the skull upon the back part or of the pterygoid region. In correlation with this immobility the specialized pterygoid muscles are absent. 
The jaw muscles of Sphenodom are slightly more subdivided than those of Chelydra. in correlation with the more open construction of the skull.

MUSCLES OF TIIE ADDUCTOR OR TEMPORAL GROUP

$\left(\right.$ INYERTATED $\left.B Y \mathrm{~V}_{3}\right)$

Capiti-mandibularis.

(a) Capiti-mandibularis superficialis (C. m. s.).

= Onter fibers of Osawa's temporal.

(b) Capiti-mandibularis medius (C. m. m.).

='T'emporalis, Osawa (superficialis).

(c) Capiti-mandibularis profundus (C. m. p.).

= Pterygoideus externus, Osawa.

Pterygoideus anterior (Pt. a.).

JUSCLES OF THE DEPRESSOR OR DIGASTRIC GROUP

(INYERTATED BY YII)

Depressor mandibulæ (D. m.).

= Parieto-mandibularis, Osawa.

IUUSCLES OF THE ADDUCTOR OR TEIIPORAL GROUP

$\left(I X V E R Y^{\top} A T E D \quad B Y Y_{3}\right)$

Capiti-mandibularis.- This muscle is the large muscle mass of the reptiles and it is taken to represent the mother mass of several muscles as is mentioned elsewhere in this paper. It sems to be the conjoined masceter and temporal fibers, so that the divisions of the muscle are given the names used below.

(a) Capiti-mandibularis superficiatis (C. m. s.). - This part of the temporal mass consists of the fibers that always extend over the deeper fibers in the reptiles.

(b) Capiti-mandibularis medius (C.m.m.).-This is the inner part of the main mass, or the temporal of Osawa. The capiti-mandibularis mass arises in the temporal fossa on the parietal, squamosal, quadrate, the inner side of the jugal and from the temporal fascia. It is inserted on the point of the coronoid and on the inside and outside of the posterior third of the mandible.

(c) Capiti-mandibularis profundus (C.m. p.).-This decper section of the temporal mass is separated in this form from the rest of the tem-

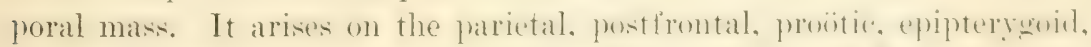
the membrane between epinterreois and the proitic and from the outer face of the pterygoid. 
Pterygoideus anterior (Pt. a.).-This short, strong muscle arises on the ventral border and inner side of the quadrate, from the inter-orbital floor, pteryonil and transverse. It has the typical reptilian insertion of this muscle. wrapping aromed the posterior ent of the articular. It is inserted on the melial face and rentral borler of the posterior fifth of the mandible.

MUSCLES OF THE DEPIESSOR OR DIGASTRIC GROUP

(INNERVATED BY VII)

Depressor mandibula (D. m.).-This muscle, the homologue of the lepressor of other animals, is caller parieto-mandibularis by Osawa. It is a large muscle which arises from the posterior border of the parietal, from the ligamentum nuchar, and to a slight extent from the squamosal. It is inserted on the posterior face of the articular or on its retroarticular process.

\section{ALILIGATOR}

Plate VI, Figs. 5, 6

In the alliwator skull there is a great reduction of the posterior region and a corresponding elongation of the antorbital region. The palate is closer by the approximation of the secondary shelves of the maxilla, palatines and pterruoids, so that the condition partly resembles that of the mammals. The pterygoids are also rery closely appressed, so that the posterior internal nares are forced far to the rear and are almost ventral to the articulation of the mandible with the quartrate. There has been a progressive reduction of the temporal fenestra, so that the heavily roofed skull of the alligator represents the specialized modern form of an ancient order that had a much more open skull with large fenestræ and very different proportions of the skull. The supratemporal fossa has been reduced until it is almost rudimentary, while the rest of the posterior region has also been encroached upon until the muscle space is quite small. The qualrate has shifted its position by inclining posteriorly, giving the animals a much larger gape; the quadrate is fixed or monimostylic. The auditory region is much changed by the secondary closing of the otic notch, so that the meatus appears to be in a different positim: hut this conclition is merely the result of the closing in of the noteh. so that its original position is masked. The small size of the posterior rewom of the skull and the corresponding reduction of the capiti-mandibularis is in a way compensated for by the great development of the pterygoideus anterior muscle which has extended over the floor of the 
palate and into the maxilla. This musele has an important part in the closing of the long mandibles.

The jaw muscles of the alligator are of the type found in monimostylic reptiles. The fixed pteryegids and palatines demand no museles for their morement and consequently the muscles that function in Foranus and other streptostylic forms are not differentiated. The muscles of the capiti-manclibularis are pinched up. especially in the temporal section, as the temporal fossa is much reduced in most modern Crocodilia. 'This reduction is secondary, for the early fossil forms show no such reduction, but rather the opposite condition, with lare supratemporal and laterotemporal fenestræ and small orbits. Most of the Mesosuchia show a large supratemporal fenestra as in Toleosturus. where the fenestrue are of large size. There is a progressive closing of this fenestra from Totensaurus of the Jura through Geosaurus, Goniopholis and Tomistoma. This closing and the pinching in of the temporal region means that the outer, or masseter, slip of the capiti-mandibularis (capiti-mandibularis superficialis) is enlarging and is taking over the principal work of closing the jaws, while the temporal slip is being progressively reduced. The pterygoid muscle is peculiar in that its anterior portion (ptervonicteus anterior) has dug its way under the eve and into the maxilla, extending to a point far anterior to the eye, since it lies on the palatine and penetrates far into the maxilla. The depressing of the jaw is done by the usual muscle, the depressor mandibulie. The crocodilia spend much of their time lying on the mur, and the action of the depresor in this position is to raise the hear if the mandible is resting on something fairly firm. The Crocodilia have some peculiar external ear muscles, necessary in the crocodile from the advanced condition of the ear with its external flap. The nerves divide the muscles into two groups.

MUUSCLES WW THE ADDUCTOR OR TEMPORAI, GROUP

$\left(\begin{array}{llll}I N V E R V^{+} & \text {TED } B Y \mathrm{~V}_{3}\end{array}\right)$

Capiti-mandibularis.

(a) Capiti-mandibularis superficialis.

= Masseter portion.

(b) Capiti-mandibularis medius.

= Temporal slip.

(c) Capiti-mandibularis profundus.

$=$ Deep part of temporal mass.

Pterygoideus anterior.

= Pterygo-mandibularis, Bradley.

Pterygoideus posterior, Lubosch. 
MUSCLES OF THE DEPRESSOR OR DIGASTRIC GROUP (IXNERYATED BY VII)

Depressor mandibulæ.

MUSCLES OF THE ADINUCTOR OR TEMPORAL GROUP (IXIERT ATED HY $\mathrm{T}_{3}$ )

Capiti-mandibularis.

(a) Capiti-mandibularis superficialis (C. m. s.).- This is the outer slip of the temporal mass, which does most of the work in the closing of the jaw. It arises on the parietal, squamosal, quadrate and quadratojugal and is inserted in the supramectelian fossa, extending forward into the dentary. It fills the region of the skull behind the pterygoids. The large extermal fenestra of the mandible gives the muscle room for expansion. The superficial layer (masseter) is subdivided into several layers, one being attached to the surangular.

(b) Capiti-mandibularis modius (C. m. m.).-This is the smaller of the slips of the mass. It extends down on the inner side of the capitimandibularis mass, arising on the homes surromeling the supratemporal fossa, into which it extends. It arises on the parietal, squamosal and postfrontal. Its insertion is on the coronoid, where it curves around the anterior edge of the capiti-mandibularis superficialis and extends under this slip to the mandible. The mandibular nerve separates it from the superficial slip. A small capiti-mandibularis profumdus (pteryoidens post. Lubosch) attaches to the tendon of this muscle. Lubosch (1914, p. $699)$ says :

Sehen wir rom Masseter und Pterygoideus anterior ab, so inseriert der sehr schwahe, zweischichtige Temporalis mit einer kräiftigen kurzen Sehne am complementare. Ein Teil der Fasern endet an einer knorpelharten Zwisehensehne. Von dieser Zwischensehne entspringen fraglichen Muskelportionen, welche ihrerseits zum Pterygoideus posterior gehören.

(c) Capiti-mandibutaris profundus (C. m. p.).-This small muscle which joins the temporal mass is given this name, as it is assumed to belong to the inmer layer of the temporal mass.

Pterygoideus anterior.-This anterior slip arises on the palatine, maxilla. pteryoid and transverse (ectopteryoid), extending over the floor formed by these bones and digging into the maxillæ. It extends inward to the limits of the narial passage. This muscle is the same as the creat piteryoud muscle in chelydre and is typical of the monimostylic reptiles. In the crocodile, however, it has a much greater forward extension. 
Pterygoideus posterior. - This muscle (called poteryondeus posterior hy Lubosch, who also includes a small slip that joins the capiti-mandibularis), arises on the quadratojugal and quadrate and joins with the anterior slip to be inserted on the mandible. A small slip from this joins the temporal mass and is designated as the profundus in this paper.

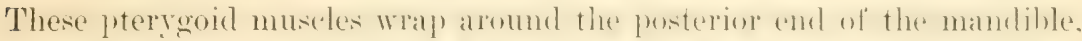
where they swell out, making a lange maks on the postoro-rentral side of the jaw. This enlarement of the muscle at its insertion is paralleder in Cryptobranchus, as observed by Lubosch (1914, p. 698), who says: "Der Pterygoideus, zerfällt seiner Innervation nach wiederum in zwei Komplexe, der Pterygoideus anterior und der Pterygoideus posterior, worin Übereinstimmung mit Verhältnissen der Urodelen besteht."

\section{WUSCLES OF THE DEPRESSOR OR DIGASTRIC GROUR}

(INVERTATED BY VII)

Depressor mandibula.-This is the typical depressor of the reptiles, arising on the parietal, squamosal and exoccipital. It is firmly inserted on the posterior prolongation of the articular.

\section{IGUANA}

l'late VII, Figs. 1, 2

The skull of Iguana is of the streptostylic type, although it is quite solidly constructed and much less specialized than that of Taranus. There is very little movement in the quadrate and pterygoid region, so that the muscles that move these parts in Taranus are not differentiated. The rest of the jaw musculature is very similar to that of Taranus, which is more fully described under its section in this paper. 'The fenestration in the temporal region of the skull of Iguana is similar to that of Varanus, with a large supratemporal fenestra and with a large sinus below the postorbital and squamosal, this giving the muscles plenty of room to expand. The skull has accommodated itself to the muscles in several ways. The supratemporal tenestra is latge and the parietal has expanterl dorsally and posteriorly to make a latege origin for the captiti-mandilularis.

MUSCLES OF THE ADDUCTOR OR TEMPORAL GROUI

(INAERVATED $B Y \mathrm{~V}_{3}$ )

Capiti-mandibularis.

(a) Capiti-mandibularis superficialis.

= Masseter slip. 
(b) Capiti-mandibularis medius.

$=$ Temporalis.

(c) Capiti-mandibularis profundus.

= External pterygoid of Mivart.

$=$ Pterygoideus externus, Hoffmann.

= Pterygo-mandibularis, Hoffmann.

$=$ Internal pterygoid, Sanders.

$=$ Entopterygoid, Sanders.

= Pterygoidien externe, Cuvier, Duméril.

Pterygoideus anterior.

$=$ Pterygoidien interne, Cuvier, Stannius.

$=$ Pterygoideus internus, Hoflmann.

$=$ Internal pterygoid, Mivart, Edgeworth.

$=$ External pterygoid, Sanders.

$=$ Ectopterygoid, Sanders.

$=$ Pterygo-mandibularis, Bradley, Watkinson.

$=$ Pterygoideus, Versluys.

MIUSCLES OF THE DEPRESSOR OR DIGASTRIC GROUP

(INNERVATED BY YII)

Depressor mandibulæ.

MUSCLES OF TIEE ADDUCTOR OR TEMPORAL GROUP

(INNERVATED BY $V_{3}$.

Capiti-mandibularis.-This is the large temporal muscle which is divided into three slips in this paper.

(a) Capiti-mandibularis superficialis (C. m. s.).-This masseter slip is lower down on the outside of the mass. It arises on the quadrate, squamosal and quadratojugal. Its fihers extend over the fibers of the temporal slip and blent with them to be inserted on the coronoid and the dorsal edge of the mandible. They extend down on the outer face to quite an extent, which is not common in the reptiles, as usually the insertion is entirely on the inner side of the mandible. They also extend down on the inner side. This crossing of the temporal and the masseter slips gives two pulls to the mandible, a straight dorsal and a posterior one.

(b) Capiti-mandibularis medius (C. m. m.).-The temporal or median slip fills the temporal fossa; it arises on the parietal, postfrontal and sfuamosial. The supratemporal fossa is larece and the parietal is extended out, so as to furnish a large insertion for this part of the muscle. It extends down between the masseter and the inner slip to be inserted on the mandible. 
(c) Capiti-mandibularis profundus (C. m. p.).-This muscle is the homologue of the muscle of the same name in larams and is strongly developed in reptiles with a columella cranii (epipteryoid). It arises on the outer face of the epipteryoud and on the outer lace of the pterygoid, extends rentrally, and is inserted on the mandible on the lower part of the posterior inner face of the mandible.

Pterygoideus anterior (Pt. a.).-This arises on the pterygoid and wraps around the end of the mamlible. The origin is on the molcer side of the pterygoid; from there it extends aromul the end of the mandible, making a large belly at the posterior ventral end. It is inserted along the ventral face of the angular and wraps around the articular, so that it is on the inside of the mandible at the posterior end.

\section{MUSCLES OF THE DEPRESSOR OR DIGASTRIC GROUP}

(INNERVATED BY TII)

Depressor mandibula (D. m.).-This muscle arises on the posterior face of the parietal, extends ventrally, and is inserted on the retroarticular process of the mandible.

\section{VARANUS}

Plate VII, Figs. $3,4,5$

The almost snake-like skull of Varanus is a typical example of the streptostylic skull, with the bones of the skull more or less movalble. especially in the quadrate region. 'There is a joint between the frontals and the parietals which has possibilities of morement, while the quadrate with its loose articulation on the squamosal and pteryogid forms another morable element. In fact the jaws, pterygo-palatine, and the qualrate region are all movable, with the posterior part of the skull as a base. The fenestrie are large so that the muscles have room for derelopment. The large supratemporal lenestra serves as the origin of the temporal slip of the capiti-mandihularis, while the lateral fenestra gives it rom for development. This fenestration approaches the ophidian type where the opening out has been complete.

The musculature of the pteryoid region is rery museh sperialized in the streptostylic forms and is a cxnotelic character. 'These special muscles conld not have been present in the cotylosiurs or stewerephalians. where there is no need of them. as the stull is rigil. The spredial muscles for moving the upper jaw and the facial part of the skull arise on the parietals, epipterygoid and basisphenoid and are attached along the whole npper surface of the ptergonid from the articulation with the transwerse 
to the quadrate. This type of musculature is carried to the extreme in the (Ophidia, where the streptostylism in complete and practically all of the bones are movable. There is a sharp contrast between the streptostylic and the monimostylic types of musculature; the streptostylic represonts high specialization, with great mobility of the skull parts and the demand for many muscles, while the solid monimostylic skull is rigid with the bones solidly fixed and attached by strong sutures, while the muscles present are of a simpler kind, namely, those needed to raise and lower the mandible.

There is much confusion in the nomenclature of the muscles owing to the fact that the mammal names are applied to them by most workers. The nomenclature would be cleared if the entire list of names were dropped and a new set adopted that had no direct reference to the names of the mammalian muscles. ${ }^{4}$

\section{IUSCLES OF THE ADDUCTOR OR TEMPORAL GROUP}

$$
\text { (INIERTATED BY } \mathrm{T}_{3} \text { ) }
$$

Capiti-mandibularis.

(a) Capiti-mandibularis superficialis (C. m. s.).

= Outer fibers of the capiti-mandibularis.

(b) Capiti-mandibularis medius (C.m.m.).

= Temporal of Bradley (whole mass).

(c) Capiti-mandibularis profundus (C. m. p.).

= Upper slip of the pterygoid of Bradley.

- Pterygoideus externus of Mivart.

Pterygoideus anterior (Pt. a.).

$=$ Pterygo-mandibularis of Bradley.

$=$ Pterygoideus internus of others.

Pterygoideus posterior (Pt. p.).

$=$ Lower slip of the Pterygoideus of Bradley.

Pterygo-parietalis (Pt. par.) (Bradley).

Pterygo-sphenoidalis posterior (Pt. sph. po.) (Bradley).

MUSCLES OF THE DEPRESSOR OR DIGASTRIC GROUP

(INVERTATED BY VII)

Depressor mandibulæ (D. m.).

MUSCLES OF THE ADIUCTOR OR TEMPORAL GROUP

(IYNERVATED IFY $\left.\mathrm{I}_{3}\right)$

c'apili-mumdibularis.-This is the large temporal muscle mass. divided into three parts in this paper.

${ }^{4}$ The papers nsed in the study of Varunus were: Bradley (1903) and Watkinson (1!)(i). 
(a) Capiti-mandibularis superficialis (C. m. s.) = Masseter portion. Arises on the quadratojugal, squamosal and quadrate.

(b) Capiti-mandibularis medius (C. m. m.) - This is the inner part of the temporal sheet arising on postfrontal, proitic, squamosal and quadrate under the fibers of the outer or masseteric portion. These two slips are not separate.

(c) Capiti-mandibularis mrofundus (C.m. p.).- The deeper portion of the mass. It arises on the parietal and is inserted on the coronoid along with the rest of the capiti-mandibularis. (A lower part of this muscle arises from the columella cranii and is considered as pteryoirleus posterior.)

Pterygoideus anterior (Pt. a.).- This muscle arises on the whole outer surface of the pterygoid (except the branch to the palatine) and is inserted on the posterior part of the jaw.

Pterygoideus posterior (Pt. p.).-This with the exception of the lowest part arises on the columella cranii and is inserted on the mandible, posterior to the insertion of the capiti-mandibularis profundus.

Pterygo-parictalis (Pt. par.).-This muscle is peculiar to reptiles with a rodlike columella cranii. It arises on the downward projection of the parietal and is inserted on the whole upper surface of the pterygoid, immediately in front of the articulation with the columella. It seems to represent a part of the inner layer of capiti-mandibularis profundus that separated oft for the service of the pterygoid. The same might be said of the muscle following.

Pterygo-sphenoidatis posterior. - This muscle arises on the basisphenoid below the gasserian notch and is inserted on the upper and lower surface of the pteryoid for its whole length to a level of the articulation of the basipteryouid process of the sphenoid and the pterygoirl. It pulls the pterygoid upward and backward. This may represent a lower slip from the capiti-mandibularis profundus.

IIUSCLES OF THE DEPRESSOR OR DIGASTRIC GROUP'

(INVERVATED BY VII)

Depressor mandibule (D. m.).- - It arises on the parietal and nuchal fascia and is inserted in the end of the mandible.

\section{Aves}

\section{GATIUS}

Plate VIII, Figs. 1, 2, 3

The musculature of the bird, Gallus. follows in most particulars that of reptiles. It offers one of the most convincing items of evinence that 
the birks and the reptiles are very close in their origin. The most important characters of the bird skull are:

(1) Grat expansion of the brain case with corresponding changes in the base of the cranium.

(2) Loss of the upper temporal arcade, the lower temporal arcade (quadratojugal and jugal) being left intact.

(i) Radial changes in the pterygoid and palatine region where great changes occur even within the class.

(4) Loss of teeth and assumption of a beak.

(5) Loss of sutures and lightening of all the elements. The bird skull is fundamentally similar to that of the primitive pseudosuchian EuparTicria capensis of Broom (1913). 'The maxilla, jugal and quadratojugal articulate with the quadrate in true reptilian fashion, while the quadrate is movable as in many reptiles.

\section{JUSCIES OF THE ADDUCTOR OR TEIIPORAL GROUP}

(INYERVATED BY $\mathrm{V}_{3}$ )

Capiti-mandibularis.

(a) Capiti-mandibularis superficialis (C. m. s.).

= Masseter of Shufeldt and Gadow.

(b) Capiti-mandibularis medius (C. m. m.).

$=$ Temporalis of Shufeldt, Gadow.

(c) Capiti-mandibularis profundus (C. m. p.).

Not present in Gallus.

Pterygoideus anterior (Pt. a.).

Pterygoideus posterior (Pt. p.).

MUSCLES OF THE DEPRESSOR OR DIGASTRIC GROUP

(INVERYATED BY VII)

Depressor mandibulæ.

MUSCLES OF THE ADDUCTOR OR TEMPORAL GROUP (INNERTATED BY $\left.V_{3}\right)$

The capiti-mandibularis mass of the bird is divided into separate muscles, and we assume that they are represented in the reptiles as unseluaterl parts of the capiti-mandibularis, and for that reason they are given the names used in the reptiles.

(a) Capiti-mandibularis superficiatis (C. m. s.).-This muscle may be rlividerl into two parts: one rises as a tendon from the bony ridge of the sfuamosil, above the auditory entrance; the other head which is fleshy arises from the quadrate. The insertion on the mandible is by 
tendon and by a fleshy slip); the tendon is inserted on the coronoid process and the fleshy slip extends along the outside of the mandible. This muscle is the most imprortant of the mandible, as it extends along the side and has a very wide attachment.

(b) Capiti-mandibularis medius (et profundus) (C. m. et p.).-.This muscle, usually called the temporal. is assumed to represent the middle and deep part of the reptilian capiti-mandibularis. The region for its origin is much reduced and there is no room for much differentiation of this part of the muscle. It fills the temporal fossa in the hirt. It arises from the hones surrounding the fossa, extends flownarl, posterior to the postorbital process, and is inserted on the coronoid process of the mandible.

Pterygoideus anterior (Pt. a.).-This is a large muscle that covers the floor of the skull at the posterior part of the palatines. It arises along this posterior part of the palatines, spreading out orer this to a part of the pterygoids and the orbito-sphenoid. The insertion is on the under sicle of the articular process and along the inner sicle of the mancible. This muscle pulls inward and forwart on the mandihle, thus pulling the quarlate forward - a movement that is very important in the Psittaci, where the maxillø are raised with the anterior part of the skull.

Pteryyoideus posterior (Pt. p.).- This is a smaller muscle that crosses the pterygoideus anterior, going under it. It arises on the orbital process of the quadrate and is inserted on the inner side of the mandible near the posterior end. It draws the mandible hackwart and pulls down on the quadrate, thus aiding in the closing of the jaw.

\section{MUSCLES OF THE DEPRESSOR OR DIGASTRIC GROUP}

(INNERVATED BY VII)

Depressor mandibula (D. m.).--The depressor of birds is the same as that of reptiles and amphibians, heing a part of the $\mathrm{C}_{2}$ mol of Ruge and innervated by the seventh nerve. In the birds it is short and thick, more like the same muscle in the Chelonia than like that of Sphenodon or Varanus. It arises on the squamosal as in the Chelonia, as this region has grown out laterally, so that the origin on the parietal is no longer wailable. It arises along the ridge of the sfuamosal ami is inserted on the retroarticular process as in reptiles. It opens the mamlihles with the aid of some of the long, ventral hyoid muscles of the throat region. 


\section{MIALMALIA}

The jaw muscles of the mammals are remarkably constant in character thromehout the groul), except in the monotremes and some edentates where extrandinary combitions occur. Thronghout the group the muscles are chesely correlated with the dentition and with function. The chewing muscles are limited to the digastric. masseter, temporal, pterygoideus externus and pterygoideus internus. There is much individual variation in these muscles, but they are always present, except the digastric, which is absent in some monotremes and edentates, and the internal pterygoid, which is sometimes not differentiated from the temporal.

The temporal fosse of the mammals are opened out, so that there is free play for the muscles, except where there is a secondary covering of plates.

The ramus mandibularis of the trigeminus nerve innervates all the muscles of mastication except the posterior belly of the digastric and its allies. The muscles innervated by $V_{3}$ represent what remains of the capiti-mandibularis of the reptiles. The temporal is the largest muscle of this group in most of the mammals. It is closely associated with the masceter, which is a slip that has separated completely in the mammals, but still remains a part of the temporal mass in the reptiles. The temporal is variable in its size, as the masseter is often larger, usurping its functions in the rodents and in some other groups. It is partially dirided in the mammals, as we find it with a single head in Homo and with three in the monotremes, but although the condition may vary the origin and insertion remain quite constant.

The masseter is much more variable than the temporal muscle. It is double-headed in man, and also is divided into two muscles in the monotremes, each with two slips, and we may have as many as five slips in the rodents. Its size and condition depend on the special conditions and the importance of the muscle. In the rodents, where it takes the place of the temporal to a certain extent, it is large and very much specialized. Its origin varies, as it may partly cover the temporal as in Didelphys, or may extend forward, anterior to the eyes in the rodents, or divide into two sulparate muscles as in the monotremes. This muscle in the mammals is always associated with the development of the zygomatic arch and represents the outer portion of the temporal mass that may be traced from the Pisces to reptiles. where the outer fibers of the capiti-mandibularis mass are always slightly differentiated from the deep fibers by having a different rirection, althomgh there is no separation in the reptiles to the extent found in mammals. The pull of the masseter is usually slightly forward, 
against the pull of the temporal, which, together with the pull of the pterygoid muscles, gives the stealiness that is necessary in the mandibles. In many cases there is a comnection of the masseter with the auditory region. In Tamandua (Lubosch, 1908, p. 541) this small muscle is seen, as it were, in the process of splitting off from the masseter and attaching itself to the tympanic. Bralypus rillosus (Luhosch) shows this same condition, where a small muscle extends from the angle of the jaw to the tympanic. This small muscle is innervated, according to Lubosch, by the auriculo-temporalis nerve. The tendency of the masseter to extend to the auditory region probably may go back to the reptilian condition, where this muscle was attached to the quadrate or to one of the bones in this region.

The ptergoid muscles arise on the hasicranial or ptergond region and, although usually small, they are of importance in the working of the jaws. They vary in form in different groups and the relation between the pterygoids and the dentition is rery close. They are largely developed in herbivorous but small in carnirorous mammals. They function in giving the jaw steadiness in opening and chosing: they prevent the heary temporal muscles from tearing the mandibles apart in forms with a loose symphysis and they make possible the grinding motion of the tecth in herbivorous forms. The elentates and monotremes offer exceptional conditions, for here the reduced or modified condition of the mandible makes the pterygoid muscle of little importance.

The internal pterygoid is the more important of the two, as it aids in the closing of the jaw and pulls inward against the pull of the temporal, masseter, etc. The external pterygoid pulls the jaw forward, out of the glenoid carity, and assists in this way in opening the jaw and in the forward movement of the jaw in herbivorous forms.

The origins of these muscles are plainly seen in mammalian skulls and the conclition of the pteryonid region has probably heen rery much molified by their action, as a comparison with the reptilian condition shows that the pteryoul region is pinched in and pulled to the rear. We assume that this condition has been hromelyt about lareely by the action of pterygoid muscles. In cynodonts the opposite pterronid homes meet in the

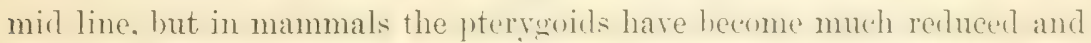
separated so as to leave the primary flow of the hrain catse exposed (hasisphenoid, presphenoid) (Gregory and Adams, 1915).

The capiti-mandibularis protumdus (extemal pteryouil) withe reptiles seems to be in a favorable position to give rise to the whole pterygoid mass of the mammals, since it is inserted on the coronoid region of the mandible, and might easily shift its insertion down on the imner side of 
the upgrowing dentary without interfering with the other muscles. No doubt its importance increased when the new joint was formed between the dentary and the squamosal and when the old anterior pterygoid muscle beame reduced. Its subdivision into two slips followed, which are the external and internal pterygoid of mammals.

The digastric muscle of mammals (Fig. 4) represents a part of the scound constrictor of the Pisces, joined with one of the rentral muscles of the throat region $\left(A, V_{3}\right)$. It is a muscle with two bellies, a tendon ustally sepating them, but this varies in different forms; so we may sar that the muscle varies from the so-called monogastric to the typical double-bellied condition. As stated below, the muscle is constant in mammals with the exception of monotremes and some edentates. It is the only compound muscle in the muscles of the jaw and represents two muscles, one innervated by the facialis, the other by the ramus mandibularis trigemini, joined end to end. but still retaining the old immervation. The older anatomists all homologized the posterior belly of the digastric with the depressor mandibula of reptiles and amphibians, but the work done on the immervation by Schulman, Luhosch, Ruge and others has shown that there is a common origin for them, but that they represent different slips from the same constrictor.

The variation of the digastric has been discussed by Chaine, Toldt, Bijroet. Parsons, Rourière, Fürbringer, Dobson, Futamura and others, so that there is not much left to work out in this line, although the interpretations of the authors are very variable.

Chaîne (1914) classifies the digastric of mammals as follows:

(a) Those with two bellies:

Macropus
Delphinus (Toldt)
Rodentia
Chiroptera
Insectivora $^{5}$
Prosimix

Bradypus
Artiodactyla
Carnivora
Pteropus
Simiæe

(b) Those with a single belly:

$\begin{array}{ll}\text { Hydrochorus } & \text { Cavia } \\ \text { Dotichotes } & \text { Lepus }\end{array}$

(c) Digastric absent:

Monotremes

Tatusia

Delphinus

Tursiops

In Talpa europacus there is a small tendon from the posterior belly to the mandible. 
Parsons' views (1898, pp. 436-437) are expressed in the following quotations :

'The most important point to bear in mind, in considering this muscie, is that it is not always really a digastric, but that even when it appears monogastric it has a double nerve supply. Our knowledge of the anatomy of fishes tells us that the muscles developed from the first, or mandibular arch, are supplied by the fifth nerve, while those formed in the second, or hyoid arch, derive their nerves from the seventh. In three Ornithorhynchi I found a muscle ruming from the sub-hyoid septum, outward and a little forward to the mandible, not far from the angle; it was supplied by the fifth nerve and lay superficial to the mylohyoid muscle, of which it appeared to be a delamination, and with which the fibers had the same general direction. In the same animal a single muscle runs from the long, tubular external auditory meatus to the subhyoidean septum; it is supplied by the facial nerve, and probably corresponds to the combined stylohyoid and posterior belly of the digastric. From this I am inclined to think that the anterior belly is an older muscle than the posterior, or, in other words, that the anterior belly is differentiated from the mylohyoid layer before the posterior belly is split off from the stylohyoid. This possibility may be the reason why the absence of the anterior belly of the digastric is rare in man, but the absence of the stylohyoid is fairly common.

\section{Describing the digastric with two bellies, Parsons says:}

In the first [type] the anterior and the posterior bellies are separated by a considerable length of tendon. The posterior belly runs forward until it is over the hyoid and then rums inward and meets its fellow from the opposite side, forming an arch. The anterior bellies of the digastric spring from this arch and go forward. The muscle is not attached to the hyoid but is connected by connective tissue.

This type is found in many rodents (sciuromorphs, Pteromys), in most ernomorph monkeys and in certain anthropoid apes (orangs. chimpanzee).

Parsons places under his second division those with a psendo-monogastric muscle. Here the muscle seems to have one belly, but there is always a small rudiment of the median tendon. This type attaches to the mandible, midway between the symphysis and the angle, and instead of forming flat planes meeting along the median line of the neck they are rounded, as some expanse of mylohyoid separates them.

Parsons' third type is that found in man, where the bellies are distinet with a tendon separating them, the anterior bellies not meeting in the median line of the neck but formard near the symplysis. This type is found in most lemurs, many monkers, especially the platrohini, gibbous (IIytobates) and in many specimens of gorilla. The stages are all united by transitional stages. 

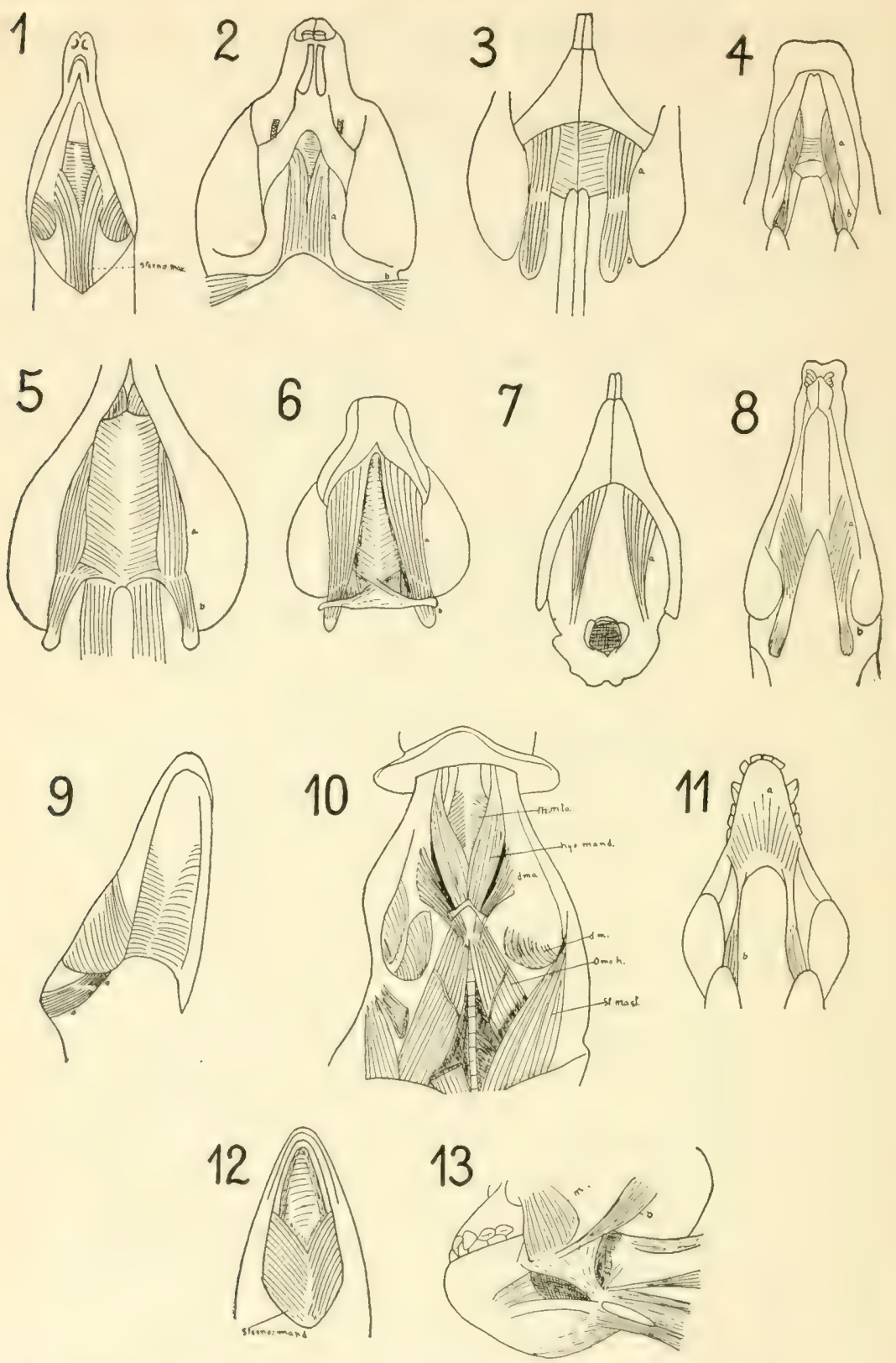
1. Tatusia
5. Macrolus
2. Pteromys
6. Felis leo
3. Cavia
7. Lepus
4. Bos

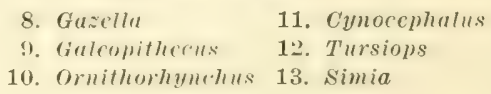


Parsons also mentions a fourth type, where there is a true monogastric muscle in which the anterior or the posterior belly is suppressed. It is found in lagomorph, or hare-like rodents. The posterior belly is represented by a small tendon in these. In many orangs the anterior belly is wanting and the posterior belly is attached close to the angle.

Parsons' division differs from Chaîne's in that he talies into consideration the condition of the anterior belly, whether joined with its fellow of the opposite side or free from it. Humplerey considered that the anterior belly was from the same myotome as the pteryoids, and the posterior belly was from the hyoid arch muscles, or hyoid myotome. He considered the tendon as a remnant of the myocommata connecting the two myotomes. These divisions of the digastric as given by Chaine and Parsons show some of the variations that are met with in this muscle. The posterior part of the muscle is not troublesme, hut the anterior part, or the part innervated by nerve $V_{3}$, has caused the anatomists much trouble.

Some of the ideas as to the homology of the anterior helly are interesting, and show the diversity of opinion on this topic. Bijroet (190s) gives an interesting summary of the ideas of different authors as to its origin. $\mathrm{He}$ considers that Ornithorhynchus shows the primitive stage of the

\section{DESCRIPTION OF FIgURE 2}

Variations of the digastric in mammals. (Mainly after Chrine and Parsons.)

The digastric muscle is found only in typical mammals and is not clearly recognizable in the monotremes. It is a compound muscle typically consisting of anterior and posterior bellies united by ligament. The anterior belly is probabiy a derivative of the primitive throat muscles of reptiles and is innervated by the mylohyoid branch of nerve $V_{3}$. The posterior belly probably represents a separate slip from the stylohyoid muscle, and both muscles are innervated by closely associated branches of the seventh nerve. r'robably both bellies of the digastric formerly converged toward the lower surface of the basi-hyal cartilages, along with the mylohoid and other muscles, and the tendinous portion between the anterior and posterior bellies may represent part of the fascia into which they were formerly inserted.

Probably the most primitive type is seen in the monotreme ornithorfynchus $(10)$. Iere the "detrahens mandibula anterior" $\left(D, m, a_{-}\right)$(which may be a slip of the mylo. hyoid) may represent the anterior belly of the digastric, while the posterior belly is not yet separate from the stylohyoid (l'arsons).

The marsupial yacropus (5) shows well the association of the anterior belly $(a)$ with the mylobyoid and the connection of both bellies with the basi-hyal. In most types the anterior and posterior bellies are both present and separated by tendon (as in Figs. $2,4,5,6,8,9,11)$. Either one of the bellies may be restigial or wanting. In No, 7 the posterior belly is reduced to a small tendon. In No. 13 the anterior belly is tendinous. The so-called monogastric types $(3,6,9)$ generally show at least a restige of the tendinous septum between the two bellies. In Nos. 1, 12 the digastric is entirely absent, being functionally replaced by other muscles. The posterior belly usually arises from the paroccipital process of the exoccipital. The insertion of the anterior belly varies greatly as well as its relations both to its fellow of the opposite side and to the inylohyoid (cf. Nos. 2, 3, $7,9,11$ ). It is primitirely inserted on the inferior border of the mandible beneath the masseter, but may shift either to the region of the symplysis ( 21 ) or to the posterior part. 
formation of the digastric and that the anterior belly is the detrahens mandibulæ, a muscle related to the stylohyoideus.

Chaîne (1914) thought that the digastric came from a muscle that originally stretched from the jaw to the sternum, that it lost its hold on the sternum and moved first to the vertebræ and then to its hold on the mastoid. He accounted for the tendon between the bellies of the digastric by assuming that it was a remnant of the segmental areas found in primitive muscles.

Dobson does not consider the digastric.

Futamura (1906, 190i) had some interesting ideas on the origin of the digastric of man. In the first paper on the digastric of man he says: "The dinastric is at first entirely supplied by the nervus facialis: later, as the anterior belly becomes constricted off from the posterior, the former obtains its motor nerve secondarily from the nervus mylohyoideus" (translation). He recants this in a later paper (190\%) as follows:

Der proximal Teil des Digastricus teilt sich in zwei Teile deren rorderer am Reichertschen Knorpel inseriert, deren hinteren um die hintere Seite des Knorpels herum ventralwiirts verliuft und am ventralen Ende des Meckelschen Knorpels inseriert. Der Muskel wird ron zwei Nerven bereits innerviert; N. facialis und N. mylohyoideus. Beim Menchen glaubte ich aussprechen zu diirfen dass die zwischensehne an der doppelten Innervierung des Muskels schuld sei. Das kann aber doch nicht der Fall sein, weil beim Schwein, bei dem der Biventer keine zwischensehne besitzt, doch die zweifache Innervierung nachzuweisen ist.

Gegenbaur (1898, p. 632) held that the anterior belly of the digastric came from the mrlolyyoid by splitting. He took the anterior belly from the mylohyoid and the posterior belly from the depressor mandibulie of the reptiles. He cited the horse with its peculiar condition, where there is a secondary insertion of the posterior belly on the angle of the mandible, as an indication of this.

His (1885, p. 92) derived the digastric from the sterno-cleido-mastoid, which he separates into two parts: the mylohyoideus and the outer tongue muscles. He derives the anterior belly of the digastric from the superficial layer and the posterior belly from the deep layer of the sternocleido-mastoid.

Leche (1889) liad the same idea as Futamura and thought that the diustric was a muscle with a single nerre and that it acquired, secondarily, a second supply from the trigeminus.

Rouvière (1906) derived the anterior belly from the same origin as the geniohyoid and says that in the fishes, amphibians, reptiles and bircts, anly the anterior helly is present. Te derives the posterior belly from 
the m. jugularis transversus, the same mass from which the stylohyoid is separated. He considers the digastric to be the result of the joining of these two muscles.

Toldt (1908) gives the following points on the anterior belly of the digastric:

(1) The digastric as such is found only in the mammals. 'The attempts to derive it from the muscles of the non-mammalia have not been successful. The hinder belly is not the depressor mandibula of the Sauropsida nor is it derived from the depressor of the monotremes. (Schulman shows that it is not derived from the depressor of monotremes.)

(2) The depressor of the monotremes is a special primitive condition and is a slip from the masseter innervated by $T_{3}$. The writer thinks this is not a primitive condition but a rery specialized condition in a primitive form.

(3) The anterior belly of the digastric has its origin with the $\mathrm{m}$. mylohyoideus muscle and belongs with the risceral muscles that extend along the floor of the mouth. They are innervated by $V_{3}$.

(4) The posterior belly is a part of the stylohyoideus in the lower vertebrates and is originally a visceral muscle intercalated between the musculature of the mouth floor and throat and directly or indirectly connected with the tongue bones.

(5) The joining of this originally separate muscle to the digastric, as well as the identity of the hinder belly and the stylohyoideus, is shown well in the monotremes. The line of separation is shown by the inscriptio tendinea.

Toldt correlates the condition of the digastric with the trpe of food that the animal eats and with the question whether the food is held in the mouth or swallowed immediately. This, he thinks, gives an explanation of the joining of the forward bellies in some forms and separation of them in some of the carnivorous forms. But a comparison of the varying forms of digastric seems to show that there is no correlation with food habits, as there seems to be no definite functional criteria by which the different conditions may be classified.

From a review of the literature on the digastric the variations are plainly evident both in the muscle and in the ideas conceming it. There seems to be no very stable insertion for the anterior belly. Its insertion varies from the inside of the chin, as in Homo, to the posterior part of the mandible, on the angle in some other forms. Only the anterior part is of uncertain origin, as most of the writers agree on the derivation of the posterior belly. The anterior part lends itself to hypotheses, as nothing definite seems to have beren boumht forwarl at the present time 
and all may be more or less right. The double innervation and the tendon seem to make certain the fact that the muscle has a double origin. Some of the older writers speak of a single-bellied digastric, but most of them agree that some evidence of the double origin always exists, and that in the monogastric muscles remains of the tendon are in evidence in the middle of the muscle, or, as in Lepus, the anterior muscle may be almost gone while the tendon remains to represent the junction of the two parts. In a few forms undoubtedly one of the muscles is missingthat is, one belly is missing and it is not really a monogastric muscle but a single belly in the sense that either the anterior or the posterior belly has disappeared, and not that the one represents both bellies.

So far I have spent very little time on the mylohyoid and the other rentral muscles, reserving them for future work on the comparative musculature throughout the vertebrates. The discussion of this phase of the jaw muscles is made very brief and merely points out some of the comprehensive work of Toldt, Chaîne, Rouvière, Bijyoet and others on the digastric musculature in the mammals.

The relation of the jaw muscles to the special types of dentition is very close throughout the mammalian groups. In fact a highly differentiated muscle system in which each muscle does a certain type of work alone makes posible the highly specialized dentitions of rodents and ungulates. The teeth of mammals are, roughly, of three kinds-herbivorous, carnivorous and degenerate. The herbivorous dentition is correlated with the pernliar type of condyle and glenoid joint that makes its specialized work possilyle. 'The condyle of the truical herbivorous animal is much rounded and the articulation in the glenoid cavity is flat, so that there is much freedom of movement. In chewing the jaw is rotated in a lateral, anteroposterior and vertical movement, so that to accommodate this movement the articulation must be very loose. Accordingly, there is always a well dereloped pterygoid region in the basicranial region, with well dereloped pteryoid muscles. This strong derelopment of the pterygoid muscles is characteristic of Hacropus, IIatmaturus, Castor, Sciurus, Equus and Bos. In these animals the molar teeth bear cross-ridges and the transierse motion needed for trituration is given by the strong pterygoid muscles. Many herbivorous mammals chew on one side at a time. The pterygoid muscle, acting in connection with the large temporal and masseter muscles of one side, make this movement possible.

In the rollents where the srmphysis is weak the pteryoid muscles also counterbalance the pull of the huge masseters, as in some of the forms with a weak symphysis the pull of the masseters alone would tear the jaws apart. 'The carnivorous mammals have an entirely different ar- 
rangement, as their jaw atem is primarily a straight opening and closing movement, either a hard, steady pull, or with a snap. 'The opposite halves of the mandible are usually strongly lastened together at the symphysis. The condyle is lengthened out laterally toward the median line and the glenoid cavity has a large protecting shelf to give a firm hold on the condyle. In fact in some of the carnivorous types with strong jaws the articulation is locked, so that the borders of the glenoid cavity must be broken in order to separate the mandible from the skull (Gulo luscus). With the shearing teeth and the locked type of articulation for the condyles of the jaw the pterygoid muscles are of little value and in carnivorous forms are always weak, as in Canis, Gulo, Lutra, Didelphys. In these animals the basicranial region of the skull shows the reduction of the pterygoid muscles.

\section{MONOTREMES}

Plate IX, Figs. 1-7

Skull.-The skull and jaws in both Ornithorhynchus and Echidna are of very aberrant and more or less degenerate types. In both genera, also, the pterygoid region is highly modified, and thus the homology of the so-called pterygoid elements is open to question. Ornithorynchus requires fairly strong jaws for the crushing of small molluse shells, while Echidmu has practically restigial jaws and hepends mostly on the tongue muscles.

The condition of the jaw musculature in the monotremes is quite suggestive of the reptiles. The massed condition of the temporal-masseter group suggest the condition of the capiti-mandibularis of the reptiles. The head muscles as a whole seem to be homologous with those of other mammals, especially as regarts the temporalis-masceter, pterygoidens extermus and muscles of the ventral hroil wromp, with the exception wh the anterior belly of the missing digastric, which may be represented by the muscle called depressor mandibulx anterior. However, this hyoid region in the monotremes is very specialized, so that the derivation of the anterior helly from this region is rather obscure, although some anatomists hold this opinion. It is probably a slip from the mylohyoid. The ducklike bill of the Ornithorhynchus repuires a spectal musculature which is developed from the $\mathrm{V}_{3}$ muscles.

The monotremes are so different from other animals in many impurtant details of their myology that it is probably correct to assume that they split off from the mammalian strm at a very early perion. This assumption is strengthened by the fact that the osteology and soft anatomy are 
also very aluerant, so that it is not strange to find different conditions in the musculature. The jaw muscles of monotremes include the following:

IUSCLES OF THE ADDUOTOR OR TEMPORAL GROUP $\left(\right.$ INNERVATED $\left.B Y V_{3}\right)$

Masseter

Temporalis

Pterygo-spinosus
Pterygo-tympanicus

Depressor mandibulæ anterior

Detrahens mandibulæ

\section{IIUSCLES OF THE DIGASTRIC GROUP}

(INNERVATED BY VII)

These are not present.

Monotremes have the following peculiar conditions of the jaw muscles: They have no true digastric. The masseter and temporal muscles are mascerl together. They have no pteryoidens internus. Presence of the ptergo-spinosus and pteryo-tympanicus. Presence of the detrahens mandibulix instead of the digastric. Extensive development of the mylohyoid group of muscles.

Absence of the digastric.-The digastric is fairly constant in the mammals except momotremes, erlentates and some Cetacea. Perhaps it is absent in the monotremes because they separated from the mammal stem at a very early period and thus have missed this arrangement. Ornithorhynchus with its fairly large jaws needs a depressor, and this function is filled by the detrahens muscle and by the depressor mandibulie anterior of the hroid croup. Echidna is so degenerate in the mandibular region that there is very little need for a specialized depressor. Other mammals in which this muscle is missing have degenerate jaws. Chaîne mentions Trlusin of the elentates and Defphimus of the Cetacea, where the true digastric has been lost.

Imperfect separation of the masseter and temporal.-The condition of the maseter-temporal mass in the monotremes is very suggestive of the capriti-mantibularis in the reptiles, as it is not differentiated as much as in other mammals. The mass has several heads, but the separation is not so (omplete. The peculiar shape of the skulls in the monotreme may be responsible for this condition. There is very little room for muscles in Erhilmu, as the mass is completely covered by bone. Schulman (1906) wives a division of the muscles showing their complexity and tendency to break up into small slips.

Absence of the internal pterygoid.-The absence of the pterygoideus internus is striking, as it is one of the constant muscles of the mammalian skull. Sume writers gave the monotremes an intemal ptergoid, 
but from the recent work of Schulman (1906) it seems that this is a mistake. Evidently its separation from the temporal mass is not complete. Sehulman says that the pteryouleus internus of Teckel is innervater by a nerve that supplies the temporalis and assumes that this muscle is a part of the temporalis, which he calls "caput anterius." He offers the suggestion that it might have appeared in the mammals after the monotremes had been cut off from the mammalian line. He says:

Der M. pterygoideus internus wird, aller Wahrscheinlichkeit nach, bei Ornithorhynchus vermisst. Nicht einmal das Mikroskop zeigte in der ventral und medial ron dem R. II trigemini befindlichen Gesend Muskelreste zwisthen dem Schädel und dem Unterkiefer, d. h. an dem Platz, wo dieser muskel bei den Siiugethiere rorzukommen pflegt.

Ob die Wesenheit des M. pterygoideus internus bei den Monotremen ein Riickbildungserscheinung ist, oder ob dieser Muskel erst mit dem Typus der über den Monotremen stehenden echten Säugethiere enstanden ist, bleibt rorläiufig eine offene Frage.

The homology of the "pterygoid" in monotremes is in question, and if the conclusions of some of the authors are true, the small muscle called the ptrryo-spinosus might he called a pterrad musle hut for the fact that it appears in man as a rudiment or an anomaly and appears as a regular element in Cholrmus. Tamandua, Manis. Tatusia and Das!nme.

Presence of the pterygo-spinosus and pterygo-tympanicus.-The presence of the ptergo-spinosus and the pteryo-tympanic sugrests the unsettled state of the pteryoids in mammals, for in the animals in which it is found the attachment greatly raries. Its positions are as follows:

(a) It is attached to the sphenoid in man and to the lamina lateralis of the pterygoid process (Thane, McAllister, Poland, Kreutzer).

(b) It is attached to the ligament assessorium mediale (Kreutzer).

(c) It is attached to the mandible (Gruber, Kreutzer).

(d) It is attached to the pterygoid internus (Poland, Gruber, Kreutzer).

From these variations Lubosch believes that the insertion is lost. Schulman (1906) says:

Es kann daran gedacht werden, die bei den höheren Säugethieren rorkommen zwei Muskeln auf das Velum palatinum sich ausbreitenden M. tensor reli tympani und den an einem unbeweglichem Iterygoidknochen sich anheften rudimentiiren M. pterga-spinosus, vor einen, bei den l'romammalia mit einem bewarlichen Pteryoideum verbunden, undifferenzirten Muskel ahzuleiten, der danath as Muttermuskel für die M. tensor veli palatini und ptersco-spinosus anzusprechen wäre. Doch bedarf es zur Sicherung dieser Vermutung viel auschreiteterer Cntersuchungen als die hier angestellten. Auch witre heirhei die Frage zu erörtern, ob die Beweglichkeit des Pterygoids von Ornithm!m -hus eine primäre oder sekundäre ist. 
The most typical attachment of this muscle is to the ammulus of the ear and to the pterygoid bone from the mandible. In spite of all the work dome on the ptrygoids of mammals, one may say that they are of rather minitisfactory status as ret. Gaupp assumes that they are derired from the paralmals and that they are not homologous with those of other mammal.: It is hoperl that the problem will be solved as a result of Iratson's recent studies on the development of the skull in the monotremes.

Presence of the detrahens mandibula.-This pair of muscles serves as the depresior of the mandible in monotremes where the digastric is entirely ahsent. It originates on the mastoid and squamosal region of the skull, wraps around the lower part of the head, and is inserted on the lower edge of the mandible with a good attachment on the sides, so that it has a firm hold. It is peculiar to the monotremes and is not homolocous with the parieto-mandibularis (depressor mandibule) of reptiles which has a similar position and function. The reptilian analogue is innervated by the seventh nerve, while the detrahens mandibulie in monotremes is immervated by the trigeminus. Schulman, Toldt, Bijrot and Gaupp believe that it helongs to the dorsal muscles of the head. Gaupp and Schulman both believe that it is a slip of the capiti-mandibularis (masseter portion) of the reptiles that has slipped back to act as the depressor. The earlier investigators thought that it was a part of the mammalian digastric, as they did not know of the nerve supply. All of these investigators have changed their opinion with the working out of the inneration hy Schulman, who showed that it is innervated by the trigeminus nerve. Schulman says:

Ls unterliegt somit meiner meinung nach keinen zweifel, dass der M. detrahens mandihula zu den dorsalen Kaumuskeln gehört, und keinen Bauche des M. digastricus mandibulæ der höheren Mammalia homolog ist.

The meaning of this musculature in the monotremes seems to be that the reptilian articulation of the mandible to the jaw was lost, as the Reirhert Thenry would assume, and that in the shifting of the muscles in monotremes the new depressor was developed from the capiti-mandibnlaris instear of from the depressor mandibula or its mother mass. This would place the monotremes in a different line, and their anatomy justly plares them at some distance from the rest of the mammals, so perhaps this conclusion is not far wrong. 


\section{DIDELPHYS}

Plate X, Figs. 1, 2

The skull of Didetphys is remarkably similar to that of lower Eocene Carnivora in so far as it has a very narrow brain case, high sagittal crest, long heary muzzle, stout zygomata and stout curver mandibles. The pterygoid bones are reduced, as is frequently the case in carnivorous mammals.

MIUSCLES OF THE ADDUCTOR OR TEMPORAL GROUP $\left(\right.$ INNERVATED BY $\left.V_{8}\right)$

Masseter

Temporalis

Pterygoideus externus

MUSCLES OF THE DEPRESSOR OR DIGASTRIC GROUP (INNERVATED BY VII)

Digastricus (pars posterior)

MUSCLES OF THE ADDUCTOR OR TEMPORAL GROUP $\left(\begin{array}{llll}I . N E R V A T E D & B Y & V_{3}\end{array}\right)$

Masseter.-This is a very large and strong muscle, arising on the under side of the zygomatic arch and from the fascia extending up orer the temporal muscle. The insertion is on the posterior, ventral part of the angle of the mandible.

Temporatis. - This is a large inuscle filling the temporal fossa and extending to the high sagittal crest. The insertion is on the coronoid process of the mandible.

Pterygoideus externus.-Arises behind the pterygoideus internus on the alisphenoid and is inserted on the inner side of the mandible.

Pterygoideus internus.-Arises on the pterygoid wing of the alisphenoid and is inserted on the inner side of the angle of the mandible.

\section{MUSCLES OF THE DEPRESSOR OR DIGASTRIO GROUP}

\section{(INNERVATED BY VII)}

Digastricus posterior.-This is quite a large muscle, arising on the mastoid and inserted on the inner side of the mandible. well formard. 


\section{SOLENODON}

Plate X, Figs. 3, 4

The skull of Solenodon is remarkable for its degenerate zygomata, for the great elongation of the muzzle, verticality of the enlarged anterior incisor, small brain ease with low sagittal erest, and sharply tritubercular molars.

JUSCLES OF THE ADDUCTOR OR TEIIPORAL GROUP

$$
\left(\begin{array}{llll}
\text { INVERTATED } & B Y V_{3}
\end{array}\right)
$$

Masseter

Temporalis

Pterygoideus externus

MUSCLES OF THE DEIRESSOR OR DIGASTRIC GROUP

(INVERVATED BY VII)

Digastricus (pars posterior)

MUSCLES OF THE ADDUCTOR OR TEMPORAL GROUP $\left(\right.$ INNERVATED BY $\Gamma_{3}$ )

Masseter.-A thick, heavy muscle arising on the zygomatic process of the maxillary and from the fascia over the temporalis. It wraps around the posterior angle of the jaw.

Temporalis.-A large muscle arising in the temporal fossa and on the squamosal. 'The insertion is on both the inner and outer surfaces of the coronoid process.

Pterygoideus externus. - A small muscle with a small origin on the alisphenoid. Inserted on the imner side of the head of the condyle. The muscle is slight, as the animal has a carnivorous dentition.

Pterygoideus internus.-Arises in the pterygoid fossa and is inserted on the imner side of the posterior angle of the mandible.

\section{MUSCLES OF THE DEPTESSOR OR DIGASTRIC GROUP}

(INNERVATED BY VII)

Digastricus (pars posterior).-This is a large heavy muscle which arises on the mastoid process and is inserted on a bony process on the lower side of the mandible under the coronoid process. 
MUS

Plate $\mathrm{X}$, Figs. 5,6

The relations of the jaw muscles to the dentition and form of jaw and skull are nowhere more apparent than in the rodents.

The rodents have a great development and diflerentiation of the masseters which overshadows the temporals. 'This is characteristic of the group and the jaw action is very complex.

\section{MUSCLES OF THE ADDUCTOR OR TEUPORAL GROUP}

(INAERYATED BY $\mathrm{V}_{3}$ )

Masseter

Temporalis

Pterygoideus extermus

MUSCLES OF THE DEPRESSOR OR DIGASTRIC GROUP
Pterygoideus internus

Digastricus (pars anterior)

\section{(INVERYATED BY TII)}

Digastricus (pars posterior)

MUSCLES OF THE ADDUCTOR OR TEIIPORAL GROUP $\left(\begin{array}{lll}I N N E R Y A T E D & B Y & V_{3}\end{array}\right)$

Masseter.-This muscle is very large and much subdivided. It arises along the zygomatic arch, extending some distance in front of the eyes where the zygomatic process of the manclible is much expanded to give it a foundation.

The posterior part of the expanded mandible forms the base of the insertion. This insertion is rery large in comparison with that of most mammals.

Temporatis.-This muscle arises in the temporal fossa and is inserted on the inner side of the mandible. It is of medium size in Mus, although in some of the rodents it is much reduced.

Pterygoideus externus.-This muscle arises on the pteryoid fossa and is inserted on the mandible, where it has a good hold on the expanded angle. It holds against the pull of the masseters and pulls the mandible forward.

Pterygoideus internus. - This muscle is much larger than the external pteryoid, arising in the pterygoid fossa and inserted with a large insertion on the large expanded angle of the mandible. It holds against the pull of the other temporal muscles and prevents the tearing apart of the jaws where the symphysis is weak, as it is in many rodents. 
MUSCLES OF THE DEPRESSOR OR DIGASTRIO GROUP

(INNERVATED BY VII)

Digastricus (pars posterior).-The digastric as a whole is a large muscle arising on the mastoid and inserted on the lower edge of the mandible, posterior to the symphysis.

\section{FELIS}

The cat furnishes a good example of a specialized carnivorous jaw with chiefly orthal or vertical movement.

\section{MUSCLES OF THE ADDUCTOR OR TEMPORAL GROUP}

$\left(\right.$ (INNERVATED $\left.B Y V_{8}\right)$

Masseter

Temporalis

Pterygoideus externus
Pterygoideus internus

Digastricus (pars anterior)

MUSCLES OF THE DEPRESSOR OR DIGASTRIC GROUP (INNERVATED BY VII)

Digastricus (pars posterior)

IIUSCLES OF THE ADDUCTOR OR TEMPORAL GROUP (INNERVATED $B Y V_{3}$ )

Masseter.-This has three layers in the cat, but it has about the same insertion and origin as in man.

Temporalis. - This is more extended than in man, reaching to the parietal crest. Its insertion is on the outer side of the coronoid process.

Pterygoideus cxternus. - Arises in the external pterygoid fossa hetween the foramen rotundum and the spheno-palatine foramen. Its insertion is on the inner side of the coronoid process. The coronoid process is very high and the condyle very low, so that the muscle has changed its insertion.

Pterygoideus internus.-Arises in the pterygoid fossa in about the same position as in man. The insertion is on the inner border of the mandible and extends back to the angle. Its fibers on the inner side go to the masseter, and it is partly united with the pterygoideus externus and the stylo-hyoid ligament.

\section{MUSCLES OF THE DEPRESSOR OR DIGASTRIC GROUP}

(INNERVATED BY VII)

Digastricus (pars posterior).-The digastric as a whole arises on the mastoid and occipital bones. Inserted on the lower edge of the mandible, just anterior to the first premolar. It is entirely inside of the jaw. 
HOMO

Plate $\mathbf{X}$, Figs. 7, 8

Riegner (1906) gives the results of some interesting experiments that he had made upon chloroformed apes. He stimulated the jaw muscles of the meonscious apes and watched the jaw actions, which may be summarized as follows:

The masseter lifts the jaw and pulls it laterally.

The temporalis lifts the opened jaw.

The pterygoideus externus opens the closed jaw to some extent, pulling it slightly medianward and toward the opposite side.

The pterygoideus internus closes or lifts the open jaw and pulls in opposition to the masseter, $i$. e., toward the opposite side.

The digastric (anterior belly) opens the jaw. Without it a nominal movement to the opposite side takes place. The hinder belly has little to do with the jaw movements in the ape.

The geniohyoid gives the jaw a straight pull in opening it.

This work on the apes gives about the action that takes place in man, but it is not an entirely accurate account of what happens in some of the mammals with a different type of skull (see also Strasser, 1908).

MUSCLES OF THE ADDUCTOR OR TEMPORAL GROUP $\left(\right.$ INNERVATED $\left.B Y V_{3}\right)$

Masseter

Temporalis

Pterygoideus externus

MUSCLES OF THE DEPRESSOR OR DIGASTRIC GROUP

(INNERVATED BY VII)

Digastricus (pars posterior)

MUSCLES OF THE ADDUCTOR OR TEIIPORAL GROUT

$\left(\right.$ INNERVATED BY $\left.V_{3}\right)$

Masseter.-Arises from the lower border and inner surface of the zygomatic arch and is inserted on the outer face of the posterior end of the mandible and on the coronoid process.

Tempnratis.- Arises from the whole surface of the temporal fossa, extends lown under the zygomatic arch and attaches itself to a point of the roromoir process, the insertion extending slightly down on hoth sides.

Pferygoideus externus. - Arises hy two heads, from the under surface 
of the great wing of the sphenoid and from the outer surface of the extemal pterygoid plate. It is inserted in a depression in front of the neck of the mandibular condyle and in the inter-articular fibro-cartilage and capsule of the temporo-maxillary articulation.

Pterygoideus internus. - Arises by two heads: one from the deep surface of the extemal pterygoid plate and another by a stout tendon from the tuberosity of the mandible. Both heads are inserted in a triangular area on the immer, posterior surface of the mandible.

\section{MUSCLES OF THE DEPRESSOR OR DIGASTRIC GROUP}

Digastricus (pars posterior). - The digastric as a whole arises in the digastric groove of the mastoid process of the temporal and is inserted in the lower, inner border of the anterior portion of the mandible. It is a two-bellied muscle, the two bellies being separated by a stout tendon. A slight tendon also attaches to the middle of the muscle to the hyoid bone.

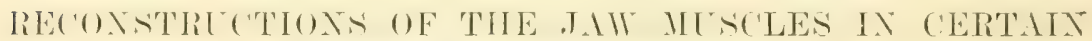 EXTINCT VER'TEBRATES}

\section{PLACODERMI}

The great class of the Placodermi, including many specialized forms, apparently never attained true gnathostome jaws. Gregory says:

All the known ostracoderms appear to be aberrantly specialized in certain directions, but long consideration of their many peculiar characters has conrinced me that they stand far below the true fishes and that the group as a whole may represent an important stage in the genealogy of the rertebrates.

In the upper Silurian we have many forms, like Birhenia and Lasanius of the order Anaspida, Lanarkia and Thelodus of the order Heterostraci, without true gnathostome jaws, so far as has been discovered. The mouth in these forms was probably a sucking type with a sphincter around it. Dr. Gregory (1915) has the same idea:

Of the many beantifully preserved specimens of Birlienia, Lanarkia, Drepanispis, Pteraspis. Tremataspis, Cephalispis and allied genera. none show the least indications of an internal skeleton, nor is there ever any trace of the branchial arches and internal jaws. . . The ostracoderms represent a stage in chordate phylogeny immediately preceding the acquisition of a cartilaginous skeleton impreguated with mineral salts; their first visceral arches, if present, had not been transformed into primary or cartilaginous jaws; the process of cephalogenesis was in a low stage and the elements of their shelly exoskeleton were potentially homologous with cosmine, vasodentine and isopodine of the primitive ganoids. To that extent they stand in a "pre-gnatho- 
stome" stage of evolution and probably represent the forerumers of the ganoids and Tetrapoda, while possibly having remote relationships also in another direction with ancestral clasmobranchs. . . The Antiarchi have advanced beyond the typieal Ostracoderms in having the head sharply differentiated from the thorax and the mouth armed with functional jaws, which are fashioned from the dermal skeleton. But not even the exquisitely preserved specimens of Bothriolepis described by Patten (1912) show any traces of the cartilaginous jaws, branchial arches or cartilaginous axial skeleton.

In another passage this author writes:

The upper Silurian Birkenia of Traquair apparently had no biting jaws and may have sucked in small particles of food like the larval lamprey. Well preserved material showed that none of the Ostracoderms had curtilaginous jaws or teeth, but the dermal plaques around the oral hood sometimes functioned as jaws. Typically carniyorous habits, involving true cartilage jaws, true teeth, and both paired and median fins, are first shown in the Acanthorlian sharks of the upper Silurian and Deronian.

We may therefore assume that cartilaginous jaws first appeared as such in the true fishes (elasmobranchs). In the Silurian and Devonian ostracoderms there is a progressice series that shows some of the many attempts to produce workable jaws. The Anaspida, though fish-like in form, have progressed but slightly toward the true fishes. Lasanius had some structures back of the poorly formed head that suggest dermal gill supports. In certain Heterostaci (Thelodus and Lanarkia) the skin was covered with denticles that resemble those of elasmobranchs. These denticles would strengthen the skin and give the muscles of the skin fascia much better support. The Drepanaspidie show marked progress in the strengthening of the skin by the formation of plates of different sizes. Drepanaspis and Pteraspis show a differentation in the head region, but it is more to be compared to the hard corering of some insects, as the cartilaginous supports of the interior were feeble or lacking. 'The mouth was unlike that of either elasmobranchs or teleosts, but seems to have been a wide slit stiffened by dermal scutes. The Ostrastraci show more specialization along this same line, but with no better results. The clumsy plates of Cephalaspis, Tremataspis, etc., give little promise of anything that would be much better than the arthropod jaw. 'The placoderm fishes of the order Antiarchi made a more clearly defined attempt to have movable jaws formed from dermal plates. A study of the fossils slrows that they had a mouth that was functionally analogous to the mouth of fishes-that is, their dermal jaws correspond in position, but are not homologous with dermal premaxilla, maxilla and mandibles. 'The head is slightly movable on the shoulder, as in Arthrodira, and the jaws could apparently move laterally as well as vertically. Patten (1912) holds that they were bottom- 

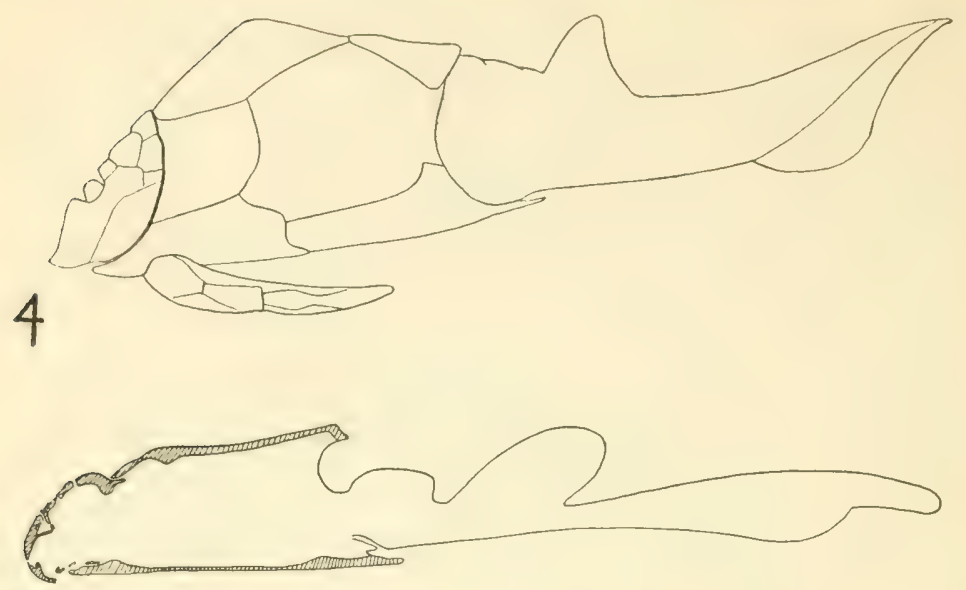

3
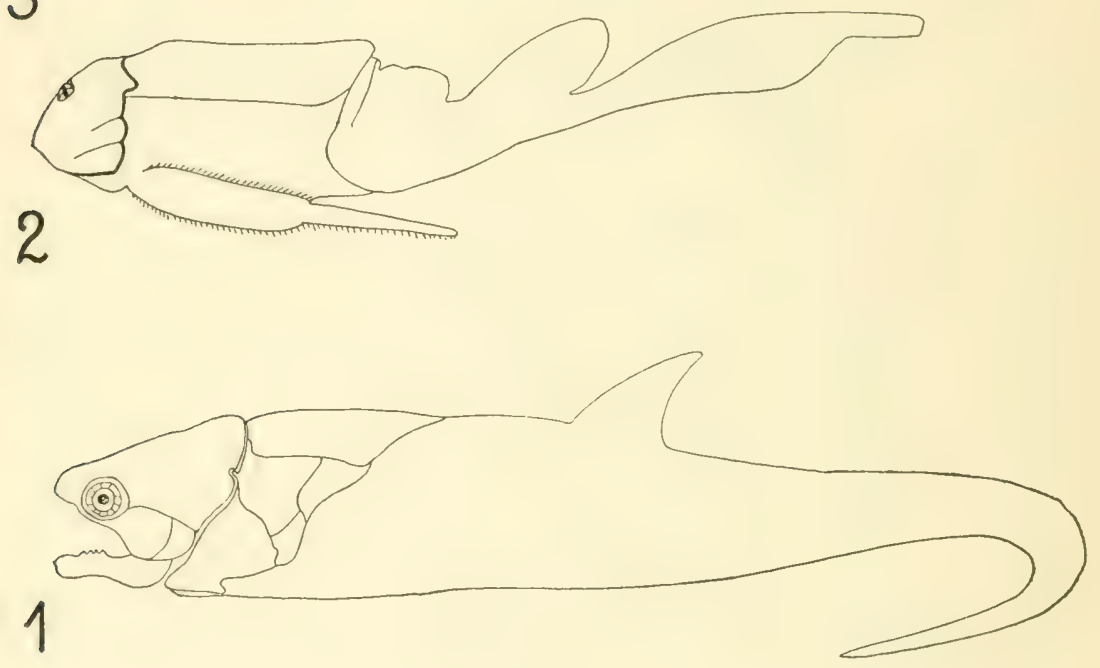

Figure 3

1. Outline restoration of Coccosteus, a primitive arthrodire. After Patten.

The well-armored head and thorax are sharply differentiated from each other. They are connected by a peg-and-socket joint in the neck region.

2. Outline restoration of an antiarch, Bothriolepis. After Patten.

Head and thorax are well defined, but the head is less movable than in Coccosteus. Very probably the oral and the branchial pouches with their respective muscles were becoming differentiated from each other.

3. Longitudinal section of Bothriolepis, showing the lack of endoskeletal structures, such as calcified risceral arches and the dermal character of the functional jaws. After Patten.

4. Outline of Pterichthys. After Patten. 
feeders and either took slow-moving animals that they could engulf or led on regetation. Patten says that they were herbivorous, for he found carbonaceous residue in their bodies.

'The right combination of cartilage jaws covered with hony dermal plates was first worked out by the gamoid fishes, ancestors of the modern fishes on the one hand and of the land-living vertehrates on the other.

\section{Dinichthys}

Plate XI, Figs. 1, 2

The great arthrodires of the Deronian made the hest presnathostome attempt to form a mouth with skeletal supports, lut they made the fatal error of trying to form those supports solely from the bony plates of the skin rather than from the branchial cartilages. C'occosteus and Dinichthys both show in the shull a fine apparatus that serves for seizing their prer. The arthrodiran jaw must have been a formilable weapon, as it was armerl with great sharp bony projections analogous to teeth. That these great jaws were much used for biting and shearing is shown by their worn shearing surfaces. Hussakof (1906) says: "The deep scars found on the outer side of certain Dinichthys plates also bear testimony to the savage attacks of their fellows."

The jaws seem to have worked on the principle of the joints of the insect leg. with most of the muscles attached chiefly to the plates of the body and head. The Arthrodira marle another fatal mistake in that they moved the head perhaps more than the mandible. There is a joint between the head and the shoulder plates (Fig. 2), with a good pegr-antsocket articulation, so that while the mandihles remained more or less stationary the great heal with its dermal plates moved up and down against them: thus we have the anomaly in the rertebrates of a relatirely stationary jaw and a morable hear, just as though the mandible of the wnathostomes was attached immorably to the stermum. while the maxilla and skull mored against it.

It seems surprising that in the discussions as to the relatimships of the Arthrodira so little importance should have heren wiren to the peculiar motion of the hear upon the thoracic shieh, which is unkinown among true Pisces. The morement of the mandible of Dinich thys has heen very carefully studied hy Dr. Hussakof (1906). to whose kindness I owe the opportunity of studring the great collection of arthocliram fossils in the American Ifuseum of Natural ITistory. The movement of the heal upon the mandihle appeared. howerer, to have reveived tou little attelution, and this I have accordingly studied with great care. 
The mandibles in the arthrodires were not stationary, but they have no sign of the ordinary piscine articulation even in the best preserved fossils (Fig. 4). They appear to have been attached to the skull plates somewhat as the scapula in mammals is attached to the borly, namely, by ligaments, muscles and connective tissue. From the mechanical point of view, there seems to be three possibilities for movement in these arthrodiran jaws: first, they might have had the muscles so arranged that there would have been a synchronous movement of the head and jaws, and from a study of Dinichthys this seems to be the best arrangement, as it is the one that lends itself best to the arrangement of the muscular system; secondly, the jaws might have been arranged so as to work against the skull, but the movable joint at the back of the head seems to make this rather disadvantageous, as the head is not a stationary structure, and part of the force of the morement would be lost, as the joint in the neck would give and the head would be pushed back until it touched the dorsal shield. The usual joint or condyle in the neck region is not prominent and must have been an uncalcified cartilaginous articulation, if anything, for the dorso-ventral movement of the head would tend to dislocate any ordinary articulation between the head and the neck.

In brief, these agnathous forms developed their dermal plates just as the gnathostomes did, but while the gnathostomes put the emphasis on the cartilaginous substratum and developed from it the.principal structures of the head and jaws, thus making the membrane bones subservient to the cartilage and finally drawing them in as a covering for the cartilage, the ostracolerms and arthrodires put all the stress on the outer dermal plates and developed the movable parts from these elements, while apparently neglecting the development of the cartilaginous viseral arches.

The peculiar head structure of the Arthrodira seems to imply an equally peculiar musculature as follows: (1) The joint between the dermal plates of the head and dorsal shield implies the existence of muscles to raise and lower the head. (2) As stated above, there appears to be no surface on the mandible that could articulate with a quadrate in the ordinary piscine fashion, so that from the present knowledge of arthrodiran anatomy the adductor mandibulx of the Pisces could not be applied to these forms. Thus it seems probable that any system of musculature that would be effective in its mechanical action would be entirely unfishlike. Accordingly, in Plate XI the musculature of Dinichthys is figured according to the mechanical requirements and follows no fish type. The morements of the head would require two large muscles in order to move the head up and down on the ginglymoid joint. One pair would be in the posterior region of the skull where the marks are plain 

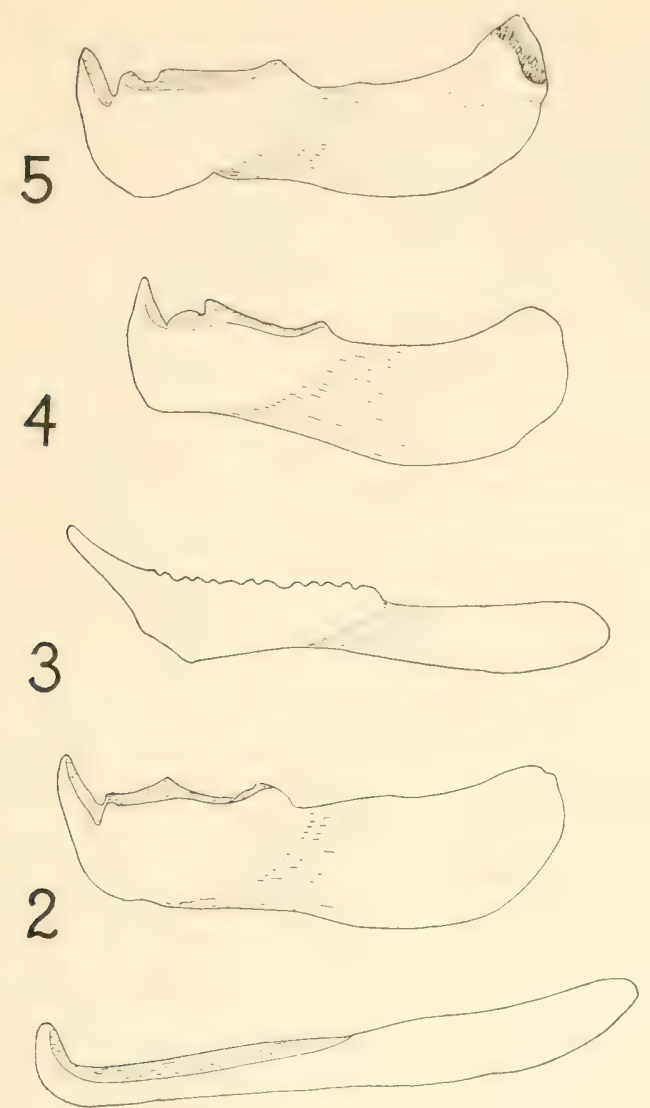

1

Frgere 4

Dermal jaw bones of rarious arthrodires, lateral surfaces; from specimens in the American Museum of Natural History.

The dermal lower jaws of arthrodires were probably not connected with the upper faw by means of quadrate and articular cartilages as in true fishes, but may hare been fastened in the thick dermis surrounding the oral cavity.

1. Stenognathus gracilis.-This represents a long-jawed specialization irom a D)inichthys-like type.

․ Dinichthys intermedius.--The shearing portion of the jaw is raised abote the plame of the horizontal ramus which was probably embedded in the thick dermis.

3. Diplognathus mirabilis. - A rery peculin oftshoot of the coccosteid type. The symphyseal border of the lower jaw bears tooth-like projections which apparently indicate that each jaw plate could be twisted on the long axis in a manner impossible in true fishes (Dean).

4. Dinichthys curtus.

5. Dinichthys intermedius. - To the npper end of this specimen on the onter side is attached a triangular bone which may have serred for the insertion of museles and fascia movably connecting the mandible with the inner side of the skull, somewhat as the scapula of mammals is connected with the body. 
in the specimns, showing that there were large muscles there. These muscles might be called the levator capitis muscles, as they raise the head. From the insertion areas this appears to have been a double muscle, one on each side of the median line. 'The attachment would be under the dorsal shield, where there is a strong keel that would serve as a good insertion for so important a muscle. 'The depressor capitis must have arisen on the heary, imner part of the skull, and the specimens show areas that might well have served for this purpose. There is a large depression at the posterior end of the immer side and a strong ridge along the side of the large paired elements that might have covered the cartilage protecting the brain and might have given a base for the muscles. The insertion of this muscle is problematical. It could hardly be inserted on the plastron, for there it would be in the way of the digestive tract. The only other likely place for the insertion of the depressor capitis muscle would be on the so-called "clavicular element," as the muscle could not have been attached to any part of the skull itself.

The problem of the musculature of the mandibles is even more of a puzzle than the musculature of the skull. This mandible has been interpreted in rarious ways: as a splenial by Eastman and as some other elements hy rarioms writers. Whaterer its history has been, it is apparently similar to nothing in the Pisces. If it is a splenial it is utterly unlike the splenial of the dipnoans, for they all show a distinct concarity on the outer side of the splenial for the reception of the Meckelian cartilage: and examination of the specimens in the American Musenm of Natural History shows no arthrodiran that has any concavity for the Meckel's cartilage. The splenial of Ceratodus is quite concave on the outer side and is shaped in a peculiar manner at the posterior end where the articulation with the quadrate takes place. There is none of this in any of the Arthrodira. If this mandible represents one of the outside bones of the mathostome mantible, the same difficulty remains, for the tipnoan shows that the outer elements are concare on the inside to make a place for the Meckelian cartilage. Thus the arthrodiran mandible sexms to be something quite different. From the texture of the outside of the mandible, it would appear that at least the anterior half has been on the surface, while the depressen. posterior half might have been imbedded in tissue. The shape of the posterior end of the mandible makes it very evident that it is more or less free, as is seen in the free end of the teleost maxilla or operculum, where the free end is always thin and blade-like. From analogr, we might well conclude that the same is true in the Arthrodira.

In the American Museum of Natural History a new mandible of Jimichllys, which will he fully described by Dr. Hussakof, shows a pecu- 
liar triangular plate on the outer face, and at the posterior end this triangular plate is roughened for the insertion of a supporting cartilage or ligament. Very probably it articulated with the inside of the cheek plate or with some other external plate and not with a quadrate. In the mandible of Alylostoma. Dr. Eastman (1906) found an irregular mass on the inner side which he interpreted as the Meckelian cartilage. Fut if these mandibles were articulated with a quadrate they should show some indication of it at their posterior end. If the mandible, with the strong action that must have been present, as evidenced from the great marks of the shear, were pulled against the quartrate by the usual adductor muscles of the Pisces, it is reasonable to suppose that instear of heing blade-like the arthrodiran mandible would show the characteristic romeling and blunting that comes with this kind of strain. as is shown in exery mandible of Pisces where there is strong pressure in the hack part of the mandible.

The reconstruction of the musculature of Dinichthys mandibles. as shown in Plate XI, is worked out from a mechanical point of view, as it appeared to be impossible to adapt the ordinary piscine musculature to the arthrodiran jaws. In this reconstruction it is considered that there must have been a synchronous movement of the skull and mandibles. and the musculature is figured out on this basis. From the peculiar construction of the head, it is inferred that Dinichthys and its allies are the ent memhers of a group that mover the head and had the jaws more or less fixed. The most efficient mechanical construction scemed to require that the inner face of the mandible should be connected by ligament or muscle with the "clavicular element," which extends forward on the inside of the mandible. If the attachment at this place were by ligament and fascia and the posterior end were appresserl to the inner side of the cheek plinte or to some other plate in this region and worked as the scapula works on the body of a mammal, we would have the movement desired, as the raising of the head would aid in raising the back part ant lowering the front part of the mandible, while lowering the head would close it. The mechanism of this part must have been rery perfect, for the shear is always in one plane, with no rounding of the edges. On the inner side of the mandible at the anterior end are depressions that show where the mandibles were fastened by strong ligaments.

In conclusion, the evidenee gained from a stuily of the jaw mechanism of Dinichthys seems to faror the conclusion which has heen adrocated by many writers, especially Dean and Inssakof, that the Arthrodira are related by common origin with the Antiarchi. 


\section{ERTOPS}

Plate XII, Fig. 1

The massive, frog-like skull of Eryops, a Permian stegoceph, is restored with the anuran type of musculature, though some modifications have been made because of the changes that have taken place in the anuran skull. The skulls of the stegocephalians and of the Anura are strikingly similar in general pattern; that of Eryops with the dermal roofing bones covering the whole skull; that of the Amura with these bones modified, partly eliminated, and all more or less sunken beneath the skin. The large palatine racuity is similar in both. Gregory has suggested that the ancestor of the Anura was an animal much like Eryops, but that through the changes of the geologic ages the anuran skull became simplified, specialized, and the dermal temporal covering became fenestrated, partly as a result of the action of the muscles. The pterygoid region has changed slightly and has lost the flange that in Eryops projects down in a very reptilian-like mamner. The mandibles are quite similar, although Eryops did not have the backward extension of the articular for the insertion of the depressor mandibulie as in the frog, and the frog has lost the prominent suprameckelian fossa in the mandible that is so prominent in Eryops. In the Anura the muscles are all very far back on the skull, and we may assume from the Eryops skull that its muscles had a similar position, except that to make the jaw stable it should hare had an anterior pterygoid muscle on the floor of the downwardly projecting pterygoid process. The loss of the anterior pterygoid muscle in the Anura is a peculiar specialization which, very probably, had not been attained by Eryops.

The restoration of Eryops gives the following muscles:

MUSCLES OF THE ADDUCTOR OR TEMPORAL GROUP

$\left(\right.$ INVERTATED BY $\mathrm{V}_{3}$ )

Capiti-mandibularis superficialis (C. m. s.).

Capiti-mandibularis medius (C. m. m.).

Capiti-mandibularis profundus (C. m. p.).

Pterygoideus anterior.

IUSCLES OF THE DEPRESSOR OR DIGASTRIC GROUP

(INTERTATED BY YII)

Depressor mandibula.

MUSCLES OF THE ADDUCTOR OR TEMPORAL GROUP

$\left(\right.$ IXNERTATED $\left.B \mathrm{Y} \mathrm{V}_{3}\right)$

Capili-mandibutaris superficialis (C. m. s.).- The masseter element would occupy the posterior part of the skull in the space under the 
squamosal. It rould probably have its origin on the inner side of the squamosal and puadratojugal. with a few fibers rumber to the quadrate and extending ventrally; it would be inserted on the borders of the suprameckelian fossa of the mandible. It is on the outside of the mandible in the Anura; but from the shape of the skull and the mandible there is no chance for it to be inserted there in Eryops. The muscle is split in the Anura and so the masseter of Eryops might have had two parts, the smaller one posterior, in the region of the small quadrate.

Capiti-mandibularis medius (C. m. m.).-This temporal slip of the adductor mass would be under the superficial portion and over the pterygoid muscle. It would have its origin on the imner side of the parietal, with perhaps a slight attachment on the postfrontal. It would be inserted in the suprameckelian fossa. The muscle could extend quite far in the parietal region, taking hold under the skull roof. Possibly the deep part of this mass may have had a separate slip, corresponding to the capitimandibularis profundus or "pterygoideus externus" of reptiles.

Pterygoideus anterior (Pt. a.).-The pterygoid muscle of Eryops was probably not homologous with the so-called "pterygoid" of the frog, but was more probably homologous with the anterior pterygoid muscle of primitive reptiles. The pterygoid bone is quite different from that of Anura, in that it has a descending flange, much like that of the Crocodilia, that fits snugly along the inside of the mandible and serves as a guide for it. As this flange in the reptiles is functionally comnected with the anterior pterygoid, it seems probable that Eryops had an anterior pterygoid muscle that extended along the pterygoid bone as far as the orbit. A pterygoid muscle is needed here for mechanical reasons, as from the teeth one would judge that the jaw was used differently from that of Anura, and there is need of a muscle here to oppose the pull of the temporal muscles, which would tend to pull the symphysis apart. Thus a pterygoid in this region would steady the jaw and pull the jaw forward against the other muscles. It would have to be inserted in the suprameckelian fossa, possibly extending to the back part.

Capiti-mandibularis profundus (C.m. p.).-There is a strong possibility that there was a deep slip of the adductor mass, deep under the muscles, that would correspond to pterygoideus posterior of the reptiles.

MUSCLES OF THE DEPRESSOR OR DIGASTRIC GROUP

(INIERYATED BY TII)

Depressor mandibula.-The articular of Eryops does not have the posterior process and the muscle must have been inserted on the under side of the articular. In some American Museum specimens the mandible 
seems to show a place where the depressor could have been attached. The origin of the depressor would have been on the squamosal, alongside the otic notch. since in the Anura the origin is on the posterior limb of the squamosal and on the tympanic annulus. The Anura have a second part of the depressor arising from the dorsal fascia, and Eryops also could well have had this second part of the depressor.

From the inferred arrangement of the muscles in Eryops, perhaps some explanation may be given of the changes and losses that have taken place in the anuran skmll. First, the capiti-mandibularis medius was no douht attached to the parietal region and the capiti-mandibularis superficialis to the squamosal. To account for the open condition of the temporal roof in the Anura and for the loss of the tabulare, supratemporal, squamosal, postfrontal and postorbital, we may adopt the hypothesis that these muscles were pulling against one another; that the region between them gave way and made breaks and openings which did not exist in the primitive form with its unbroken temporal covering. The region between the parietal and the squamosal would lie between the pulls of these muscles and the first break would appear here. The disappearance of the dermosupraoccipitals, tabulars and supratemporals was probably correlated with the opening out of the temporal region and with the extension of the temporal muscles up on to the top of the skull.

\section{LABIDOSAURUS}

Plate XII, Figs. 2, 3, 4

This primitive cotylosaur shows the covered or rooferl temporal region, which it has inherited from the Stegocephalia and from such fishes as Osteolepix. Polypterus and Amia. in which the dermal bones are still in their primitive position in the skin and not sunken below it. The quadrate is fixed, so that in that region there is no morement. The stout teeth demand strong jaw muscles and there is ample room for a large (apriti-mandibularis heneath the temporal roof. The massive lower jaw with its large suprameckelian fossa also requires large muscles. The pteryond region and the base of the brain case are essentially similar to those of splienodon and imply a corresponding similarity in the pterygoid muscles.

MUSCLES OF THE ADDUCTOR OR TEAPORAL GROUP

(INNERVATED BY $\nabla_{8}$ )

Capiti-mandibularis superficialis (C. m. s.).

Capiti-mandibularis medius (C. m. m.). 
Capiti-mandibularis profundus (C. m. p.).

Pterygoideus anterior (Pt. a.).

MUSCLES OF THE DEPRESSOR OR DIGASTRIC GROUP

(INNERVATED BY VII)

Depressor mandibulæ.

MUSCLES OF THE ADDUCTOR OR TEMPORAL GROUP

(INNERVATED BY $\nabla_{3}$ )

Capiti-mandibularis superficialis (C. m. s.).-This slip of the capitimandibularis would cover the deeper fibers and arise from the quatrate, squamosal and jugal and be inserted with the medius in the suprameckelian fossa.

Capiti-mandibularis medius (C. m. m.).-This slip would arise on the upper part of the shull and be attached to the prarietal, squamosil, and perahps to some of the bones of the otic region. It would join the rest of the capiti-mandibularis in its insertion.

Capiti-mandibularis profundus (C.m. p.).-This deep slip would arise on the alisphenoid and outer face of the pterygoid and be inserted with the rest of the mass on the mandible. The whole capiti-mandibularis mass would probably be inserted in the suprameckelian fossa. It would be attached to the bones surrounding the fossa and extend down into it, after the manner of other reptiles. where the whole insertion of the capitimandibularis is on the inside of the mandible.

Pterygoideus anterior (Pt. a.).-This muscle was no doubt strongly developed as in all typical reptiles. It arose on the under side of the pteryoul and might have extended over the upper face of the pteryonid region as in chelydru. The form of the articular shows plainly that the muscle must have been inserted on the ventral side of the articular, for there is no evidence that it extended more than slightly into the outer face of the bone.

\section{IUUSCLES OF THE DEPRESSOR OR DIGASTRIC GROUP} (INNERVATED BY $\nabla I I)$

Depressor mandibula (D. m.).-This muscle was no doubt arranged as in other reptiles. It arose on the parietal and extended around the squamosal to be inserted on the upper face of the retroarticular process of the articular, which plainly shows the marks of the insertion. 


\section{I'YRANNOSAURUS}

Plate XIII, Fig. 1

The reconstruction of this form was attempted after some comparative study of types like Alligator, Chelydra, Aves and Euparkeria (Fig. 5). 'The skull in Tyramosamms is secombarily monimostylie, as the quatrates and the upper jaws were less movable than in the more primitive Allo-
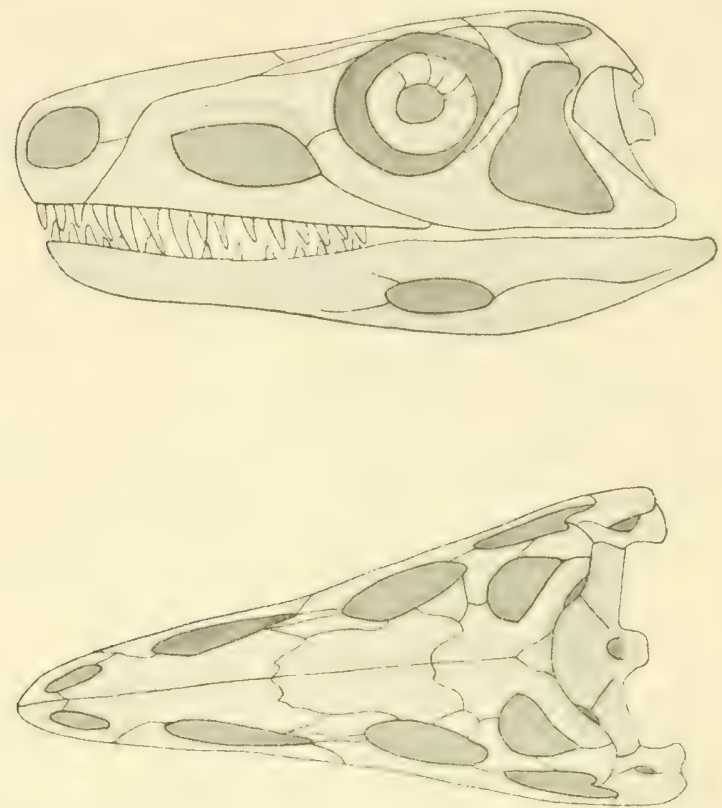

IIGURE 5

Skull of a pseudosuchian, Euparkeria capensis. After Broom

The borders of the large preorbital fenestra may serve for the attachment of the anterior part of the pterygoideus anterior muscle. Around the bons margin of the supratemporal fenestra arose the capiti-mandibularis. Both the supra- and the lateral temporal fenestre gave room for the expansion of the capiti-mandibularis, while the lateral fenestra of the mandible served a like function for the lower end of the same muscle.

saurus. The monimostylic type is quite stable in its musculature and the reason for this is evident, as the complicated musculature needed for the movable quadrate and pterygoid is lost when the bones become fixed.

Tyramnosaumes was a huge carnivorous type with massive skull and jaws; thus the musculature must have been very heary. 
MUSCLES OF THE ADDUCTOR OR TEMPORAL GROUP

$\left(\right.$ INAERTATED BY $\left.V_{3}\right)$

Capiti-mandibularis (with three unseparated slips).

(a) Capiti-mandibularis superficialis.

(b) Capiti-mandibularis medius.

(c) Capiti-mandibularis profundus.

Pterygoideus anterior.

MUSCLES OF THE DEPRESSOR OR DIGASTRIC GROTYP

(INNERTATED BY VII)

Depressor mandibulie.

MUSCLES OF THE ADDUCTOR OR TEIIPORAL GROUP

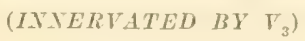

Capiti-mandibutaris.-This muscle is considered to have three slips, designated as superficialis, medius and profundus. They are not competely separated in the Reptilia. The temporal fenestræ show that this muscle had retained its freedom of morement, which it had inherited from some remote aëtosaur-like ancestor. There is a long fenestra under the eye, a lateral temporal and a supratemporal fenestra. The capitimandibularis would probably conform to the Alligator or Chelydra type. The presence of the supratemporal fenestra means that the temporal or medius slip extended through and was attached to the parietal crest. Thus the medius slip probably arose on the parietal, extended through the supratemporal fenestra and under the superficial slip to be inserted on the coronoid or in the supramechelian fossa which is large. The superficialis slip would have fibers extending posteriorly over the rest of the mass. This slip would arise on the squamosal, quadratojugal and be inserted along the upper edge of the mandible and in the suprameckeliar: fossa. In a few forms this muscle is partly inserted on the outside of the mandible, but the outside insertion is small in typical reptiles. A deep slip might have been present, representing the capiti-mandibularis profundus.

Pterygoideus anterior.-The insertion of this muscle is plainly indicated in the mandible of specimen No. 502\%, American Museum, which shows the place where the anterior pterygoid was wrapped around the posterior end of the jaw as in typial reptiles. The musele probahly arowe in the space below and in front of the orbits and above the palatines and

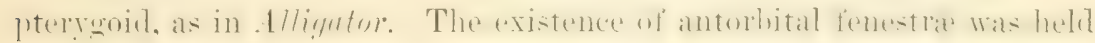
by Dollo and by Gregory and Adams (1915) to be correlated with the anterior extension of the anterior pterygoid muscle- a riew adopted here. 


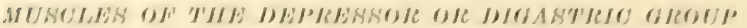

\section{(INNHルVATWリ HY VII)}

T'Jis musce is comstant in the Reptilia and its insertion is evident on the spereimen No. 50\%\%, Ameriean Mu-reum. In many reptiles where thes back part of the skull is not greatly morlified jts origin is on the parietal, but here it seems to have been on the paroccipital. 'I'lie muscle arose on the ventral end of the paroceipitals, the ventral ends of which are roughaned for a muscle insertion. Its insertion on the mandible was on the

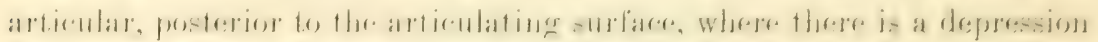
similar to that seen in most reptiles.

\section{CyNORNATJUS}

I'late XIII, Figs. 2-5

'The skull is reptilian as a whole, but parts of it very plainly show the

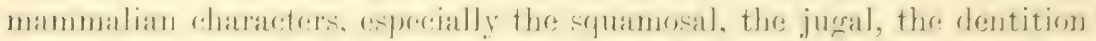

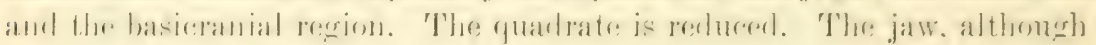
reptilian, is of' a type that foreshadows that of mammals. 'The dentary

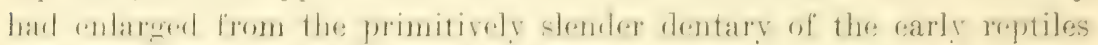
until it was the most important part of the mandible and mus have car-

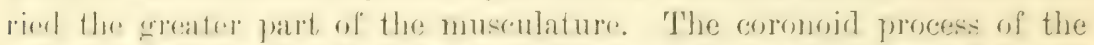
frutary is larere and ascencls far into the trmporal fossa. 'The angle of the lentary is developing and shows platuly. The posterior part of the jaw, onsisting of the articular and other elements, is becomine small and is so loosely attached to the dentary that in fossil specimens it is usually missing or found separate from the skull. 'The old reptilian articulation with the skull had herome reducerl, but was still functional. Allowgh the new articulation with the jaw harl not yet been formen. I infor, from the shape of the temporal fosea and from the direction of the muscles, that the jaw was pullerl not directly against the quardrate but toward a point above it on the squamosal.

MUSOLES OF THW ADIDUOTOR OR TWMPORAL GROUP

(INNERVAT'ED BY $V_{\mathrm{g}}$ )

Capiti-mandibularis.

(a) Capiti-mandibularis superficialis.

(b) Capiti-mandibularis medius.

(c) Capiti-mandibularis profundus.

P'terygoideus anterior. 


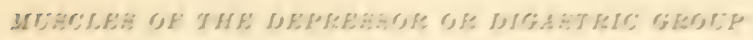

(IXYEFYATED EZ VII)

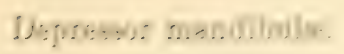

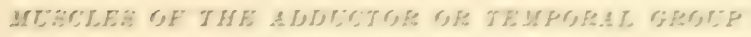

(YMERTATEL ET $\bar{I}_{2}$ )

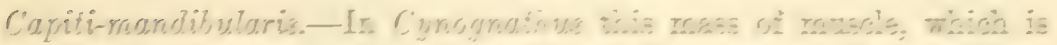

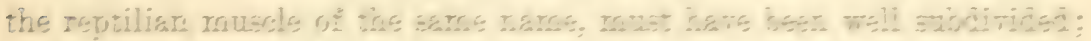

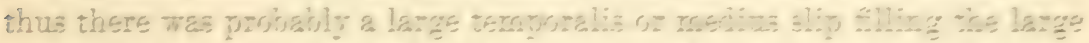

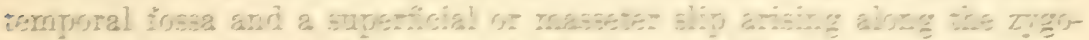

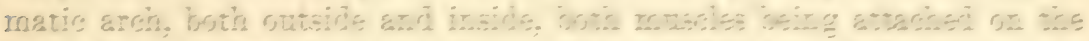

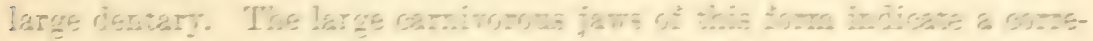

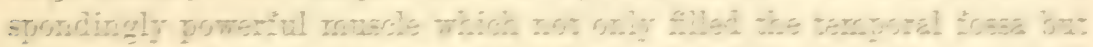

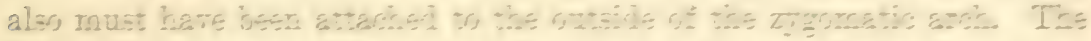

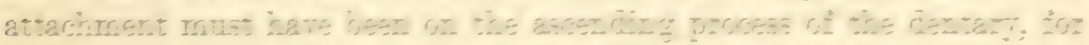

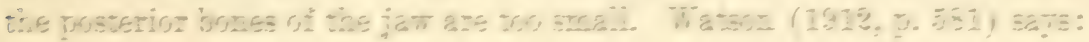

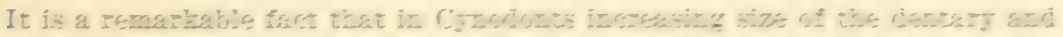

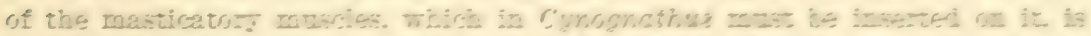

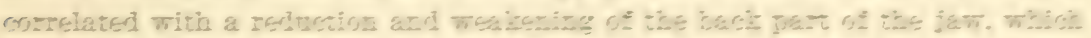

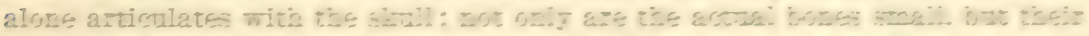

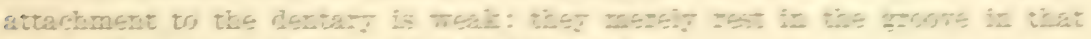

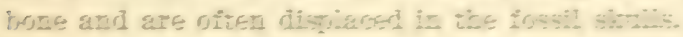

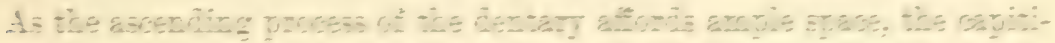

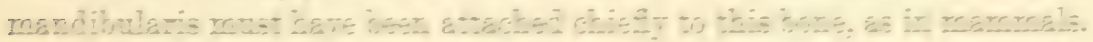

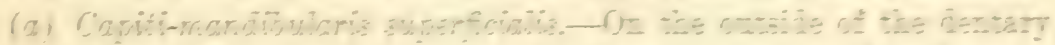

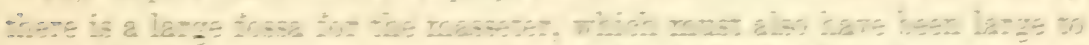

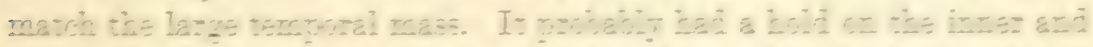

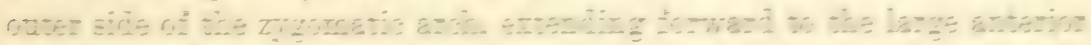

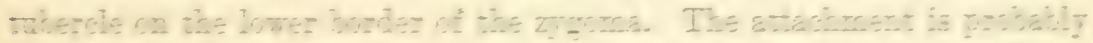

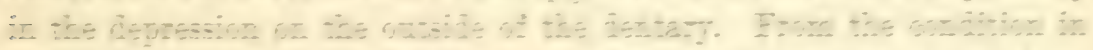

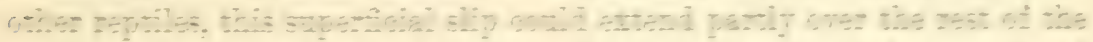

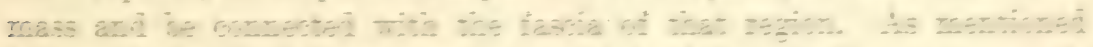

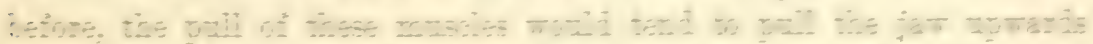

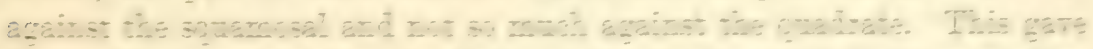

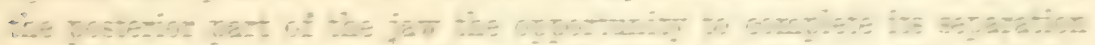

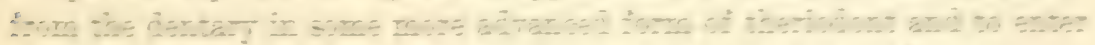

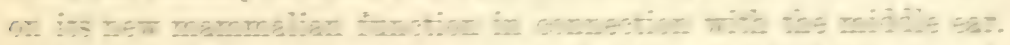

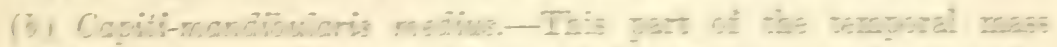
कi cto tha dentar. 
(c) Capiti-mandibularis profundus. - This deep slip must have taken its origin on the imner side of the temporal mass and have been inserted on the ascending process of the dentary.

Pterygoideus anterior.-To counterbalance the pull of the capiti-mandihularis mas the anterior ptergoids must have played an important part. The ascending process of the pterygoid is quite large, thus giving an attachment for large pterygoids. There is no need for the complex musculature of the type found in streptostylic reptiles, so it was probably more of the chelonian or rhynchocephalian type. The pterygoid bones of Cynognathus are bowed inward to the mid line, covering the primary skull base and forming on each side an extended longitudinal fossa for the origin of the anterior pterygoid muscle. Although the articular, prearticular and angular bones are small, they seem sufficiently large for the insertion of the anterior pterygoid in the normal place at the back part of the jaw. The insertion of this muscle $i n$ all recent reptiles is at or near the rear end of the jaw, and in view of the general fact that insertion areas are less variable than origin areas, there seems no reason for regarding Cynognathus as having an exceptional insertion of the anterior pterygoid. The pull of the anterior pterygoid muscle would counterbalance that of the capiti-mandibularis mass and take some of the strain off the weak quadrate articulation. The dentary, imbedded in the temporal mass, would thus act as a cushion and the action of the jaw would be the same as though a strong articulation were present. That this action of the jaw was effective is shown by the robust character of the teeth and jaw. If Cynognathus had relied only upon the old articulation by way of the quadrate and articular, a bite on a piece of bone might have dislocated the jaw. As the dentition is carnivorous, the jaws did not have much lateral motion. The reason Cynognathus had a large ascending ramus of the dentary is that it was derived from therocephalians and ultimately from primitive Theromorpha, in which the coronoid bone was functionally replaced by an obliquely ascending process of the dentary.

MUSCLES OF THE DEPRESSOR OR DIGASTRIC GROUP (INNERVATED BY VII)

Depressor mandibula.-This muscle was in its usual position, as the posterior end of the mandible shows the insertion. In all reptiles there is a remnant of the $\mathrm{C}_{2}$ md of Ruge, and from this the mammalian digastric was probably derived. With the loss of the posterior end of the reptilian jaw the depressor mandibulæ of these forms would disappear and a new digastric rould be formed from this sheet of muscle that has persisted from the fish stage. 'The long ventral muscles of the throat could 
give much aid in lowering the mandible. Watson (1912, pp. 581-582) says :

$\Lambda$ s it is impossible that a muscle should increase while its point of attichment is degenerating, it appears probable that the ptergoid muscles were mainly inserted onto the postero-inferior angle of the dentary, which is thickened. 'Thus inserted, these muscles, while tending to close the mouth, would produce stresses in the hinder part of the jaw, in the opposite direction to those induced by the masseter and temporal muscles, in this way permitting the reduction of the hinder part of the jaw which we actually see. The fact that in higher Cynodonts all the masticatory muscles have their attachments on the dentary renders the freeing of the articular and quadrate demanded by the quadrate-incus theory of the mammalian ossicula auditus much more understandable.

It would seem that Watson's hypothesis that all of the muscles were on the dentary might be questioned, for the cast of the skull of Cynognallus shows plainly the insertion of the depressor mandibulae on the posterior end of the articular, while the insertion of the anterior pterygoid seems to have been in the usual position, wrapping around the end of the mandible as in other reptiles. This last muscle may have been reduced, but its insertion areas on the articular and prearticular seem evident.

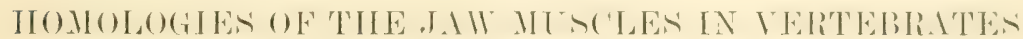

(Tables I-V')

\section{INTRODUCTION}

The first attempts to homologize the jaw muscles in the different groups of rertebrates were based purely upon similarities of function and position; and while the work was useful and gave a start in the right direction, it was not altogether reliable. The older writers quickly took up the innervation, as its importance in comparative anatomy became known, and applied it to the determination of the muscles. 'Thus a much more certain classification arose. Most of the work has been on restricted groups. Vetter in his works on the elasmobranchs and other fishes gave for the muscles of these groups the names that are still used. He divided the muscles up into groups according to their innervation and position and gave the best basis for the classification of the piscine musculature.

One of the few papers dealing with the entire vertebrate group is a dissertation by Dr. Ernst Teutleben, published in $18 \% 4$ under the title, Ueber Kaumuskeln und Kaumechanismus bei den Wirbelthiere. He examined a series of vertebrates and gave a very good description, for the 
time, of the jaw muscles in some of the common rertebrates; he also made some observations on the mechanics of the jaw action. Ife studied the following forms: Dog, horse, sheep, porpoise, bird, Crotalus durissus, alligator. frog, pike and whiting. He failed to differentiate many of the muscles and made no mention of innervation, which is one of the chief criteria used at the present time. The names applied were based upon the origin and insertion of the muscles. He applied this principle to the diflerent classes and gave the muscles names. He did not attempt homologies, except as hased upon similar lunction. Ile misinterpreted the detrahens mandibula of Ornithorkynchus, as all the others had done until the neurology was worked out by later workers.

'The greatest stimulation to the work was given by the researches of Ruge on the facialis nerve. He studied this throughout the vertebrates from the elasmobranchs to mammals and gave a reliable basis for the determination of the muscles of this group. Schulman, in his work on the trigeminus musculature of the monotremes. cleared up some of the puzzles that this aberrant group present. Lubosch, Fübringer and others have adiled much to this work. so that the comparative anatomist now has extensive material for comprason. Gaupp in his work on Reichert's theory of the origin of the auditory ossicles and Versluys in his studies on the anditory organs in reptiles have worker in this rich field and have given the material a definite meaning, especially in some of the troublesome problems relating to the changes that took place in the shifting of the bones and muscles, when reptiles of some sort were changed into mammals.

Many other investigations have given much information on the musculature of special forms of rertebrates. Chaîne. Rouvière, Bijoet, Tolit. Parsons and others have collected the necessary data on the digastric muscle and have given very full accounts of the comblition of this muscle in the mammals. Toldt, in his paper on the jaw articulation and its prohlems, gives us a basis for the classification of the types of rertebrate jaws, of their articulations and of the correlated types of musculature. Apparently the present work is the first to give a general illustrated review of the jaw muscles of rertebrates and to apply this knowledge to an interpretation of the skull structure of recent and fossil types.

The sturly of 26 different forms. representing the classes Pisces. Immhibia, Reptilia. Ires and Mammalia. has demonstrated that the muscle masses in weneral are severally homologous from the Pisces to Mammalia. and that they may be grouped into two great systems: First, the muscles innervated by the ramus mandibularis trigemini $V_{3}$, and, second, the muscles innervated by the facial nerve (VII). There is a sharp line 
between these muscular systems and their general position has been the same throughout. The trigeminus innervates the muscles of mastication that lie in front of the quadrate, while the facialis inmervates the muscles hehind the quadrate and those of the hyoid region. 'These rewions in the mammals overlap on the surface, for the reptilian sphincter colli has crept forwat over the deeper museles of the trigeminus and has formed the mimetic muscles of the face, so that while the deepl muscles. anterior to the hyoid arch, are innervated by the trigeminus the superficial muscles are innervated by the facialis. This is an example of the faithfulness with which the nerves follow the muscles in their migration (Ruge, $189 \%$ ).

Starting with the elasmobranchs, we find the adductor mandibulie muscles, which are molifferentiated masies, derived from the pro-branchial muscles before the anterior branchial arches were transformed into jaws. The alductors are not separated into speeial muscles, but represent the "mother mass" of the chief jaw-muscles of the $V_{3}$ sroup in all the higher classes of vertebrates. A depressor mandibulæ is not differentiated in the elasmobranchs or in the other classes of Pisces, hut is represented by the second dorsal superficial constrictor throughout this group, a true depressor first appearing in the Amphibia.

In the development of the Amphibia from some of the Pisces the jaw musculature was carried over in its general plan, but the muscle masses took on the peculiar modifications needed in each group. We may conceive that these "mother masses" $\mathrm{C}_{1}$ and $\mathrm{C}_{2}$ became differentiated in many ways throughout the diflerent classes of vertebrates, and that rarious slips were giren off from these masses which served their purpose and the needs of the animal, only to be dropped in the future development, while new slips arose in the higher forms. We may further conceive that these mother masses were innervated by the nerves $V_{3}$ and VII, and that in the first stages of the origin of a new muscle slip there was a mere branching of the nerve into small twigs: in this stage there was no differentiation into special nerves and no division of the muscles into separate slips, but merely partially separated portions with the nerve twigs following and gratually becoming more differentiated, as combitions demanted further separation. Finally, when these slips were separated off from the main mass, the nerve twig became a branch, and the muscle, having lost all connection with the fibers of the parent mass, micht he called a reparate muscle. This is my conception of the origin of the special musese in the diflerent classes, and with this riew the precise homolugr, exeret within the class, is sometimes doubtful. unless very primitive or ameetent forms between widely separate groups are available for study. 
This separation of the muscle slips from the mother mass may be shown in embryology; for the muscle groups start as undifferentiated masses and then become divided into the different slips. Lubosch (1913) describes the separation from the "temporal mass" of a slip which becomes the "pterygoid" of the urodele. 'I'his splitting of the muscle is quite definitely known, and in this paper I hare marle frequent use of this fact in endearoring to determine the homologies of the different groups and in reconstructing the muscular systems in extinct forms. (See chapter on reconstructions.)

Some indiridual muscles may, however, be followed through all the classes of vertebrates. If the history of a bone has been traced from the Pisces to the Nammalia, there is no reason for assuming that the muscles associated with it have changed, provided that they are present in all of the classes and have retained their origin, insertion and to a certain extent their function. Perhaps the hyomandibular (= stapes), the preopercular (= squamosal), and other bones whose history is pretty well known, might be considered as haring taken their muscles with them throughout the evolutionary changes from the fishes to mammals, if there is no mechanical or other reason for the dropping of the old and development of new muscle slips. Muscles are pliable tissues having the power of changing, either by shifting their origin or, if there is no demand for their service, by dropping out. Vestigial muscles found in each of the classes have been carrier over from an earlier class and have lost their usefulness and atrophied. A long list of such muscles might be compiled from the Mammalia or from any class. The vestigial muscles of the ears in Homo, carried over from the simian stage, restigial muscles in birds, carried orer from the Reptilia, the vestiges of the levator arcus palatini in Cryptobranchus and Amphiuma, carried over from the Pisces (Lubosch, 1913, p. \%1), the "adductor maxillæ" in Cryptobranchus from the Pisces, are all vestigial and more or less functionless muscles carried over from one class to another.

\section{Homologr of the JAw Muscles in the Pisces}

(Table I)

The primary division of the musculature may be made with the innerration as a guide, as there is a natural grouping of the muscles of the head into two systems - the muscles innervated by the fifth or trigeminus and those immervated by the seventh or facialis nerre. The muscles also divide into the same two divisions if we group them first as muscles anterior to the quadrate region and secondly as those posterior to it. The 
exceptions to this grouping are the mimetic muscles of the face in mammals, which represent the muscles from the second constrictor, innerrated by the facialis, that have extended over the face and taken their nerves with them.

If we assume that the jaw and hyoid elements represent the first two visceral arches that have changed their function in some pregnathostome stage, it is also fair to assume that the muscles went with them, and that the jaw muscles represent the much divided and specialized constrictors and adductors of primitive branchial arches. Vetter's analysis of the muscles of the visceral arches appears to hold good at the present day. He held that the adductor mass of the jaws of fishes was homologous with the "adductores arcumm visceralium." which were small muscles on the inner side of the branchial arches, "mittlere Beuger der Bogen," lying between the dorsal constrictors above and the rentral constrictors below. As these branchial arches changed into jaws and the development of the hyomandibular, quadrate and opercular elements proceeded, the constrictor and adductor muscles, which were already in position, would require but little change to take on new functions as jaw and opercular muscles. Accordingly, the constrictors of the pre-gnathostomes may be regarded as the primitive head muscles. In the elasmobranchs the constrictor became divided into different sections, so that there were dorsal, merlian and rentral sections, which were either further clifferentiater to be used as needed or held in reserve for future changes, as in the case of the digastric muscle. This is represented in the elasmobranchs (Ruge, $189 \%$ ) by the undifferentiated second constrictor, which retains its constrictor-like form until it becomes specialized in the amphibians into a definite muscle.

Throughout the gnathostomes we find muscle masses that may be homologized, but the homology of the separate slips is often questionable. In this paper the attempt is made to work out the homology of the main muscle masses ("Mother" masses) first and then, if possible, to point out the homologies of the separate slips of eateh mass. epredally in the members of the same class and where possible between classes. To homologize the separate slips through the different classes means that cne must know the ancestry and be able to demonstrate the morements and changes in the osteology, so that in default of such knowledge the result is often questionable.

The muscles of the piscine head may be divided as follows (the related muscles are placed together): 
MUSCLES INNERVATED BY THE TRIGEMINUS NFRVE

Levator maxillæ superioris.

Levator arcus palatini.

Protractor hyomandibularis.

Dilator operculi.

Adductor mandibulæe (often divided in the Pisces).

MUSCLES INNERVATED BY THE FACIALIS NERVE

Adductor hyomandibularis.

Levator operculi.

Adductor operculi.

\section{MUSCLES INNERVATED BY THE TRIGEMINUS NERVE}

Levator maxillæ superioris (Adductor $\beta$ Vetter).

Levator arcus palatini 1-5 McMurrich.-These are a series of muscles that extend from the under side of the skull to the maxillæ. They vary in number in the Pisces from one to four or five. In Acanthias they arise in a mass anterior to the spiracle and the remains of the first constrictor dorsalis superficialis and extend to the maxilla: here they form a single muscle. In Amia they are partly anterior to the eyes. They probably represent the dorsal part of the first constrictor superficialis and function in the movement of the maxillæ. In the teleosts they lose their importance and disappear, except for a few tendinous remains, while the levator arcus palatini becomes more important and usurps the place of the levators of the maxillie.

Levator arcus palatini.-This muscle raises the bones of the palatine region and is of great importance in the fishes where this region is developed. In the elasmobranchs it is not needed, but is perhaps represented hy the remains of the first constrictor, just anterior to the spiracle. It is prominent in most teleosts and Holostei, but drops out where this region becomes fixed. This muscle is closely related to the protractor hyomandibularis and the dilator operculi. McMurrich (1885) calls the protractor hyomandibularis "levator arcus palatini" in Amia. They are often close together and sometimes not entirely separated as in Amia.

I'rolraclor hyomandibularis. - This draws the hyomandibular forward. It probably represents a part of the first constrictor. It is always closely connected with the levator arcus palatini. It varies in size, being very large in Lipenser and Polyodon, of good size in the teleosts, and absent in the dipnoans, where the hyomandibular is rudimentary or absent.

Dilator operculi.-This is the posterior slip of the first constrictor. It pulls the operculum forward and slightly raises it. It is closely con- 
nected with the protractor operculi, always lying just behind it, extending over the groove for it in the hyomandibular just above the preopercular. Often the preopercular also shows where the muscle extends over the upper end of it. Practically every skull studied showed this muscle area, so that it is easily demonstrated on any skull in the teleosts or other fish group. It is inserted on the under side of the opercular in most forms.

Adductor mandibulce. - This is considered as the mother mass of the chice jaw muscles throughout the vertehrates. In the elasmobranchs it is almost a single mass, partially sublivided in the rest of the fishes and reptiles and completely divided in the Amphibia and Mammalia. It is innervated by the third branch of the trigeminus and represents a part of the first constrictor with its nerve. The condition in the elasmobranchs is usually as a single mass, although the fibers cross each other and do not always extend in the same direction, but there is no definite separation in those studied and none described in the literature on other forms. There is a tendency throughout the remaining Pisces for this mass to be partially divided. In general this muscle may be divided into two parts-a superficial part that extends across the other fibers and is attached in the quadrate and squamosal region and a deeper set of fibers which extend up to the postfrontal and parietal region. No attempt is made in this paper to homologize these portions, although they are constant and seen to be starting a condition that eventually may have resulted in the separation of these slips from the mother mass. The simplest adductor mandibule is found in Lcanthias and the most complex in 1 mia and Esox, although the division is never complete. Amia. Patinurichthys and many other forms show a peculiar specialization, where a part of the adductor ( $\mathrm{A}\left(\mathrm{m}^{4}\right)$ extends into the suprameckelian lossa and excavates the dentary, so that the bone is completely filled with this part of the muscle.

\section{IUUSCLES INNERTATED BY THE FACIALIS NERVE}

This series of three muscles is concerned with the movement of the opercular and hyomandibular bones. They represent a part of the seomd dorsal constrictor and show the characteristic innervation of this mass.

Adtuctor hyomandibularis.-This is a deep muscle which arises on the posterior part of the skull in the otic region, anterior to the other two. It is usually small and short and is not easily seen unless the opereular homes are removed. It opposes the protractor hyomanditularis and raises the hyomandibular bone. It is attacher to the immer side or to the posterior border. It is shown in Acipenser, Polyodon and Polypterus. 
Adductor operculi and levator operculi.-These are closely associated. Both arise on the posterior part of the skull in the otic region and are inserted on the imner side of the opercular bone. Often one of them is absent or perhaps they are not differentiated. They are present in almost all the Pisces with the exception of elasmobranchs. They are small in the dipnoans.

\section{Homologr of tine JAw Muscles in the Amphimi}

('Table II)

There is quite a difference between the muscles of the Pisces and those of the Amphibia, for in the latter muscles masses have become more specialized by a splitting off of the different slips, so that they may be called separate muscles. Some of these divisions were suggested in the Pisces by the direction of the fibers and by differences in the origin and insertion, but they remained a part of the parent mass, as they do, for the most part, also in the Reptilia. In the Amphibia the muscles of the anterior part of the piscine head have disappeared, being represented by vestiges only. Lubosch (1913, p. 71) says:

IBisher unbekannte Muskelrudimente wurden gefunden bei Amphiuma und Criptobranchus.

(1) Ein M. levator arcus palatini bei Amphiuma und Cryptobranchus, ron der knorpligen Nasseskapsel und (Amphiuma) der vertikalen Lamelle des Frontale (Wiedersheim) entsprigend und zur Membrana pterygomaxillaris zeihend.

(2) Ein M. adductor maxilla bei Cryptobranchus rom rorderen Rand des knöchernen Pterygoids und dem knorpligen Proc. pterygoidens quadrati entspringend und in der Nihe des Maxillare in der Membrana pteryo-maxillaris endend. Beide Muskeln werden mit feinen Aestchen aus demselben Nerven versehen, whelcher auch die Mm. pterygoidei versorgt.

The great changes in the skull of the Amphibia account for the reduction and dropping out of several of these typical piscine muscles. There is no need for the levator maxillæ superioris and the levator arcus palatini, as the parts controlled by these muscles are fixed. The new form of the bones demand a different musculature and the loss of others. The preopereular, simplectic, hyomandibular, operentar, inter- and sub-opercular and several of the bones of the skull and maxillary region have either been lost or changed their functions, so that new muscles are neerled. If the hyomandibular is considered to be the stapes of the higher forms, it seems to have discarded its original musculature in the transformation, for there are no muscles in the forms with a stapes that could have been retained from the muscles of the hyomandibular. The two hyomandibular muscles - the protractor $\left(\mathrm{V}_{3}\right)$ and the levator (VII) - 
could not have been carried through to the Mammalia, or at least there is nothing to show that such was the case, as the new stapedial muscle is regarded as a slip from the $\mathrm{C}_{2} \mathrm{~m}$ or from the reptilian depressor mandibulæ. The preoperculum, which is considered to be the squamosal of the forms above the Pisces, retains its old connection with the temporal muscle mass, so that the masseter (or superficial) slip of the urodeles and anurans is still associated with the transformed preoperculum. In the Amphibia the piscime opereulum is absent, so that the three muscles attached to it in the Pisces would be lost.

The simplest condition of the musculature is found in the urodeles, where the muscles are well separated, but are not so specialized as in the Anura and retain more of their piscine condition. They are divided into slips, three or four in number. These are separate slips that compare with those indicated in the muscles of the reptiles, but are not regarded as fully homologous with them. 'The superficial slip is the typical masseter-like muscle with the same general direction of the fibers and the same relation to the main mass. The deeper muscles of the peculiar "Temporal mass" have a peculiar specialization, in that one slip extends back over the skull and arises no longer on the parietal, but on the neck vertebra, sometimes as far back as the fourth cervical vertebra. (See urodeles.) The anterior temporal, which arises from the side of the skull, behind the eyes, and runs outward and backward to the inner side of the mandible, is apparently comparable to the pterygoideus anterior of reptiles. 'This pterygoideus anterior has separated from the under side of the capiti-mandibularis mass, but does not arise from the pterygoid.

The Anura show the highest specialization found in the amphibians, as the muscles are not only divided into slips, but the slips are well separated, both in their origins and in their insertions on the mandible. The striking thing in comnection with the anuran jaw museles is their connection with the auditory region, for the muscles of mastication and some of the neck muscles serve to keep the tympanum stretched taut. The division of the capiti-mandibularis superficialis (masseter) is suggested in the urodeles, where the fibers of the single muscle show an intermediate condition. The depressor mandibula is the same throughout the group. It has two slips, one from the skull and one from the dorsal fascia. They represent again the $\mathrm{C}_{2}$ md of Ruge, which is the mother mass of this group innervated by the VII nerve. It seems from the innervation, origin and insertion that the inclivilual slipe may he hementegized throughout the Amphibia, and the homologies as they appear are shown in Table II. 


\section{Homologies of the Jaw Muscles in the Reptilita .}

\section{(Table III)}

'The jaw muscles of the Reptilia and Ares show the same division into masses as do those of the Pisces and Amphibia. There is the same group)ing of the masses into muscles innervated by $\mathrm{V}_{3}$ and by VII and they have the same relative position as in the lower forms. The muscles show more specialization, as there is a higher specialization of the skull in Reptilia and dres and consequently a more complex musculature. In the reptiles the capiti-mandibularis mass is more homogeneous than in the Amphibia, and while the pterygoid muscles have separated off, the capiti-mandibularis superficialis remains attached. In the birds there is a complete separation of the muscles.

The great specialization in the higher or streptostylic reptilian stulls is correlated with the great complexity of the musculature. The Reptilia are divided arbitrarily into two groups according to the fixity or movability of the quadrate; but this is a relative division, for all stages are found between the streptostylic and the monimostylic conditions. The jaw muscles of the Reptilia may he grouped according to the innervation, as follows:

\section{MUSCLES OF THE CAPITI-MANDIBULARIS OR TEMPORAL GROUP}

(INNERVATED BY $V_{3}$ )

Capiti-mandibularis.

(a) Superficial slip (not separate). Masseter.

(b) Medius slip (not separate). Temporal.

(c) Profundus slip (not separate). Deep layer.

(d) Cranio-pterygoid.

Pterygoideus anterior.

Pterygoideus posterior.

IIUSCLES OF THE DEPRESSOR OR DIGASTRIC GROUP

(INNERVATED BY VII)

Depressor mandibulæ.

\section{MIUSCLES OF THE OAPITI-MIANDIBULARIS GROUP $\left(\begin{array}{llll}\text { INNERVATED } & B Y & V_{3}\end{array}\right)$}

Capili-mandibularis.-. This muscle is not rivided into separate muscles, but the ronditions suggest the divisions to appear later in the mammallike reptiles. (a) The outer or superficial slip may apparently be traced from the fish to the mammal. It always arises from the squamosal region 
and is inserted on the coronoid region of the jaw along with the rest of the mass. (b) The medius slip also is not separate, the fibers being under the superficial slip and extending to the parictal region. (c) The profundus is represented by the deep part of the mass. (d) The cranioptergoid muscles are the special muscles developed in the pteryoid region of the streptostylic reptiles and are new developments.

Pterygoideus anterior and pterygoideus posterior.-The so-called pterygroid muscles of reptiles include two quite difterent groups: the posterior group represents the deepest part of the capiti-mandibularis mass. It is usually mamed the pterygoideus externus or external pterygoid, but it is probably only party homologous with the mammalian extermal pteryond. I have named it the capiti-mandibularis profundus. It is often subdivided into two heads, which may be named caput 1 and caput. 2. The anterior pterygoid called by Mirart "Internal pterygoid" and in this paper "Pterygoideus anterior" represents the anterior part of the adductor mass or $\mathrm{C}_{1}$ smd of fishes and is foreshadowed in Polypterus. It may be the homolog also of the so-called "temporalis" of urodeles. It is far in front of the "Pterygoideus externus" and runs in the opposite direction, crossing it at a wide angle on its way from the orbital region to the back of the mandible. It is always present in the reptiles and acts in concert with the capiti-mandibularis mass in closing the jaw. More in detail the action is described in the section on reptiles.

\section{MUSCLES OF THE DEPRESSOR GROUP}

\section{(INNERVATED BY VII)}

The depressor mandibulæ acts as the depressor of the mandible. It is constant throughout the Sauropsida. It was retained throughout the series until the mammal was evolved, when probably a new slip was separated from the mother mass and the new depressor of the mammal was formed.

Futamura (190\%, p. 5\%0) on comparative and embryological evidence staterl that the stapedial muscle of the mammals and man comes from the proximal or upper part of the musces of the hyoid areh (innervated by VII) - that is, the mother mass of the depressor mandibulæ-and that the reptiles also derive their stapedial muscles from the same source. Futamura says:

Der M. stapedius stammt ron den Muskelfasern die sich rom proximalen

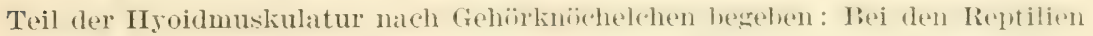
(Krokodil, Lacerta) ist er mehrfach und in seine Funktion auch rerschieden von der der Vögel und Sïugethiere. Nach Killian finden sich beim Krokodile Ohrmuskeln, die Heber, Herabzieher der Ohrklappe und Spanner des 'Trommel- 
felles sind. Dei der Lidechse konnte ieh nu zwei Muskel finden, die sich dem Levator der Ohrklappe und dem Depressor der Ohrklappe und Spanner des Trommelfellest der Krokodile verglichen hithe. Rei den Vügeln, Siiugethiere und dem Itenschen ist der stapedius einfich, geht heim Vogel an der Columella und bei den siingethiere an den steigbigel. Hier verliert er damit die direlite Perzehung zum Trommelfell und macht auch einen Funktionswechsel inureh, auf den ich hier aber nicht nïher eingehen will.

\section{SuMATARI}

The relations of the jaw muscles of reptiles and Amphibia are well summarized by Lubosch (1913, pp. 72-73) as follows:

Die Vergleichung mit den Reptilien (rerg. die Beschreibungen von Fischer, d'Alton, Sanders, Mivart, Versluys, Watkinson, Bradley) Der Organizationstypus der Urodelen ist auch heir unverkenubar vorhanden. Die Muskulatur ist zwar mässiger, aber zweifellos weiniger eingreifend gegliedert als dort. (Bei Krokodilen ist sogar Masseter und Temporalis sehr reduziert.) Der Ramus mandihularis liegt auch hier zwischen Masseter und Temporalis ausien, Pterygoideus innen. Der Pterygoideuskomplex tritt auf als Pterygo-mandibularis (Bradley) (homolog dem Pterygoideus posterior der Urodelen) und als ein als, Pterygoideus (Bradley) auch "Pterrgoideus internus" bezeichneter Muskel (Homolog dem Pterygoideus anterior der Urodelen) Bei Cheloniern (und Krokodilien . . .) sind alle Hauptteile der Muskulature scharf gesondert, bei Lacertiliern und Ophidiern scheinen sie nach den Angaben der Literature mehr zusammen-zuhäingen. Besondere Eigentïmlichkeiten lietet eine tiefe Masseter-portion dar, in betreff welcher auf die genauere Darstellung verweisen wird. Wichtig is nun vor allem die Differenzierung der motorischen Trigeminusïste.

\section{Homology of the JaW Mugcles in Aves}

\section{(Table III)}

The musculature of the jaws in birds has been derived from the reptilian position with little change. As the bird skull is streptostylic, the reptile most easily compared with it is Taranus and some of the fossil forms as mentioned in the section on Aves. 'There is a separation of the muscles, so that the capiti-mandibularis is divided into a superficial, a menlian and deep portion. The deep portion fills its msual place and the superficial las its origin on the syumosal and quadrate. These muscles

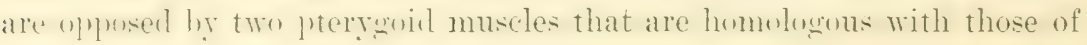
the reptiles.

'The ptergableus anterior (ptergoin intermus) is the homolog of the muscle of the same name in the Reptilia; it does not wrap around the end of the mandible but is inserted on the inner, posterior face of the mantihle as it does in some reptiles-e./.. Chelonia. Ptergoideus pos- 
terior is the posterior slip from the (ap)iti-mandibularis, which is separate in birds. It crosese the anterior pteryodid and is the homolog of the muscle of the same name in Reptilia.

The depressor mandihule is large and is the homolog of the tepressor of the Reptilia.

The presence of the stapedial muscle in the Aves shows that in some of the reptiles and Ares the stapes was comnected with a part of the deHesirer manctibulat. Futamura (190i) has shown that this was true in the embryology of the sparrow and of the duck:

Der Stapedius entspringt ron der Gehörkapsel und geht zum columella und zu der medialen Seite der Gehörgrube. Ein Teil der Muskelfasern scheint mit dem proximalen Abschnitt des Quadratum Beziehung zu haben. . . . In der Sperling der M. stapedius, der aus dem vorher erwihnten proximalen Teil der Facialismuskulatur entsteht. ist sogar sohon ziemlich deutich differenziert. Er liegt an der dorsalen Seite der ibrigen Facialismuskulatur und zieht grösstenteils an der medialen Seite des Facialisstammes nach hinten, medial, und endet dicht an der Carotiswand der Nerrus facialis ist bedentend rerlingert. In der Ente M. stapexlius, disastricus und stỵlohyoldeus differenzieren sich aus dem Blasten der post-auricularen Gegend.

\section{Homologies of the JaT MUscles in Mamatas}

(Table IV)

The great transformation of the reptilian skull into the mammalian skull has been correlated with equal changes in the jaw muscles. The temporal fossa of mammals have opened out, so that the temporal and masseter muscles extend to the surface of the head and thus gain room and free action for direrse adaptation and for expansion. By the devel"pment of the satital and oceipital crests the areas for the oring of the

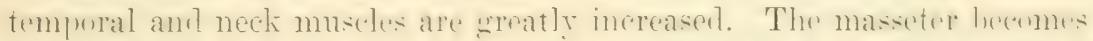

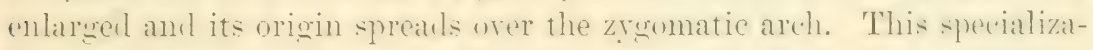
tion of the superfecial part of the temporal mass is typically mammalian. as nothing like it is seen in the reptiles.

The great changes in the mandible, the reduction of the posterior jaw elements. and the derelopment from them of the mallus and incus hare heen correlatel with an equal transformation of the museles. 'The insel'tion of the whole temporal mass has shifted from the ooronodid region we the mantilsle to the dentary, while the external muscle gare rise to buth the internal ant external muscles of the mammils. The formation of

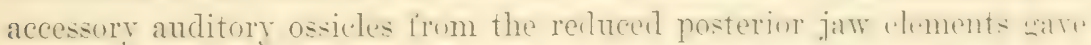
oplurtunity to certain of the reptilian muscles to assume nut innetions.

The stapedial muscle, for example, would be homologized with the 
mple part of the reptilian depressor mamlibula, as it has been shown in the sections on birds and reptiles that the elepresisor is in the position to gain the relations of the stapedial muscle of the mammals. It hardy seems possihle, from the conditions seen in Cynoynathus, that the depreson mandibula has heen carried over from the reptiles as the posterior helly of the mammalian digastric. The most satisfactory conchusion appears to be that a part of the depressor became the stapedial muscle and that the mammalian digastric is a new slip from the second constrictor mass, which was still retained in the reptiles (Ruge). Wilder (1909), in discussing the origin of the stapedius, sals: "A portion of the pusterior belly, that is, of the second levator, becomes separated from it in the reptiles, and follows the stapes into the middle ear, whence it becomes the stapedius muscle, immervated by a special branch of the facialis." That the stapedius muscle is an ancient muscle appears to be shown by the great separation of the digastric and stapedial nerves, both of which are branches of nerve VII. In other groups of related muscles the nerves, although branching and beroming more than mere nerve twigs, still indicate their relationship by their proximity to each other, as in the case of the subdivisions of the nerve $V_{3}$, where the muscles that are closely related have their nerves coming off close together. The stapedial nerve comes off at the upper part of the facialis, while the digastric nerve comes off far below it. This seems to help the hypothesis of the derivation of the stapedial and the wide separation in time from the appearance of the mammalian digastric.

Two muscles, the tensor tympani and tensor palati, appear in the mammals for the first time. They are immervated by the ramus manclibularis of the trigeminus and, according to Gampl, their homologr may be looked for in one of the pteryoid muscles of the reptiles. mamely, the "pteryomanclibularis" of Bradley, which is the "anterior pteryoid" of the present work. This muscle is in the position that would permit it to be drawn into the middle ear as the tensor tympani, and it is also in a position to give rise to the tensor palati.

The anterior pterygoid of reptiles is attached to the posterior end of the mandible, and during the change from the reptilian to the mammalian comblition it could he drawn into the mickle ear without much change. as has been shown above. A reriew of Gaupp's discussion, however, leaves me in doubt whether these muscles have both come from the reptilian pterygoideus anterior or from the reptilian external pterygoid or from both. Their connection with the pterygoideus internus of man would incliate their derivation from the leep portion of the capiti-mantibularis of reptiles. The insertion of the tensor tympani on the handle of the 
malleus would, on the other hand, indicate relationship with the anterior pteryogit, which in reptiles is inserted on the back part of the mandible. The toposraphic relations of the tensor palati suggest one of the craniopteryoud museles of reptiles. The tensor veli palatini (temsor palati) is called by Gaupp the homolog of the reptilian "piteryo-mandibularis" (anterior pterygoid). He points out that Kostanecki (1891) in Didelphys showed the close relation of tensor tympani and tensor veli palati. Killian (1890) also fomd that the two muscles were joined in the early stages of apes, man, Cheiroptera, etc. In man the two muscles aplear at ahout the fourth month to become separate from the pterreoidens intermus. 'These facts in the embryology would appear to show that tensor tympani and tensor veli palati are phylogenetically related; that they come from the pterygoid musculature of the reptiles, probably from the anterior pteryoid. Their close relations with the mammalian pterygoideus interums also indicates that they arose from the same recrion of the temporal mass. This derivation of the tensor tympani from one of the pterygoid muscles seems very plain, for it extends down along the side of the eustachian tuhe in the mammals and is attached to the handle of the malleus, so that the essential relations are not changed in the transformation of a jaw muscle into an auditory muscle.

The mammalian pterygoid muscles may possibly both be derived from the deep part of the capiti-mandibularis mass of reptiles - that is, from the apriti-mandibularis profundus or pterygoideus externus. The dhanges in the posterior part of the jaw and in the skull wonld make it almost impossible to derive these from the anterior pterrouid muscles. 'The ditticulty in deriving the pterygoid muscles of mammals from the anterior pteryouil muscles of reptiles is that the latter are inserted on the posterior part of the mandible, an element which became restigial, while the former are inserted wholly on the dentary. A study of the jaws and skull of c"ymosmuthus and the other crmolonts indicates that it would be difficult to conceive clearly the transference of the insertion point of the anterior pterygoid from the angular and prearticular region to the back part of the dentary. On the other hand, the pterygoideus or capiti-mandibularis profunclus, which is inserted in the region of the coronoid, is in such a position that the upgrowing, ascending ramus of the dentary might well invade its insertion area. In this way a muscular connection between the wall of the cranium and the inner side of the dentary might easily be established. As the reptilian palate and lower jaw became completely transformed, it is to be expected that the characteristically reptilian pteryonilens anterior would derenerate along with the alements an which it was inserted. From the innervation of the mammalian pteryoroid 
muscles, which is from different parts of the ramus mandibularis, we may assume perhaps that the pterygoideus internus has long been separated from the temporal mass, and that the pterygoideus externus is the newer muscle that still hears a close relation to the temporal muscle in the mammals; and so far as I have discovered, the pterygoideus externus is present throughout the Mammalia, while the pterygoideus internus, which has been separated from the mass lor a longer time, has in some cases (monotremes) disappeared or never developed.

Of the pterygoid externus Lubosch (1913, p. 75 ) writes:

Der I'terygoideus externus hat keinfalls seinen Mutterboden in einem der P'terygoideusteile der. Urodelen. Die I arstellung von Schulman, dass er einem tiefen Teile des Temporalis nïhestehe, liisst sich aus den Verhiiltnissen der Urodelen verständlich machen, wo der T'emporalis geradezu überraschende Differenzierungen in einzelne I'ortionen zeigt, so dass sich die Ansicht rechtfertigen liisst, das der Pterygoideus externus in bestimmten Teilen der Temporalis-muskulatur der Urodelen enthalten sei.

But unless the amplibian ancestry of the Mammalia were accepted, one would question the homology of the mammalian muscles with anything found in that group.

Of the pterygoideus internus Lubosch (1913, p. \%5) writes as follows:

Der Pterygoideus internus scheint hingegen alter Besitz der Ahnen der Sïugethiere der sogar seinen Ursprung bewahrt hat. Hinsichtlich seiner Insertion ist zu errinnern, das schon bei Fischer Ausbreitungen am Dentale bis nach vorn vorkommen (Vetter) Auch er fehlt den Monotremen, so dass hier die gesiante bei Urodelen angelegte tiefe Temporalisschict nicht rorhanden ist, der 3. Ast des Trigeminus also unmittlebar unter der Wangenshleimhaut liegt. Da sich bei Urodelen der Pterygoideus internus aber auf allen Stufen der Emanzipation rom Temporalis zeigt, so lassen sich ausgangszustände auch fuir dic Muskulatur der Monotremen mit Wahrscheinlichkeit feststellen. ohne dass die Frage hier erötert werden kann.

I certainly agree that there is no relation between the muscle of the urodcle and the mammal, except in the general scheme of homology of the temporal mass, but the rest is special development in both groups, especially in the pterygoid musculature.

Regarding the digastric, it is now generally agreed that it is not the depressor mandibula of the Reptilia, Ares, or Amphibia, but an offshoot of the same pareut mass, namely, the second constrictor, that has been retained throughout the vertebrates and has always supplied the depressor for the mandible, except in the monotremes. 


\section{General Summary of Homologies and Evolution of the $J_{A T}$ Muscles in the Vertebrates}

The following conclusions may be regarded as well established:

(1) The two chief muscle masses of the jaw, $(a)$ the adductor mass innervated by the ramus mandibularis $\left(\mathrm{V}_{3}\right)$ and $(b)$ the depressor or digastric mass innerrated hy the farcialis (VI), are homologous throughout the Vertebrata.

(2) The adductor of the Pisces is the mother mass from which the muscles of mastication in front of the quadrate are derived throughout the vertebrates, by the separation of slips of this muscle and by their aratual complete separation in nerve supply through the growth of the originally small twigs into separate nerve branches. In the evolution from fishes this adductor has changerl profoundly and much of it has been lest, but the original topographic relations of the muscle remain the same throughout the vertehrates. whether all parts are completely separated or not.

(3) Some of the so-called pteryguil muscles have becu developed independently in the amphibians, reptiles and mammals. The new developments have been slips needed in the morements of the pteryoid rewion in streptostylic reptiles, and probably a new series of pterrgoid musces for the mammals.

(4) The amphibians retain rudiments of the levator arcus palatini of the fishes, but these muscles are lost beyond this group.

(5) In the streptostylic reptiles the complex ptergoid musculature was developed to meet the needs of the movable quadrate.

(6) The complicaterl musculature of the pterygoid in the streptostylic forms which was developed by the subdivision of the capiti-mandibularis mass into numerous slips.

(i) The hirds inherit much from the reptiles, and parts of their pterygoirl musculature are untombtenly homologous with those of reptiles, as follows:

Pterrgoideus profundus of the hiris: = capiti-mandibularis profundus in the reptiles.

Pterygoideus anterior of the hirds $=$ muscle of the same name in the reptiles.

The capiti-mandihularis superfictalis and capriti-mamlibularis medius $=$ subdivided capiti-mandibularis of the reptiles.

(8) The tensor tympani and the levator reli palati of mammals appear to represent restiges of the pterygoideus anterior of reptiles. The tensor tympani took on its modern functions when the back part of the 
reptilian jaw gave up its primary function and was taken over into the service of the auditory organs. It retains its old relations with its insertion on the handle of the malleus (in reptiles it was inserted on the retroarticular process of the mandible and on the prearticular). The levator veli palatini seems to represent a part of the same pterygoideus anterior that has changed its relation slightly to serve in the region of the mammalian palate.

(9) The region innervated by the facialis has changed somewhat in the mammals. The depressor mandibulie of the reptiles has given rise to the $\mathrm{m}$. stapedius of the mammals and the rest of the muscle has disappeared.

(10) The posterior belly of the digastric of mammals appears to be a new development that has come from the remuants of the posterior part of the second constrictor $\left(\mathrm{C}_{2} \mathrm{sd}\right)$ of reptiles. It is thus believed to be a new muscle which has nothing to do with the "Digastric" of the reptiles, although it has the same functions and the same innervation. 'To this posterior belly has been added or grafted on at the anterior end one of the long rentral $V_{3}$ muscles to make the anterior belly of the mammalian digrastic.

(11) The slip that functions as the m. stapedius in mammals appears to have started in the reptiles and has been retained from the depressor mandibula. This muscle, which is connected with the distal end of the stapes in mammals, started in the reptiles and reached its perfected condition when it was drawn into the middle ear in the course of the transformation of the mammal-like reptiles into the true mammals. As mentioned above in the sections on hirds and reptiles, the future stapedial muscle was in the right position in the reptiles, where the depressor touches the distal end of the stapes, so it is not difficult to imagine how the depressor gave off a slip that became the future stapedius muscle.

\section{Relations of the JaW-Muscles to the Temporal Fenestre of Reptiles}

The following from Gregory and Adams (1915) summarizes their olservations on the relations of the jaw-muscles to the temporal fenestre:

(1) That in primitive vertebrates the chief temporal muscle-mass (adductor mandibula of sharks) was originally covered by the dermal, temporal skull-roof.

(2) That in modernized Amphibia and Reptilia, as well as in Aves and Mammalia, one or more slips of the primitive adductor mass had secured alditional rom for expansion by perforating the temporal roof 
either at the top or at the sides or in both regions at once; much as in histricomorph rodents, a slip of the masseter has invaded the region of the infraorbital foramen, so that it now extends through a willely open arcade and finds room for expansion on the side of the face.

(3) A comparative study of the sliull of Tyrannosaurus led to the suspicion that the pre-orhital fenestra of the linosaurs, phytosaurs, pterosaurs, etc., were also functionally connected with the muscles of mastication; but it was realized that proof of this view required a wider study of the jaw-muscles of living reptiles. It was afterwards found that Dollo (1851) had suggested that the pre-orbital fenestru of extinct reptiles were filled by the pterygoid muscles.

(4) The inferred conditions of the jaw musculature of Cynognathus are in harmony with the view that in the mammal the back part of the reptilian jaw hecame transformed into the accessory auditory ossicles.

(5) As a working hypothesis, it is assumed that the transformation of certain elements in the temporal and occipital regions of early 'Tetrapoda was partly conditioned by the stresses induced upon the skull-roof by the jaw and neck muscles. Comparison with lizards, Sphenodon, etc, clearly indicates that the prolongation of the parietal into the posteroexternal process, joining the true squamosal. was correlated with the squeezing effect of the capiti-mantibularis and depressor mandibula muscles. This may also be responsible for the suppression of the supratemporal and survival of the squamosal in early reptiles. The shifting of the post-parietals (lermo-supracocipitals) and tabularia from the dorsal to the posterior aspect of the oceiput was no doubt influenced also by the forward growth of the neck muscles upon the occiput. 


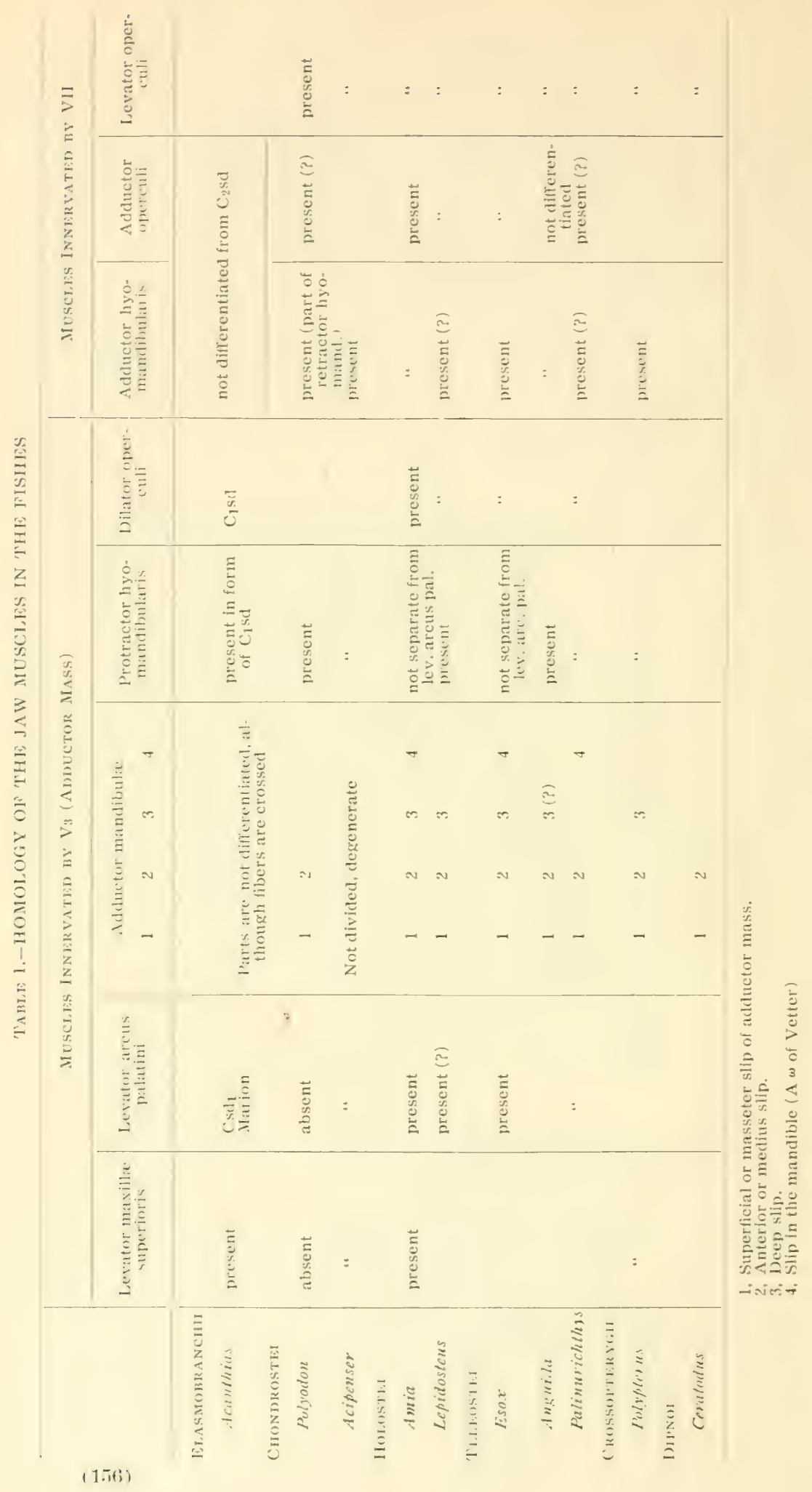


ADAIS, PHTLOGENY OF THE JAT IIUSCLES

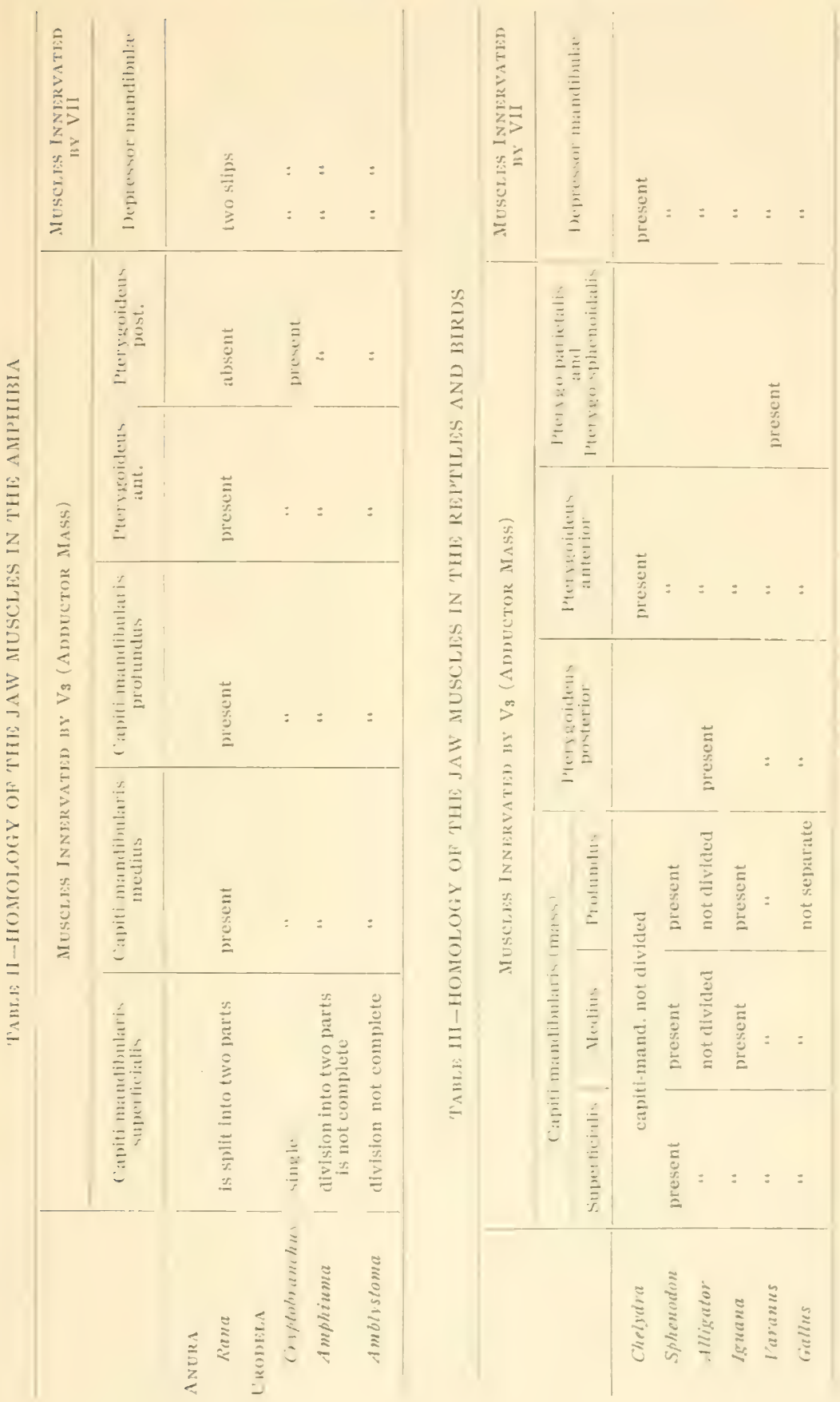




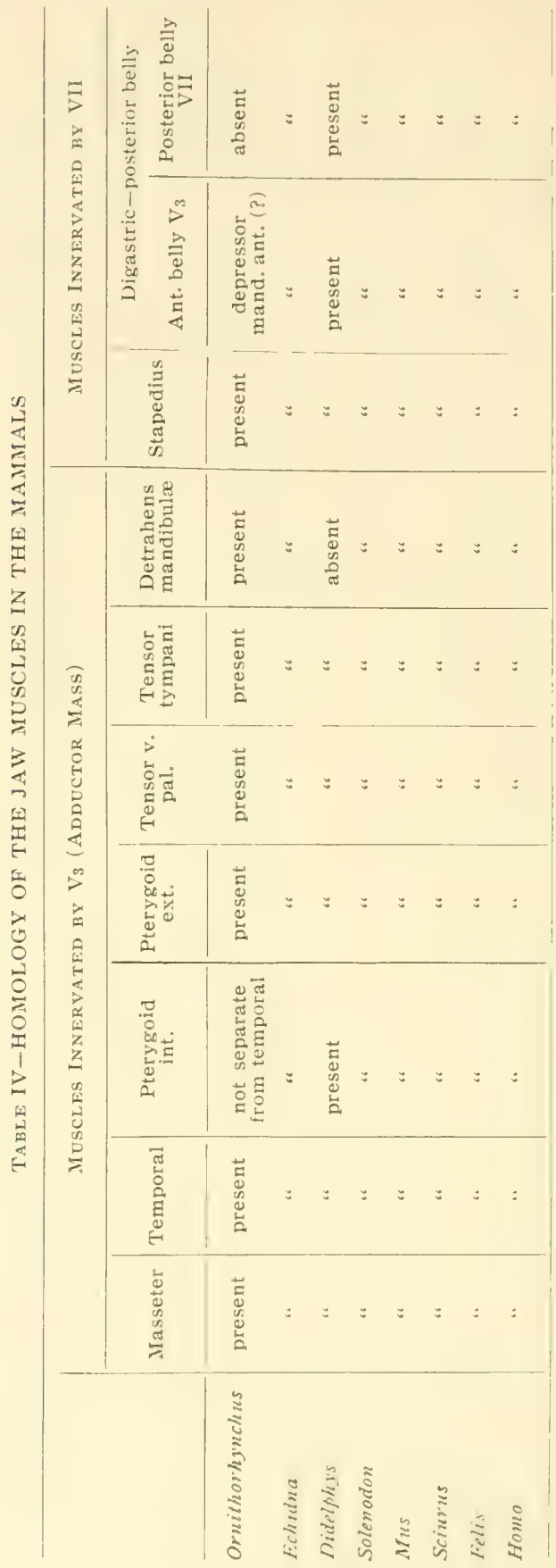




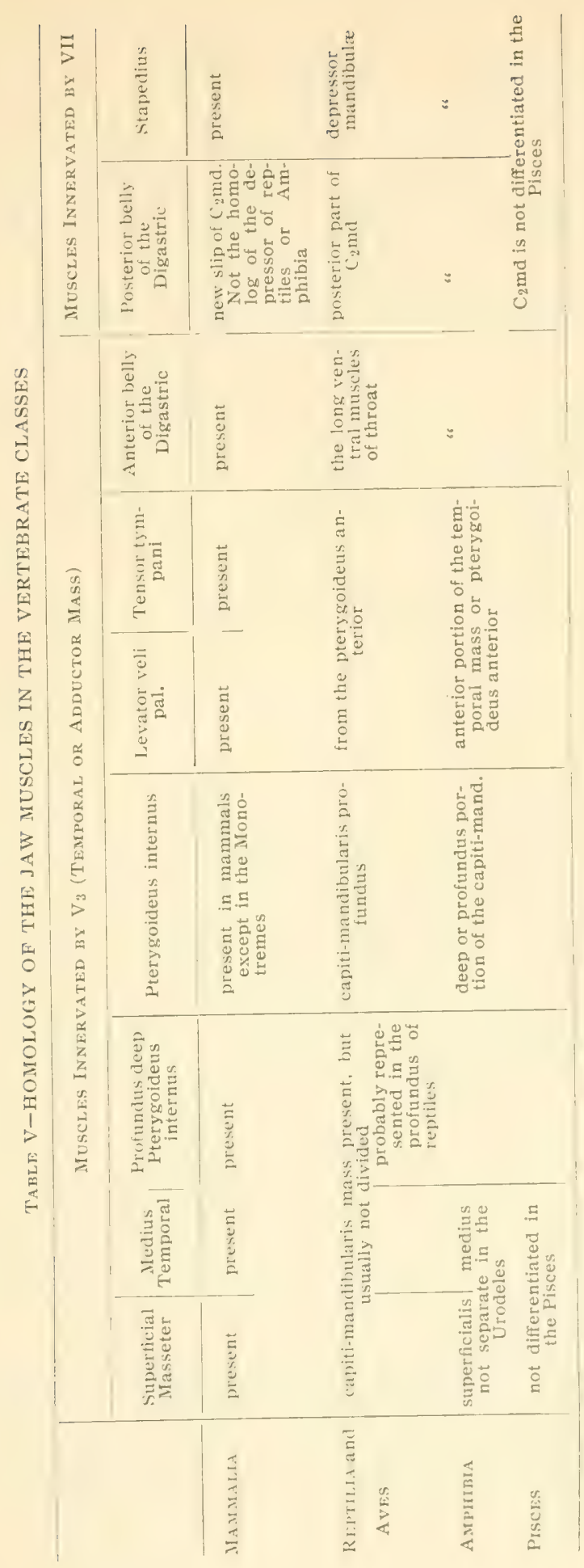




\section{BIBLIOGRAPHY}

D'Altox, E.

1534. Beschreibung des Muskelsystems eines Prthon bivitatus. Arch. f. Anat. u. Pbysiol., pp. 346, 432, 528.

Allen, $\mathrm{H}$.

1850. On the temporal and masseter muscles of mammals. Proc. Acad. Nat. Sci. Phila., XXXII, pp. 385-396.

Allis, E. Phelps.

1897. The cranial muscles and cranial and first spinal nerves in Amia calva. Jour. Morph. (3), XII, pp. 487-80s.

BARDELEBEn, ISARL Von.

1903. Muskelsystem und Mechanik. Ergebnisse d. Anat. u. Ent. Merkel u. Bonnet., XIII, pp. 114-164.

Bijvoet, W. F.

1908. Zur verwleichenden Morphologie des Musculus digastricus mandibulæ bei den Sïugethieren. Zeitschr. f. Morph. u. Anthr., XI, pp. 249-316.

Bradley, Cirarnock O.

1903. The muscles of mastication and movement of the skull in Lacertilia. Zoöl. Jahrb. Abth. f. Anat. u. Ont, XVIII, Heft 4, pp. $475-486$.

Broom, R.

1910. A comparison of the Permian reptiles of North America with those of South Africa. Bull. Amer. Mus. Nat. Hist., XXVIII, pp. $197-234$.

1911. On the structure of the skull in cynodont reptiles. Proc. Zoöl. Soc. London, pp. S93-923.

1913. Notice of some new south african fossil amphibians and reptiles. Ann. So. Afr. Mus., VII, pp. 270-278.

$1913 a$. On the Gorgonopsia, a suborder of the mammal-like reptiles. Proc. Zoöl. Soc. London, pp. 225-230.

1913b. On the South African pseudosuchian Euparkeria and allied genera. Proc. Zoöl. Soc. London, pp. 619-633.

Chaîne, J.

1914. Le Digastrique. Jour. de l'Anat. et Physiol., L, pp. 248-319, 393-417. Cords, E.

1904. Beiträge zur Lehre vom Kopfnervensystem der Vogel. Anat. Hefte, XXVI, pp. 49-100.

1910. Zur Morphologie des Gaumensegels. Anat. Anz., XXXVII, pp. 305-318.

Cunimgham, D. J.

1891. The value of nerve-supply in the determination of muscular homologies and anomalies. Jour. Anat. and Physiol., XXV, pp. 31-40.

1902. Text-book of anatomy. New York.

DANFORTH, C. H.

1913. The myology of Polyodon. Jour. Morph., XXIV, pp. 107-146. 
DEAN, BASHFORD.

1909. Studies on fossil fishes (sharks, chimaroids and arthrodires). Mem. Amer. Mus. Nat. Hist., IX, Part 5, pp. 211-287.

DoBson, G. E.

1882. On the digastric muscle, its modifications and functions. 'Trans. - Linn. Soc. London, (2), II, pp. $259-264$.

DoLLO, L.

1881. Cinquième note sur les Dinosauriens de Bernissart. Bull. Mus. Roy. de Belgique, III, pp. 129-146.

DRÜNER, L.

1903. Utber die Mruskulatur des Yisceralskelettes der Urodelen, Anat. Anz., XXIII, pp. 545-571.

1904. Studien zur Anatomie der Zungenbein-, Kiemenbogen- und Ḱchlkopfmuskeln der Urodelen. /oöl. Jahrb. Abth. f. Anat. u. Ont., XIX, Heft 3, pp. 435-62:2.

Eastmax, C. R.

1906. Structure and relations of Iylostoma. Bull. Comp. Zoöl. Harvard College, No. 1, pp. 1-29.

1906a. Dipnoan aflinities of arthhrodires. Amer. Jour. Sci., XXI, pp. 131-143.

Ecker, A., and Wiedersieidr, $\boldsymbol{I}$.

1896. Anatomie des Frosches. \& Auflage. Braunschweig.

EDGEWORTII, IT. H.

1903. The derelopment of the head-muscles in Scyllium canicula. Jour. Anat. and Physiol., XXXVII, pp. 73-88.

1907. The derelopment of the head-muscles of Gallus lomesticus, and the morphology of the head-muscles in the Sauropsida. Quart. Jour. Mic. Sci., LI, pp. 511-556.

1911. On the morphology of the cranial museles in some rertebrates. Quart. Joul. Mic. Sci., LVI, pp. 167-316.

FICK, IR.

1904. Handbuch der Anatomie und Mechanik der Gelenke Thiel I-III. 1904-1911. Jena.

Fürbringer, Mis.

1597. Über die spino-occipital Nerven der Selachier und Holocephalen und ihre vergleichende Morphologie. Festschr, f. Carl Gegenbaur, pp. $351-788$.

Futamura, R.

1906. Über die Entwickelung der Facialismuskulatur des Menchen. Anat. Hefte, XXX, Heft 2, pp. 435-514.

1907. Beitrige zur vergleichenden Entwickelungsgeschicte der Facialismusliulatur. Anat. Heft, XXXII, Heft :3, pp. 479-575.

GAUPP, E.

1905. Neue Deutung auf dem Gebeite der Lehre ron Säugethierschäid. Anat. Anz., XXVII, pp. 273-310.

1905a. Die Nicht-homologie des Unterkiefers in der Wirbeltierreihe. Ver handl. der Anat. Gesell., Versammlung 19. pp. 125-140. 
1911. Beitrïige zur Kenntnis des Unterkiefers der Wirbeltiere. I-III. Anat. Anz, XXxix, pp. 97-135, 433-473, 609, 666.

1913. Die Reichertsche Theorie. (Hammer-, Amboss- und Kieferfrage.) Archir fur Anat. u. Phys, Jahrgang 1912. Anat, Abth. (Sup. Band).

Gegenbaur, C.

1898. Vergleichende Anatomie der Wirbelthiere. I. Leipzig.

GOODRICH. E. S.

1909. A treatise on zoölogy. Lankester, E. Ray (editor), Pt. IX, pp. 7-9. London.

Gregory, W. K.

1910. The orders of mammals. Bull. Amer. Mus. Nat. Hist., XXVII, pp. $1-524$.

1912. Notes on the principles of quadrupedal locomotion and on the mechanism of the limbs in hoofed animals. Ann. N. Y. Acad. Sci., XXII, pp. 267-294.

1915. Present status of the problem of the origin of the Tetrapoda. With special reference to the skull and paired limbs. Ann, N. Y. Acad. Sci., XXVI, pp. 317-383, pl. iv.

1917. The coal measures Amphibia of North America. Amer. Nat, LI, pp. 311-320.

Gregory, W. K., and Adams, L. A.

1915. The temporal fossa of vertebrates in relation to the jaw muscles. Science, N. S., XLI, No. 1064, pp. 763-765.

GüNTHer, A.

1871. Description of Ceratodus, a genus of ganoid fishes, recently discovered in rivers of Queensland, Australia. Phil. Trans. London, CLXI, Part 2, pp. 511-571.

HaUghton, S.

1865. On the muscular anatomy of the leg of the crocodile. Ann. Mag. Nat. Hist., (3), XVI, pp. 326-331.

His, WILHELM.

1885. Anatomie menschlicher Embryonen. III, Zur Geschichte der Organe. Leipzig.

Humphrey, G. M.

1872. The muscles and nerves of Cryptobranchus japonicus. Jour. Anat. and Physiol., VI, pp. 1-61.

Huntingron, Geo. S.

1903. Present problems of myological research and the significance and classification of muscular variations. Amer. Jour; Anat, II, pp. $157-175$.

HUSSAKOF, I.

1906. Studies on the Arthrodira. Mem. Amer. Mus. Nat. Hist., IX, Pt. III, pp. 106-154.

HUXI,EY, T. H.

1876. Contributions to morphology. Ichthyopsida. No. 1. On Ceratodus forsteri. Proc. Zoöl. Soc. London, pp. 2459. 
Keibet, F., and MaLi, I. P.

1910. Manual of human embryology. I, pp. 505-509. Phila.

Killian, G.

1890. Zur vergleichenden Anatomic und vergleichenden Entwicklungs geschicte der Ohrmuskeln. Anat. Anz, V, pp. 226-229.

1890. Die Ohrmuskeln des Crocodiles, Homologie des M. stapedius. Jen. Zeitschr. f. Naturw., XXIV, pp. 632-656.

Kostanecki, K. yon.

1891. Zur Morphologie der Tubengaumenmuskulatur. Areh. f. Anat. u. Physiol., Anat. Abth., pp. 145-181.

LECHE, W.

1859. IBronn's Klassen und Ordnungen des Thierreichs. VI, Abth. 5, Bd. 1, p). $692,708,187 t-1900$.

Luboscir, IV.

1908. Das Kiefergelenk der Edentaten und Marsupialier. Semon's Zoöl. Forschungsreisen in Australien, IV, Lief 4, pp. 519556.

1913. Die Kaumuskulatur der Amphibien rergleichen mit der Sauropsiden und Siugethieren. Verhandl. d. Anat. Gesell., Versammlung 27, pp. $67-76$.

1914. Zwei vorlitufige Mitteilungen iiber die Anatomie del Kaumuskeln der Krokodile. Jen, Zeitschr. f. Naturw., LI, pp. 697-707.

IARION, G. E.

1905. Mandibular and pharyngeal muscles of Acanthias and Rai .. Tufts College Studies, II, No. 1, p1). 1-34.

MCMURRICH, J. P.

1855. The cranial muscles of Amia calva (L.), with a consideration of the relations of the post-occipital and hypoglossal nerves in the rarious vertebrate groups. Studies from the Biol. Lab. Johns Hopkins Univ., III, pp. 121-153.

IIVART, ST. G.

1867. Notes on the myology of Iguana tuberculata. I'roc. Zoöl. Soc. London, XXXV, pp. 766-797.

1870. On the myology of Chamateon parsonit. Proc. Zoül. Soc. London. pp. $850-890$.

OGUShT, K.

1913. Anatomische Studien an der japanischen dreikralligen Lippenschildkrote (Triony.x japonicus). Morph. Jahrb., XLVI, p]. $299-562$.

OSAWA, G.

1898. Beitrage zur Anatomie der Hatteria punctata. Arch. f. Mikros. Anat., LI, pp. 481-675.

OWEN, R.

1866. The anatomy of the vertebrates. II, pp. 93-94.

PALMer, R. W.

1913. Note on the lower jaw and ear ossicles of a fotal perameles.

Anat. Anz., XLII, pp. 510-515. 
PARSONS, IT. G.

1594. On the myology of the sciuromorphine and histricomorphine rodents. Proc. Zoöl. Soc. London, pp. 251-296.

1S9). Idem., pp. 159-192.

1S98. The museles of mammals with special relation to human myology. Jour. Anat. and Physiol, XXXII, pp. 428 450, 721-752.

1899. The joints of mammals compared with those of man. Jour. Anat. and Phỵsiol., XXXIV, pp. 41-68.

P'ATTEN, W.

1904. New facts concerning Bothriolepis. Biol. Bull., VII, pp. 113-124.

1912. The erolution of the rertebrates and their kin. Philadelphia.

POLLARD, H. B.

1892. On the anatomy and phylogenetic position of Polypterus. Zoöl. Jahrb. Abth. f. Anat. u. Ont., V, pp. 3S7-42S.

RABL, K.

1857. Ueber das Gebiet des Nervus facialis. Anat. Anz., II, pp. 219-227.

REIGHARD, J.. and JENNINGS, H. S.

1902. Anatomy of the cat. New York.

RIEGNER [HANS].

1906. Beiträge zur Lhysiologie der Kieferbervegungen. Theil 2.-Die Kiefermuskeln und ihre Wirkungsweise beim Affen (Macacus rhesus). Arch. f. Anat. u. P'hysiol., Anat. Abdth., pp. 109-116.

RUGE, GEO.

1895. Die Hautmusculatur der Monotremen und ihre Beziehungen zu dem Marsupial- und Mammarapparate. Semon's Zoöl. Forschungsreisen in Australien, II, Lief. 2.

1897. Ueber das peripherische Gebiet des Nerrus facialis bei Wirbelthieren. Festschr. f. Carl Gegenbaur, pp. 195-348.

ROUVIÈRE, H.

1906. Étude sur le Dévelopment plyylogénique de certain Muscles Sus hyoidiens. Jour. de l'Anat. et Physiol., XLII, pp, 487-540.

SANDERS, A.

1870. Notes on the myology of Platydactylus japonicus. Proc. Zoöl. Soc. Londou, pp. $413-426$.

Schulatax, H.

1906. Vergleichende Untersuchungen uber die Trigeminus-Muskulatur der Monotremen. Semon's Zoöl. Forschungsreisen in Australien, III. Theil 2, Lief. 3, pp. 297-400.

STANNIUS. H.

1846. Lehrbuch ter Vergleichende Anatomie. Zweiter Theil.-Wirbelthiere, p1). 161-180.

StAnNiUs, H., and Siebold, C. T. E. von.

185̃t. Lehrbuch der Vergleichende Anatomie. Zweiter Theil.-Wirbelthiere, pp. 1-128.

Strasser, H.

1908. Lehrbuch der Muskel- und Gelenkmechanik, pp. 475-502. Berlin. 
TEUTLEBEN, E. VON.

187.t. Ueber Katumuskeln mud Faumechanismus bei den TVirbelthieren. Arch. f. Naturw., pp. 7S-111.

'I'IESING, 13 .

1895. Fin Beitrag zur Kenntuis der Augen-, Kiefer- und Kiemen muskulatur acr Haie und Rochen. Theil 2. Jen. Zeitschr. f. Natulw., N. F., XXX, pp. 75-126.

'LOIIT, C.

1905. Der Winkelfortsatz des Unterkiefers beim Menchen und bei den Sïugetieren und die Beziehungen der Kaumuskeln zu demselben 'Theil 2. Sitz. d. Kais. Akad. d. Wiss. Wien. Math.-Naturw. Kl. CXIV, Abth. 3, pp. 315-476.

1908. Der Vordere Bauch des M. digastricus mandibula und seine Varie taten beim Menchen. 'Theil II. Sitz. d. Krais. Akad. d. Wiss. Wien. Math.-Naturw. K1., CXVII, Abth. 3, pl). 229-321.

TULLBERG, T.

1900. Über das System der Nagethiere. Nova Acta Reg. Soc. Seient. Upsaliensis. (3), XVIIT, Fase. 2. pp. 329-514.

VETTER, B.

1874. Untersuchungen zur vergleichenden Auatomie der Kiemen- und Kiefermuskulatux der Fische. Theil I. Jen. Zeitschr. f. Naturw.. VIII, pp. $405-458$.

1878. Theil II. Ebenda, XII, pp. 431-550.

VERSLUYS, JR., J.

1904. Über Káamusheln bei Lacertilia. Anat. Anz., XXIV, pp. 641-644.

Wathinson, Giace B.

1906. The cranial nerres of Taranus bivitatus. Morph. Jahrb., XXXV. pp. $450-472$.

IVATSON, D. MI. S.

1911. The skull of Dialemodon, with notes on those of other cynodonts. Ann. Mag. Nat. Hist. ( S), VIII, pl). 293-330.

1912. On some reptilian lower jaws. Ann. Mag. Nat. Hist. (8), X, pp. $573-58 \pi$.

1913. On some features of the structure of the therocephalian sliul. Amn. Mag. Nat. Hist. (S), XI, pp. 65-79.

1914. The Deinocephalia, an order of mammal-like reptiles. Proc. /oöl. Soc. London, pp. 749-786.

1914a. Emmotosanms africams Seeley, and the ancestry of the Chelonia. Proc. Zoöl. Soc. Londlon, pp. 1011-1020.

WTLDER, H. H.

1909. History of the human body. New Tork. P1). 245-248. 


\section{ABBREVIATIONS}

Arhluelor branehialis.................... Mr. Wr.

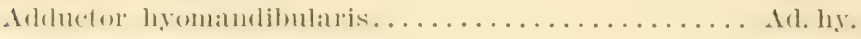

Adductor mandilute..................... Adm.

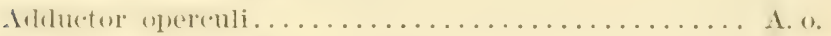

(:apiti-manclibularis.................... C. m.

Capiti-mandibularis superficialis............. C. m. s.

Capiti-mandibularis medius................. C. m. m.

Capiti-mandibularis profundus............... C. m. p.

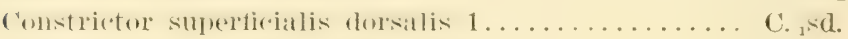

Constrictor superficialis dorsalis $2 \ldots \ldots \ldots \ldots \ldots \ldots$ C. ${ }_{2}$ sd.

Coraco-hyoideus.......................... Co. hy.

Coraco-mandibularis...................... Co. m.

Depressor cayitis....................... . .

Depressor palpebra inferior................. D. 1). i.

Depressor mambitulat. . . . . . . . . . . . . . I. m.

Depressor mandibulæ anterior................ D. m. a.

Detrahens mandibulø.................. Det. m.

Digastricu. . . . . . . . . . . . . . . . . I big.

Disastricus mandihula anterior............. Dig. a.

Digastricus mandibula posterior.............. Dig. p.

Dilator operenli...................... 1). (.

Entotympanium. .................... Ent.t.

Iycmandibulat . . . . . . . . . . . . . . . Hyo. m.

Levator arcus palatini.................... I. a. 1).

Levator capitis........................ L. c.

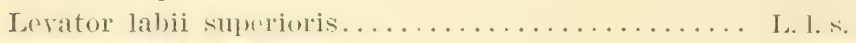

Lerator maxilla superioris................ L. m. s.

Levator operculi....................... L. o.

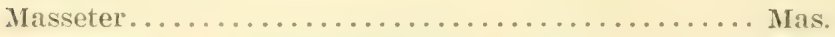

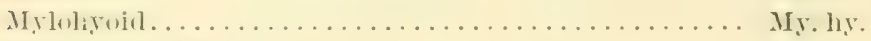

Parieto-mandibularis................... Pa. m.

Protractor-hyomandibularis............... P. hy.

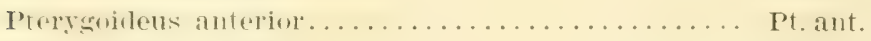

Pterygoideus externus.................... Pt. ext.

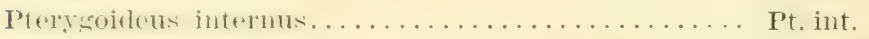

Pterygoideus posterior................... Pt. post.

Pterygoideus parietalis................. Pt. pa.

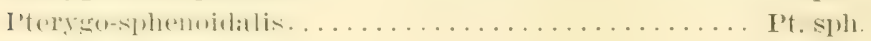

Pterygo-spinosus..................... Pt. s.

Pteryotgmpanir. . . . . . . . . . . . . . . . . Pt. ty.

Retractor hyomandibularis................. R. hy.

Spirachlar muscle..................... sir.

Styloideus. .......................... St.

Temporalis............................ T'ен.

Zygomatico-mandibularis....................... Zy. 
Jaw muscles of Scyllium and Acanthias, representing the Elasmobranchii. and of Acipenser and Polyodon, representing the Chondrostei

FTa. 1.-Scyllium (Mustelus). (Muscles mainly after Marion.)

The adductor mandibulie $(A d m$.) is seen wrapped around the posterior ends of the palatoquadrate and Meckelian cartilages. It is not differentiated into separate parts, although the fibers are crossed in certain regions. The levator' maxille superioris $\left(L, m, s_{\text {e }}\right)$ and the first dorsal superficial constrictor $\left(U_{,},{ }_{1} \ell_{\text {. }}\right)$ lie in front of the spiracle and together with the adductor are immervated by the third branch of the fifth cranial nerve $\left(V_{s}\right)$. All the pre-spiracular (1)re trematic) jaw muscles of higher rertebrites are derived from this group.

FIG. 2.-Acanthias. (Muscles mainly atter Marion.)

The muscles of the visceral arches may be divided into two sets according as they are derived from muscles which originally ran in a transverse (circular) or in a longitudinal direction (Kingsley). The jaw muscles belong to the circular group, which comprise dorsal and ventral series of constrictors and the adductors of the visceral arches. The levator' labii superioris (L. l. 8.), levator maxillo superioris $\left(L . m . s_{*}\right.$ ) belong to the series of superficial dorsal constrictors (C. ${ }_{1} \mathrm{sd} . . \mathrm{C}_{2} \mathrm{~s}$ s., etc.). The adductor mandilutia $(A d m$.) belongs to the adductor series.

Fir. :--Leipenser. (Muscles partly after Vetter.)

The adductor wandibule is small. The levator maxillic superioris is either absent or not differentiated from the large protractor hyomandibularis $\left(P . h y_{0}\right)$. This represents $C_{1}$ sd. of the elasmobranchs. It lies in front of both the spiracle and the hyomandibular and is innervated by $V_{3}$. The retractor hyomandibularis $\left(\boldsymbol{h}, h \%\right.$ ) and the levator operculi $\left(L . o_{\text {. }}\right)$ represent $\mathrm{C}_{2} \mathrm{sd}$. and are innervated by VII.

\section{FIG. 4.-Polyodon. (Museles partly after Danforth.)}

The adductor mandibulix is divided into two muscles $\left(A d \mathrm{~m}^{1}, \mathrm{Ad}^{2}\right)$. The jost-spiracular constrictor (innervated by VII is more or less subdivided into retractor hyomandibularis plus operculi $\left(R, h y_{0}+o_{0}\right)$, levator operculi $\left(L o_{0}\right)$ and adductor operculi (A. O.). 

Axidis N. Y, ACAD, SCI.

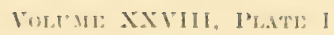
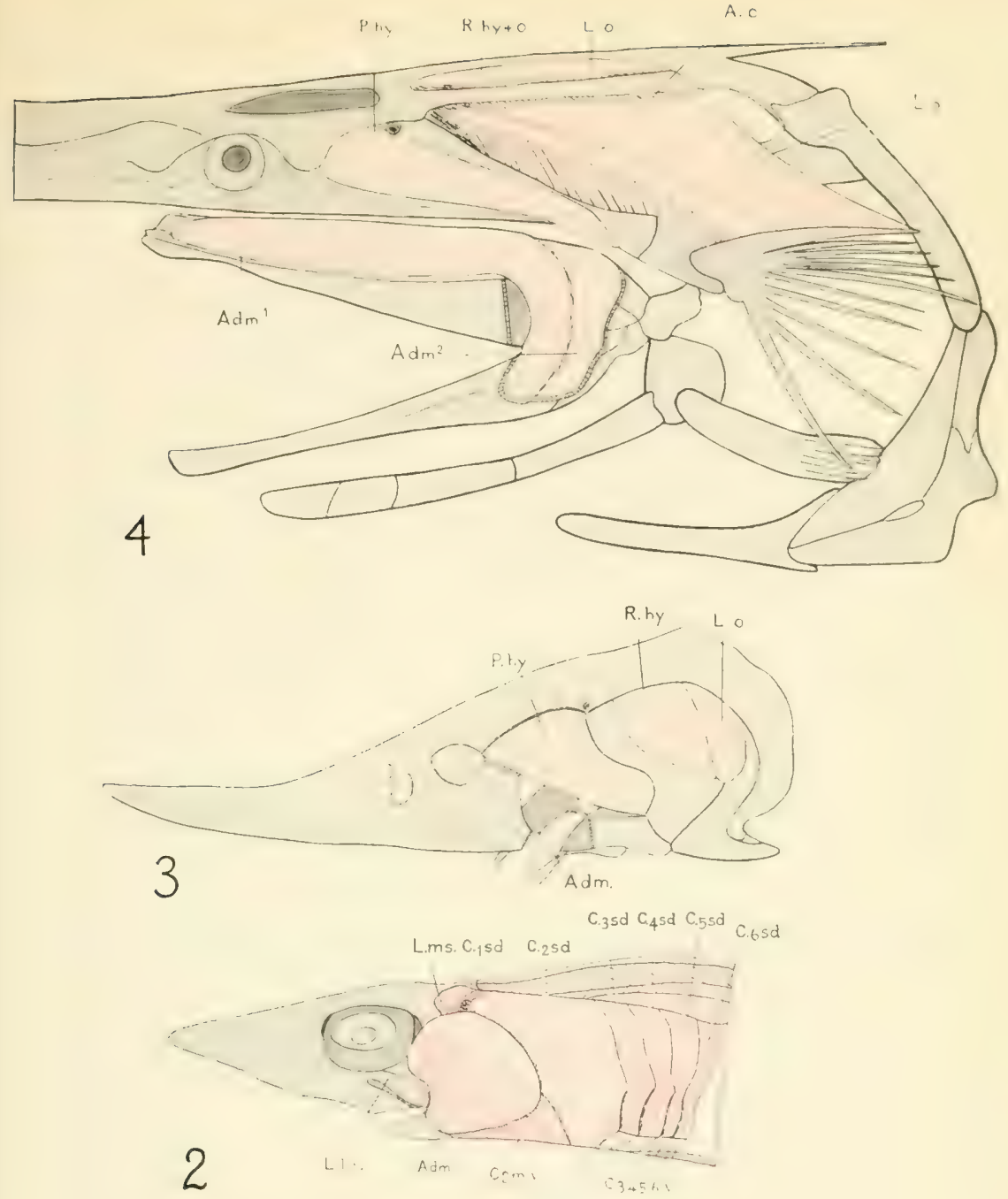

2 



\section{ixplanation of Piate II}

Jaw muscles of Amia and Lepidosteus, representing the Ganoidei Holostei, and of Anguilla, representing the 'Teleostei Apodes

Fros. 1 and 2.-Amia. (Muscles mainly after Allis.)

In the Holostei and Teleostei the adductor mandibulx and levator maxillae superioris of selachians are subdivided into numerous muscles all lying in front of the hyomandibular and innerrated by $\mathrm{V}_{3}$; while the $\mathrm{C}_{2} \mathrm{~s}$. gloup behind the hyomandibular, which is innervated by VIr, includes three muscles (Ad. hy.., A. o., L. o.). The levator areus palatini $\left(L . a_{0} p.\right)$ and the dilator operculi $\left(D\right.$. o. $_{\text {) }}$ belong to the $\mathrm{C}_{\mathrm{r}} \mathrm{sd}$. series and appear to represent the protractor hyomandibularis of the sturgeon (I'l, I, Fig. :3). The lerator maxillac superioris $(L . m . s$.$) includes several slips of which only one is shown. The$ first division of the adductor mandibulie $\left(A d m_{1}\right)$ covers the cheek behind the eye and runs from the preopereulum to the mandible. The fourth division $\left(A d m_{+}\right)$is lodged in the Meckelian fossa of the mandible: The dilator opereuli (D. o.) passes through a groove or depression in the hyomandibular and is inserted by tendon into the operculum.

FIG. 3.-Lepilosteus.

In correlation with the anteroposterior elongation of the head the jaw muscles are nearly horizontal instead of rertical. This oblique insertion gives great speed but low power in the closing of the jaw. The protractor hyomandibularis $\left(P . h y_{0}\right)$, as in Acipenser (Plate I, Fig. 3), runs from behind the eye to the anterior border of the hyomandibular. The second slip of the adductor is now above the eye instead of behind it.

Figs. 4 and 5.-Anguilla sp.

In this peculiar teleost the adductor mandibula is greatly enlarged and has spread out upon the top of the skull after the fashion of the capiti-mandibularis of certain Amphibia. The large dilator $(D, O$.$) and levator operculi$ (L. o.) muscles assist in the strong respiratory movements of the branchial region. 


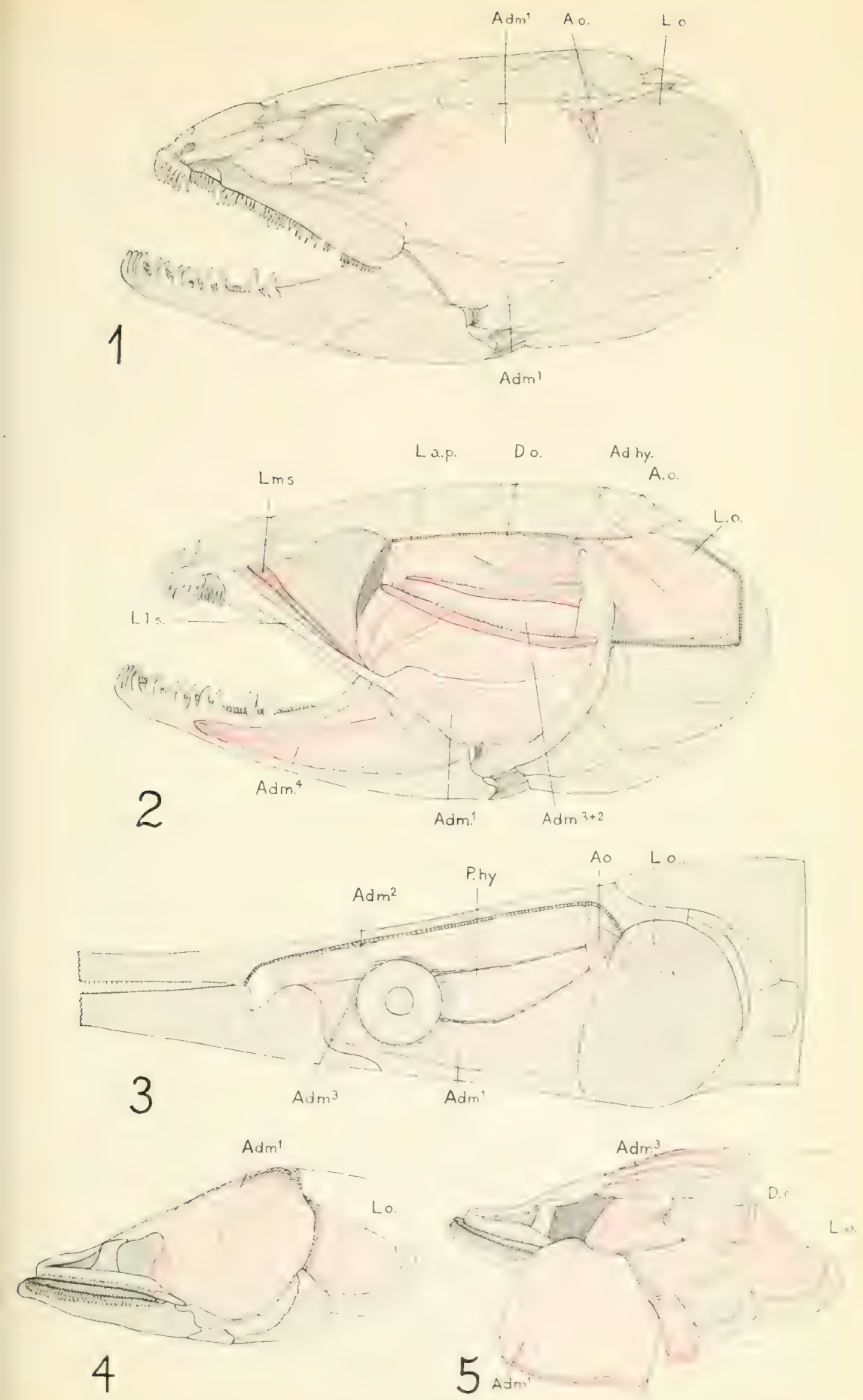

Gxplanation of Piate ill.

Jaw muscles of Esox, representing the Teleostei Haplomi, and of l'alimurichthys, representing the Teleostei Acanthopterygi

Figs. 1 and 2.-Esor. (Muscles mainly after Vetter.)

The superficial muscles are shown in Fig. 1, and the deep muscles in Fig. 2. In this rather primitive teleost the divisions of the adductor are substanially the same as in Amia (Pl. Ir, Figs, 1, 2). The protractor hyomandibularis is either absent or not separate from the levator areus palatini ( $L . a . p$. ). The fourth branch of the adductor fills the Meckelian fossa of the mandible. The dilator operculi $(D .0$.$) passes above the hyomandibular and the pre-$ opereulum in the normal manner.

FIGS. 3-5.-Palinurichthys. (Identification of muscles after Vetter in Perea.)

These are the jaw muscles of a highly evolved teleost. The protractor hyomandibularis $(P, h y$. $)$ is distinct from the well developed levator arcus palatini $\left(L_{0}\left(a_{0}, p.\right)\right.$. The retractor hyomandibularis $\left(R_{0}, h y_{0}\right)$, the levator operculi $(L .0$.$) and the so-ealled trapezins of the pectoral girdle are extended for-$ ward above the orbit, on either side of the sagittal crest. 


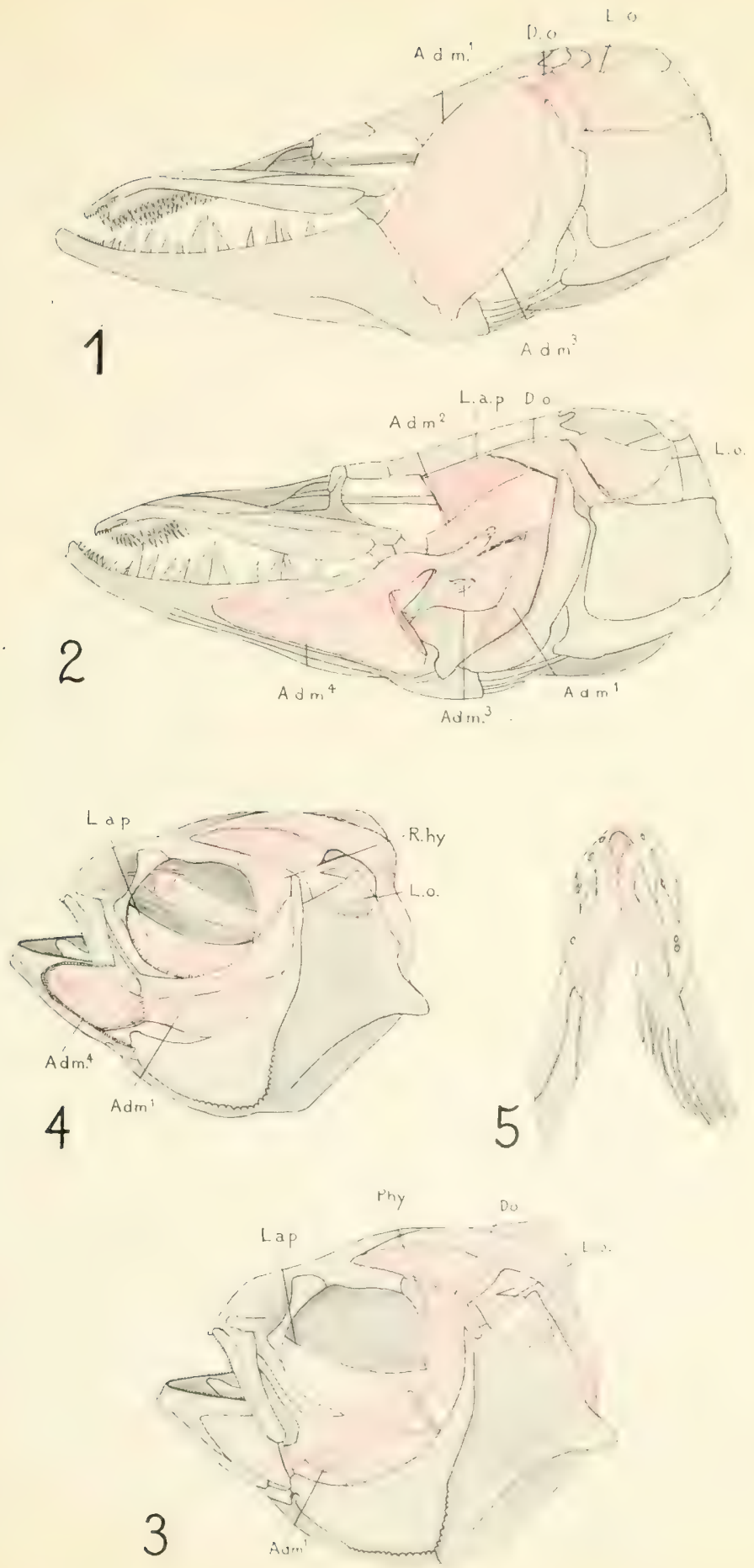

Explanation of Ptate iV

Jaw muscles of Polypterus, representing the Crossopterygii, and of Ncoceratodus, representing the Dipnoi

Frgs. 1 and 2.-Polypterus. (Muscles mainly after Pollard.)

The deep muscles are shown in Fig. 1 , after the removal of the preoperculum, and the superficial muscles in Fig. 2.

The superficial layer of the adductor mandibule ( $\left.A(m)^{1}\right)$ extends from the enlarged hyomandibular to the ascending ramus of the mandible. The deep branches $\left(A d m .^{2}, A d m .^{3}\right)$ run nearly at right angles to the onter branch and arise from the side of the skull. 'This arrangement foreshadews the differentiation of the jaw muscles in amphibians into masseter, temporal and pterygoid branches (Pollard). The levator maxilla superioris (L.m.s.) is closely associated with the protractor hyomandibularis $\left(I^{\prime} . h y.\right)$ as in elasmobranchs. A small slip of the latter muscle runs dorsad to the spiracular ossicle. The dilator operculi $\left(D . o_{\text {. }}\right.$ ) seems to be absent. In Fig. 1 the hyomandibular is seen with the area of origin of the adductor mandibula on its anterior border. The levator operculi $(L . O$.$) is elosely associated with the adductor hyoman-$ dibularis $(A d . h y$.$) .$

Fig. 3.-Neoceratodus. Side view of jaw muscles.

The superficial layer of the atductor is fastened posteriorly to the onerentat region. The middle layer $\left(A d m^{2}\right)$ - runs orer the top of the massive chondrocranium and separates the dermal skull roof from it. This part of the adductor is divided into mumerous small fascieles interspersed with commective tissue.

Fr. 4.-Neoceratodus. Viewed from above. 


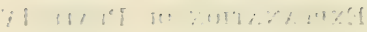

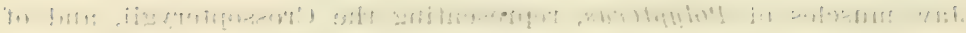

, +1 $1, \ldots 1, \ldots, \ldots .1$

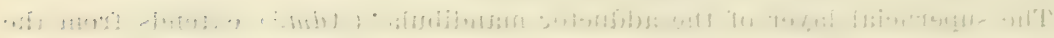

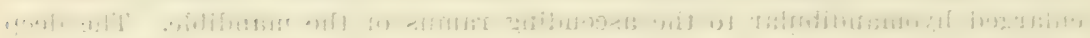

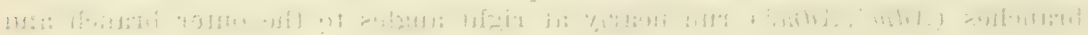

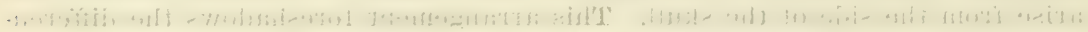
.

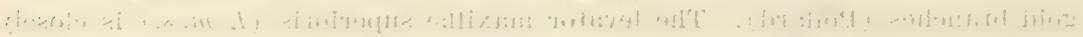

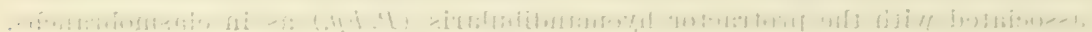

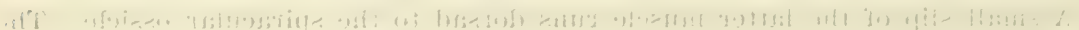

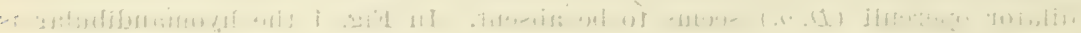

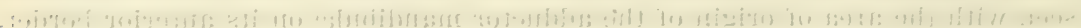
met(m)

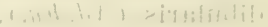

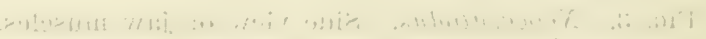

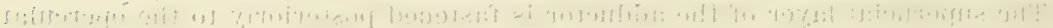

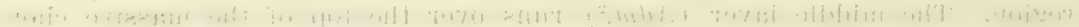

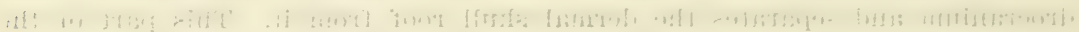

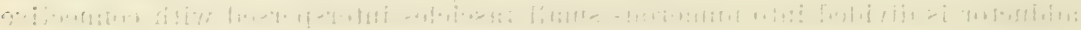



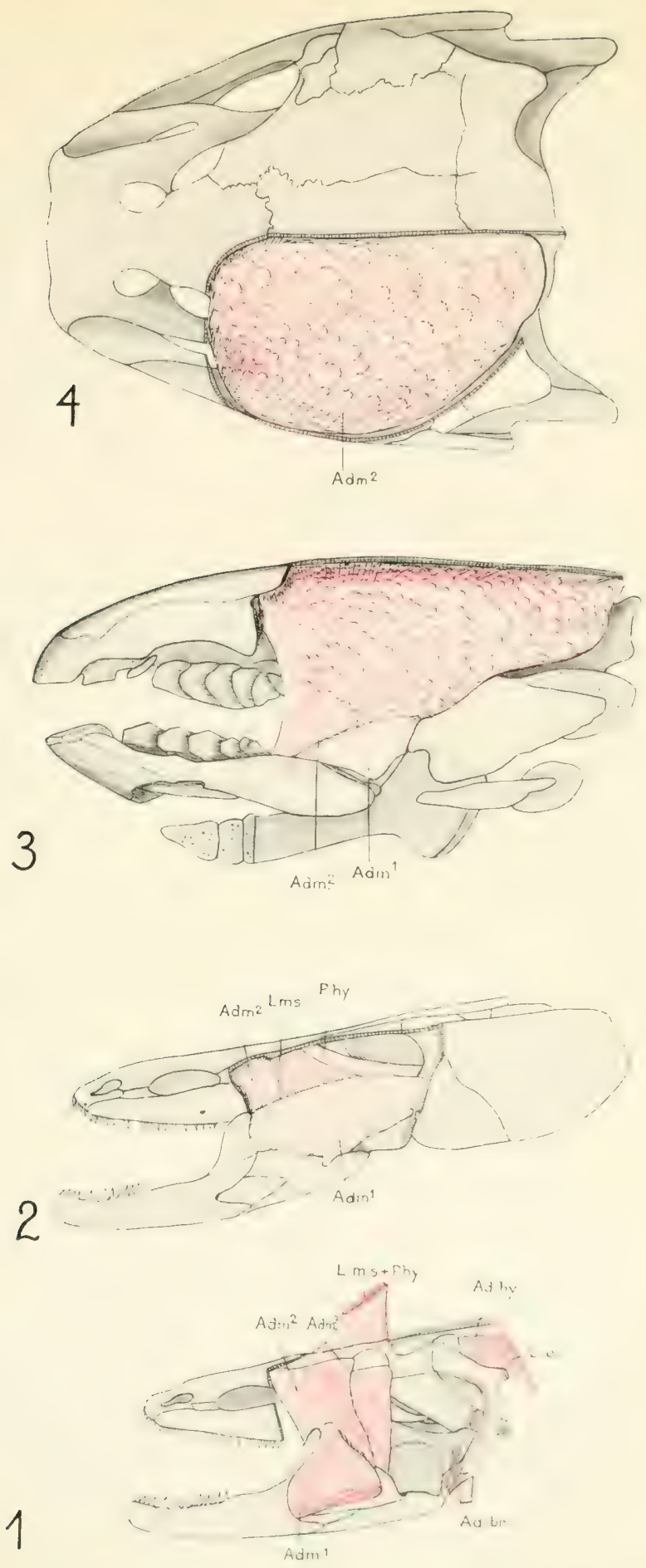

Jaw muscles of Rama, representing the Anura, and of Cryptobranchus japonicus, Amphiuma and Amblystoma, representing the Urodela

In all modern Amphibia, owing to the loss of most of the derm bones covering the occiput and temporal region, the jaw muscles lie immediately beneath the skin and extend above the parietals. The muscles are divided into a preirematic group, in front of the squamosal and quadrate. inmervated by $V_{\ldots}$ and a posttrematic gromp behind the squamosal and quadrate, innervated by VII.

Figs. 1 and 2.-Kana. (Muscles after Ecker and Wiedersheim.)

The superficial muscles after the remoral of the maxilla are shown in Fig. 1, and the deep muscles in Fig. 2.

The adduetor mass of fishes is now represented by the capiti-mandibularis (C. $m$.), which is divided into anterior and posterior slips rumning respectively from the squamosal and quadrate to the mandible. The deep part runs from the under side of the squamusal to the mandible. The pterygoideus anteriol $(l ' t$. $(n t$.$) probably represents the deepest part of the adductor mass. The$ (knessur mandibula $(\mathrm{L} . \mathrm{m}$.) lies entirely behind the otic region and is innervated by the 7 th nerve; it may have heen derived from the retractor hyomandibularis of fish (Pollard).

FIG. 3.-Cryptobranchus japonicus. (Muscles mainly after Humphrey.)

The deep anterior part of the adductor mass of fish is here represented by the much-enlarged pterygoideus anterior, the outer part by the capiti-mandibularis superficialis (c.m.s.), while the levator maxille superioris may be represented by the capiti-mandibularis profundus (c.m.p.) and pterygoideus posterior. The depressor mandibule is divided into two parts, of which the anterior is large.

Hig. 4.-The same seen from above.

FIG. 5.-Amphiuma. (Muscles mainly after Driner.)

Fras. 6 and 7.-Amblystoma. (Muscles mainly after Driner.)

The superficial and middle layers of the jaw muscles are seen in Fig. 6, and the deep muscles after the reflection of the capiti-mandibularis in Fig. $\pi$. 


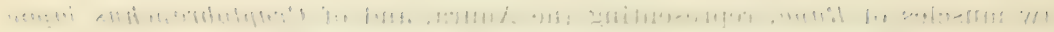

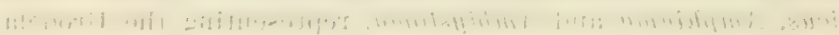

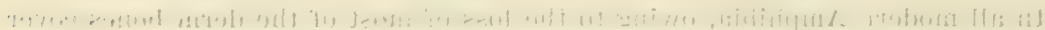

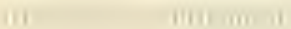

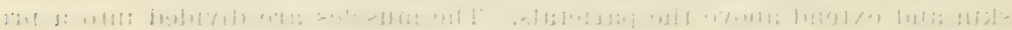

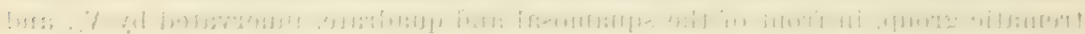

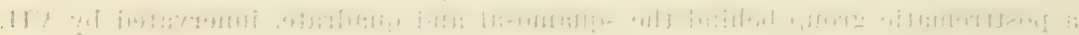

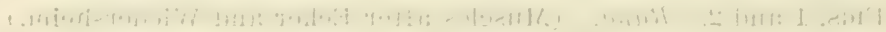

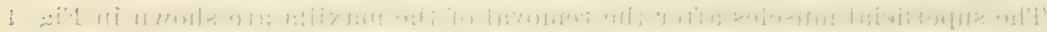

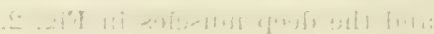

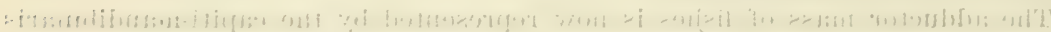

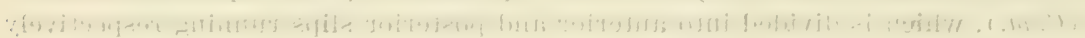

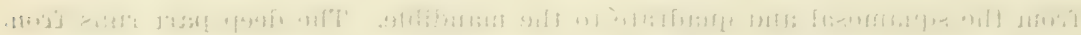

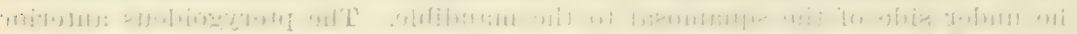

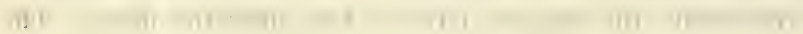

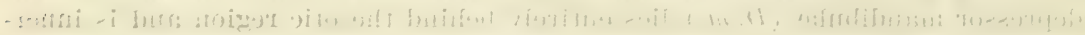

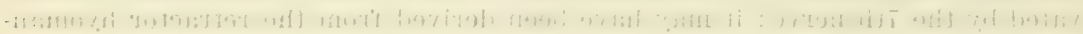

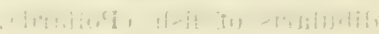

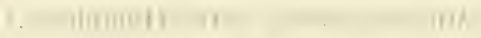

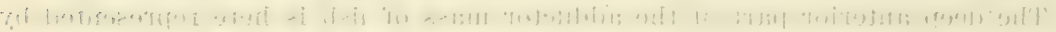

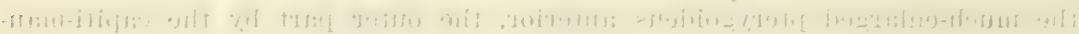

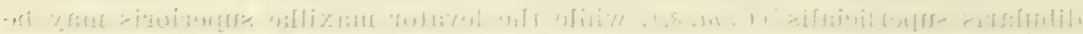

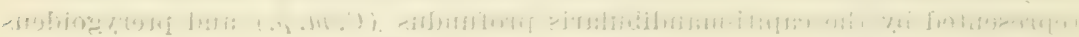

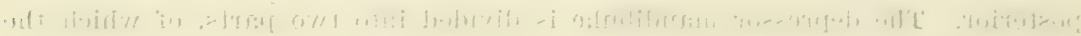

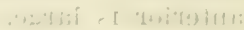

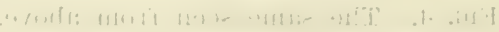

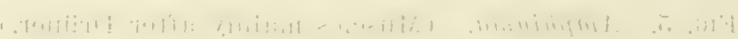

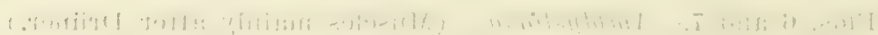

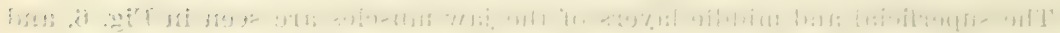

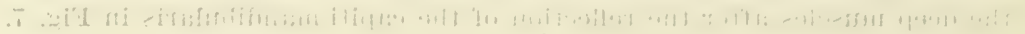



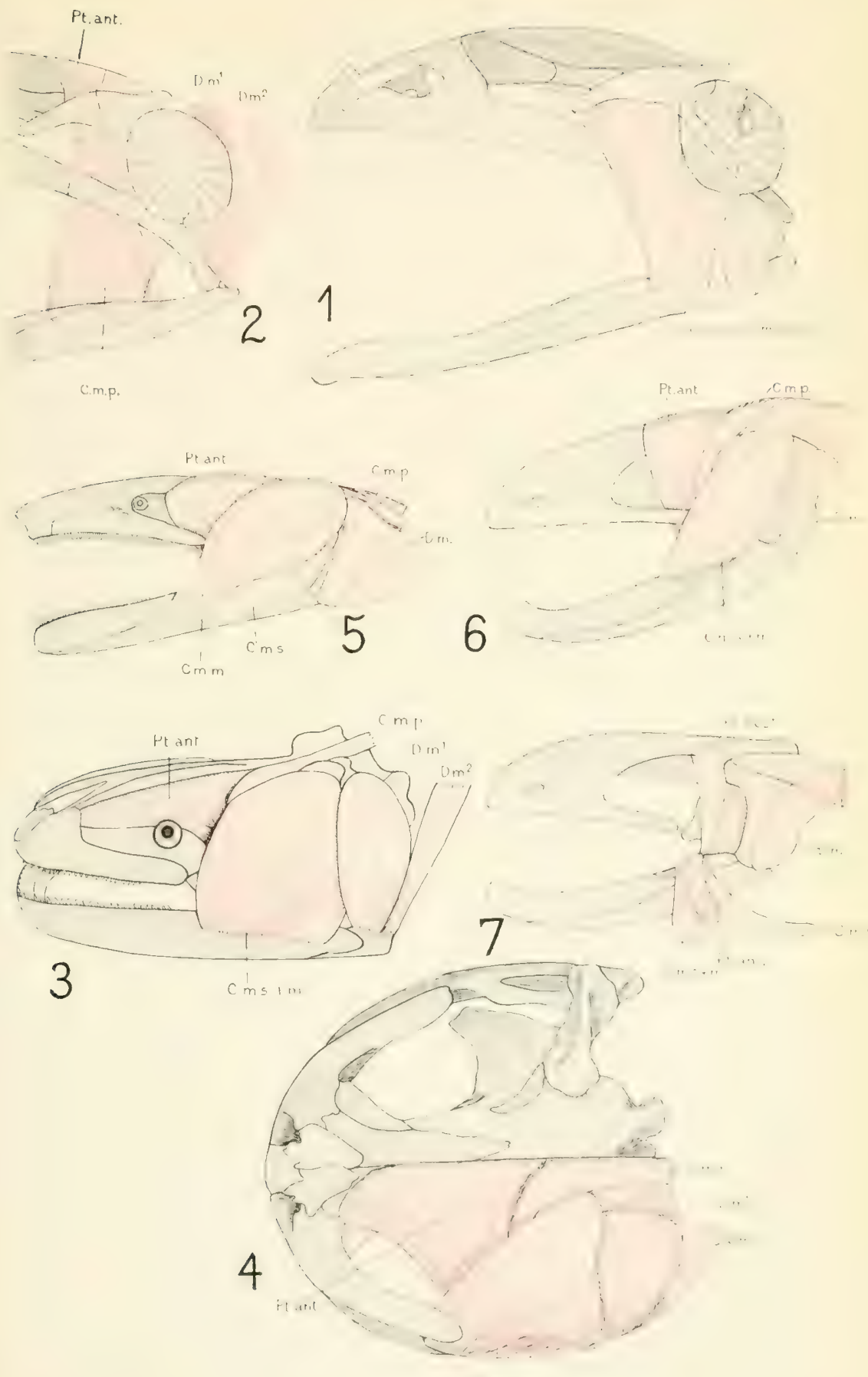

Jaw muscles of monimostylic reptiles: Chelydra, Sphenodon, and Alligator. The pretrematic muscles (innerrated by $V_{3}$ ) are seen in front of the auditory region, the posttrematic muscles (innervated by VII) are seen behind it

\section{Figs. 1 and 2.-Chelydra.}

The deep muscles are shown in Fig. 1, and the superticial in Fig. 2.

The eapiti-mandibularis $(C . m$.) has penetrated the dermal skull roof and after passing through the posttemporal oprening is attacher to the long sagittal (rest. The pterygoideus anterior runs obliquely across the calpiti-mandibularis $(C . m . s . ; C . m . m$.$) . These two muscles coöperate in closing the jaw. The$ depressor mandibule $(1), m$.) arises from the posterior horder of the syuamosal behind the auditory region and is inserted into the posterior process of the mandible. The extreme simplicity of the jaw muscles in the Chelonia is associated with the rigid fixation of the upper jaw.

Figs. : and 4.-Sphenodon. (Mainly after Osawa.)

The superficial muscles are shown in Fig. 3, and the deep muscles in Fig. $t$.

The fibres of the superficial (masseter) layer of the capiti-mandibularis $(C . m . s$.$) cross those of the middle layer nearly at right angles. The middle$ layer $(C . m . m$. ) arises around the borders of the supratemporal fenestra. The lateral temporal fenestra aftords space for the expansion of this muscle. The deep layer $(C . m . p$.$) arises from the lower borders of the supratemporal$ fenestra and from the side of the brain-case in the auditory region. The

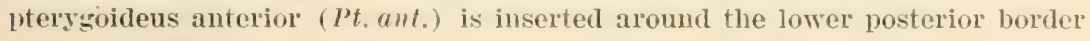
of the mandible.

Figs. is and 6.-Alligator.

The capiti-mandibularis $(C, m . s . ; C, m . m$.$) is inserted into the Meckelian$ fossa of the mandible. The middle slip rums up to the small supratemporal ienestrat. The pterygoideus anterior $(\nu t$. ant.) is extended forward beneath and in front of the orbit. The ptergoideus posterior (Pt.post.) wraps around the posterior end of the mandible. 


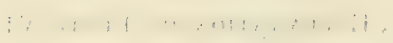

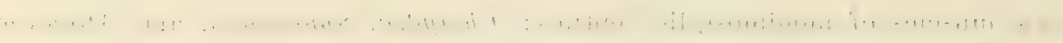

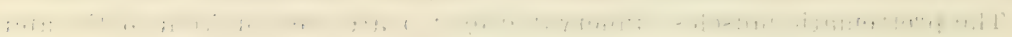

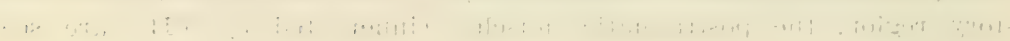
it $b_{1}: i, i, \ldots i$

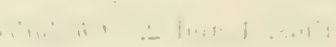

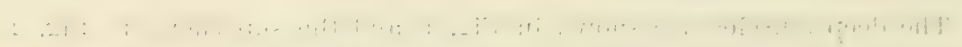

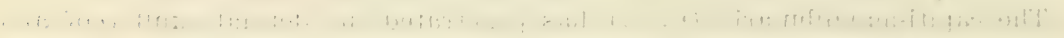

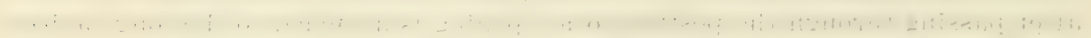

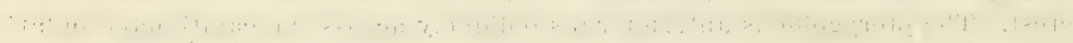

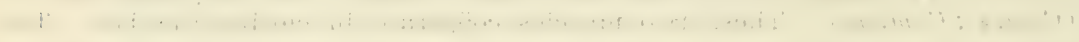

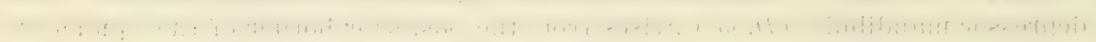

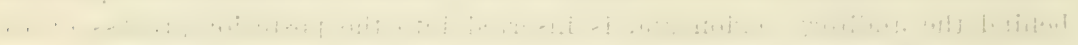

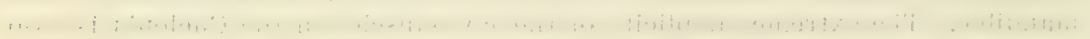

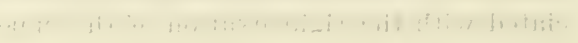

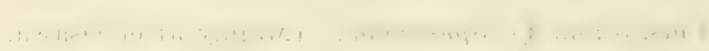

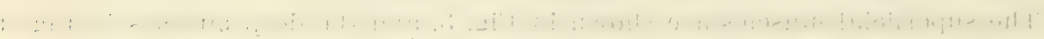

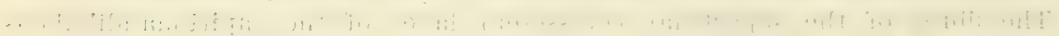

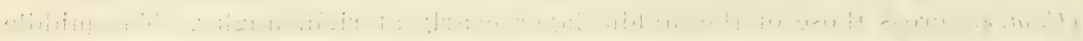

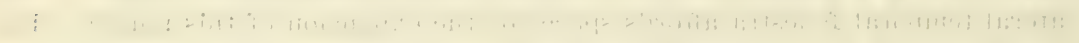

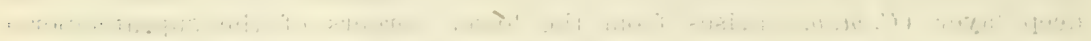

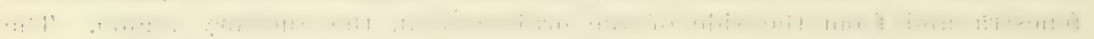

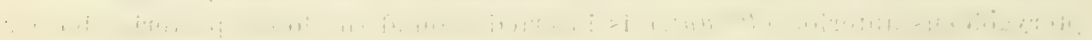
$\therefore+1,+1 ; 1:+1 ! 1 ; \cdots$

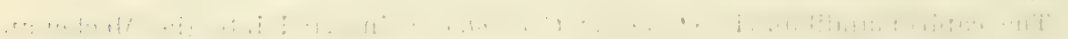

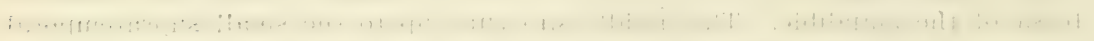

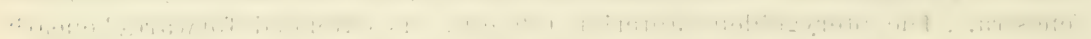

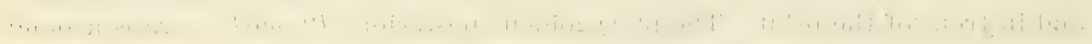

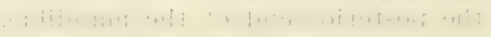



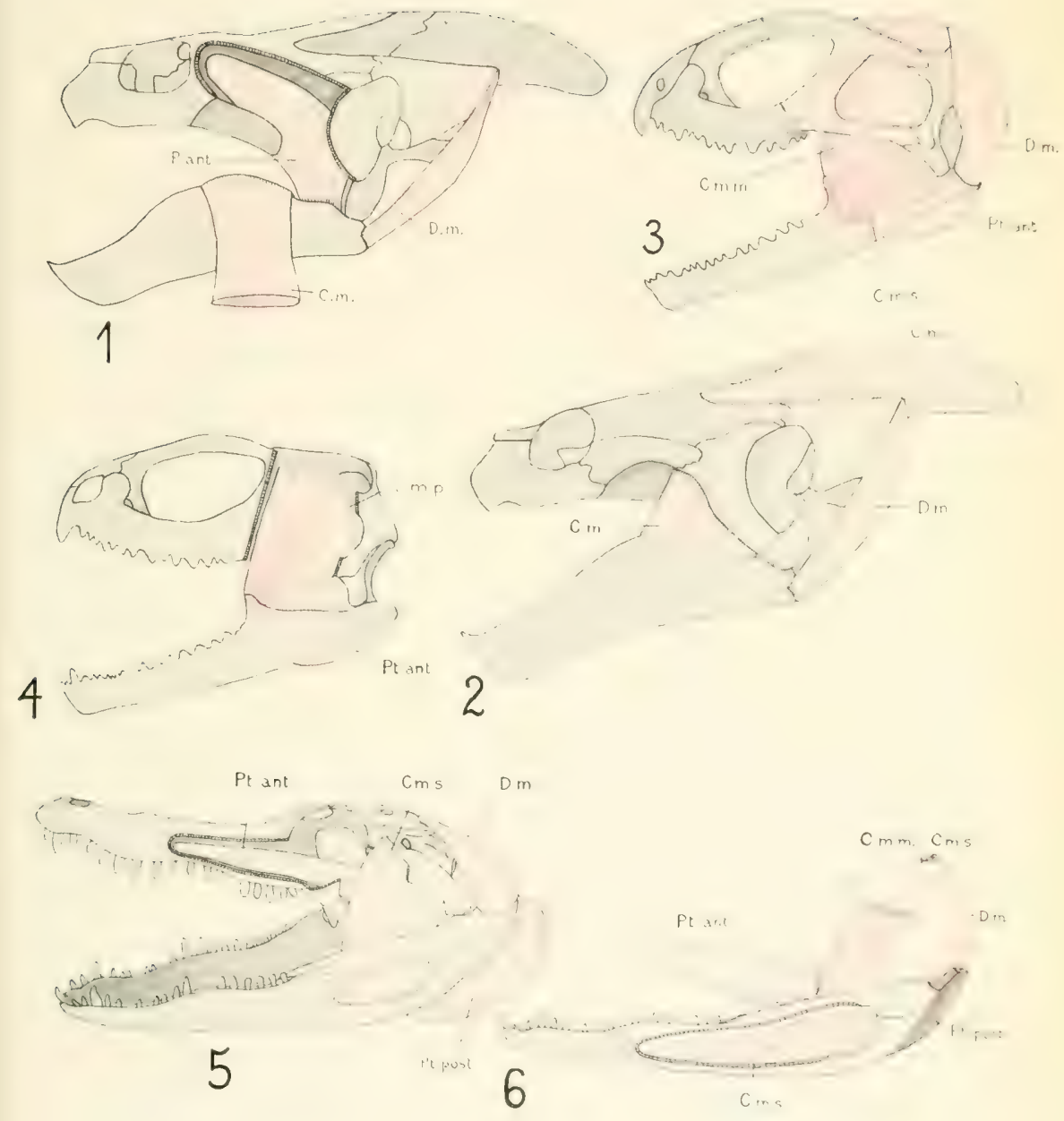

Jaw muscles of streptostylic reptiles: Igumu and Vuranus

Frgs. 1 and 2.-Iguana. (Muscles mainly after Mivart.)

The superficial muscles are shown in Fig. 1, and the deep muscles in Fis. "丷.

The capiti-mandibularis is divided into three layers. which have the same arrangement as in sphenodon. The pterygoideus anterior ( $P$ t.ant.) differs from that of Alligator in being confined to the posterior part of the skull.

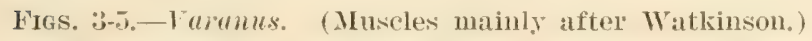

The superficial muscles are shown in Fig. 3 , the middle layers in Fig. 4 , and the deep layers in Fig. 5.

In correlation with the extreme mobility of the jaws the pterygoid muscles are differentiated into four distinct elements, pterygoideus anterior ( $P t_{\text {. }}$ ant.), pterygoideus posterior ( $P^{\prime} t$. post.), pteryo-sphenoidalis (l't.s.), and pterygoparietalis $\left(P^{\prime} t, p u_{0}\right)$. These are probably all derived from the primitive adductor mass and along with the three divisions of the capiti-mandibularis are - imnervated by $V_{s}$. 


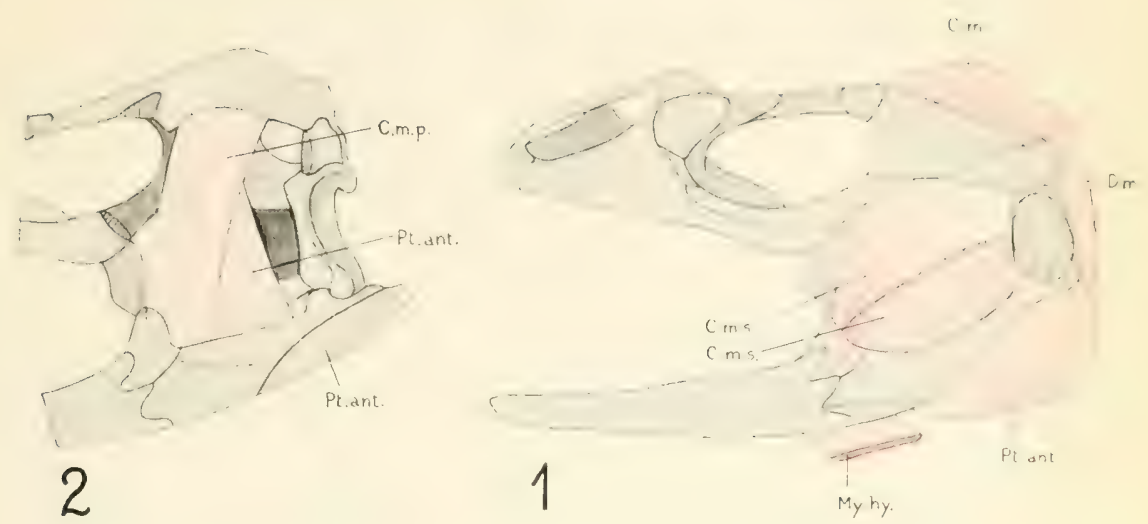

2

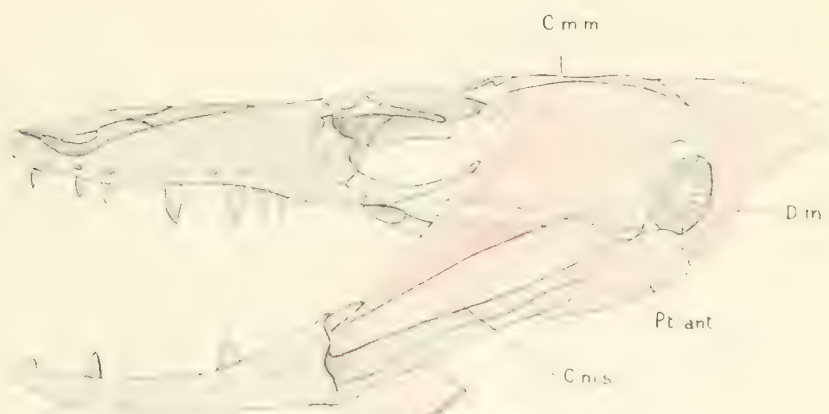

3

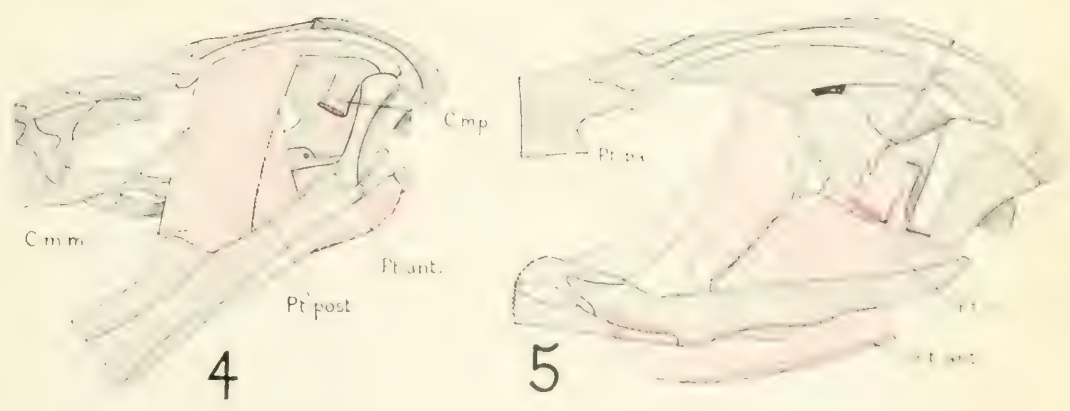



Jaw muscles of at typical birel: Gullus

Fig. 1.-Gallus. Superficial muscles.

The capiti-mandibularis is divided into a superficial layer, analogous with the masseter of mammals, and a deep layer, analogous with the temporalis. The capiti-mandibularis superficialis $(C, m, s$.$) is attached to the quadrate.$

FI $\%, 2,-$ Gallus.

Deep muscles after remoral of the capiti-mandibularis superficialis et medius.

The pteryoideus anterior $\left(P t\right.$. $\left(\omega n t_{\text {. }}\right)$ las the normal reptilian relations. The pterygoideus posterior ( $P t$. post.) perdaus is attached to the quadrate. The depressol mandibulse $(D, m$.) is of normal reptilian type.

FIG 3-Gullus.

Deep muscles as seen from below. The entotympanicus (En.ty.) muscle is a remmant of the adductor mass of lower vertebrates. The parieto-mandibularis $(P(t, m$. $)$ scems to represent a part of the depressor mandibula of reptiles. 


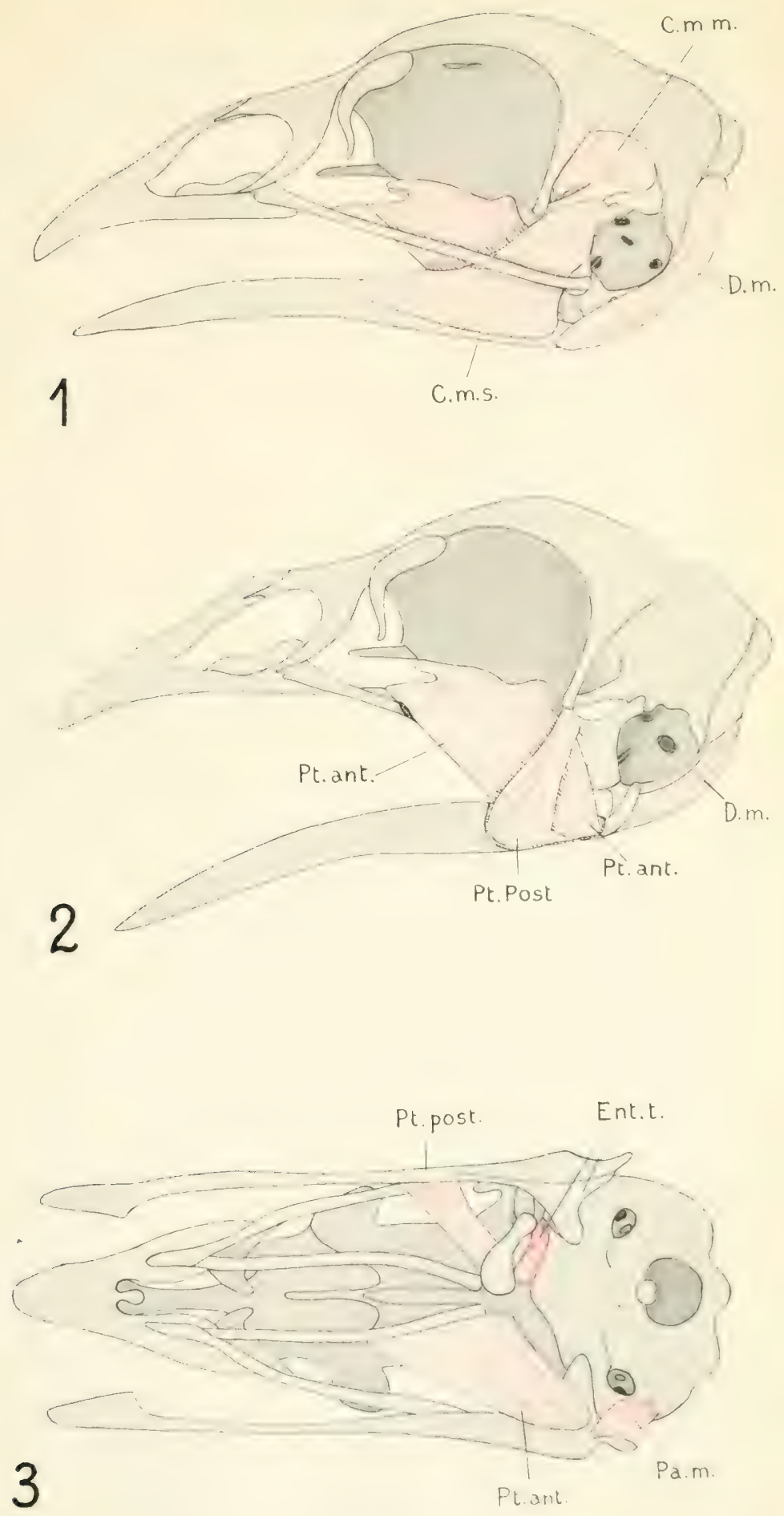

Jaw muscles of monotremes: Ornithorhynchus, Echidne. After schulman

The jaw muscles of monotremes as well as their skulls exhibit peculiar specializations along with certain very ancient characters not found in other mammals.

Fig. 1.-Omithorhynchus. Sumerficial muscles. (Muscles matiuly after Schulman.)

The capiti-mandibularis of reptiles is now represented by the masseter

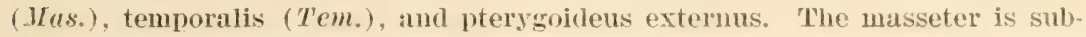
flivided into several muscles of which the detrahens mandibulx (Dot.m.) simulates the depressor mandibule or reptiles, but is imerrated by the mandibular nerve and not by the facialis. The digastric is not present as such.

Fig. 2.-Ornithorhynchus. Deej) muscles. (Muscles mainly after Schulman.)

The anterior end of the temporalis $(T \mathrm{~cm}$.) is attached to a strong ligament running from the postorbital region of the skull to the coronoid process of the mandible. Beneath the zygomatic branch of the masseter the pterygoidens externus (Pt.ext.) is seen.

FIG. :- Ornithorhynchus.

Mandible seen from below, showing the attachments of the jaw muscles.

FIG. 4.-The same seen from abore.

Figs. 5-T.-Echidna. (Aluscles mainly after Schulman.)

In correlation with the edentulous condition and great reduction of the jaws the temporalis (Tem.) and masseter (IIts.) muscles are rather feeble. The arrangement of the muscles, however, is fundamentally the same as in ornithorhynchus. The posterior belly of the digastric of mammals is probably represented by the anterior part of the stylohyoideus (\$\%). imervated by VII, while the anterior belly is probably represented by the detrahens mandibulat anterior $(D . m, a$.$) , which is imnervated by V_{5}$, and is related to the mylohyoid (Parsons). 


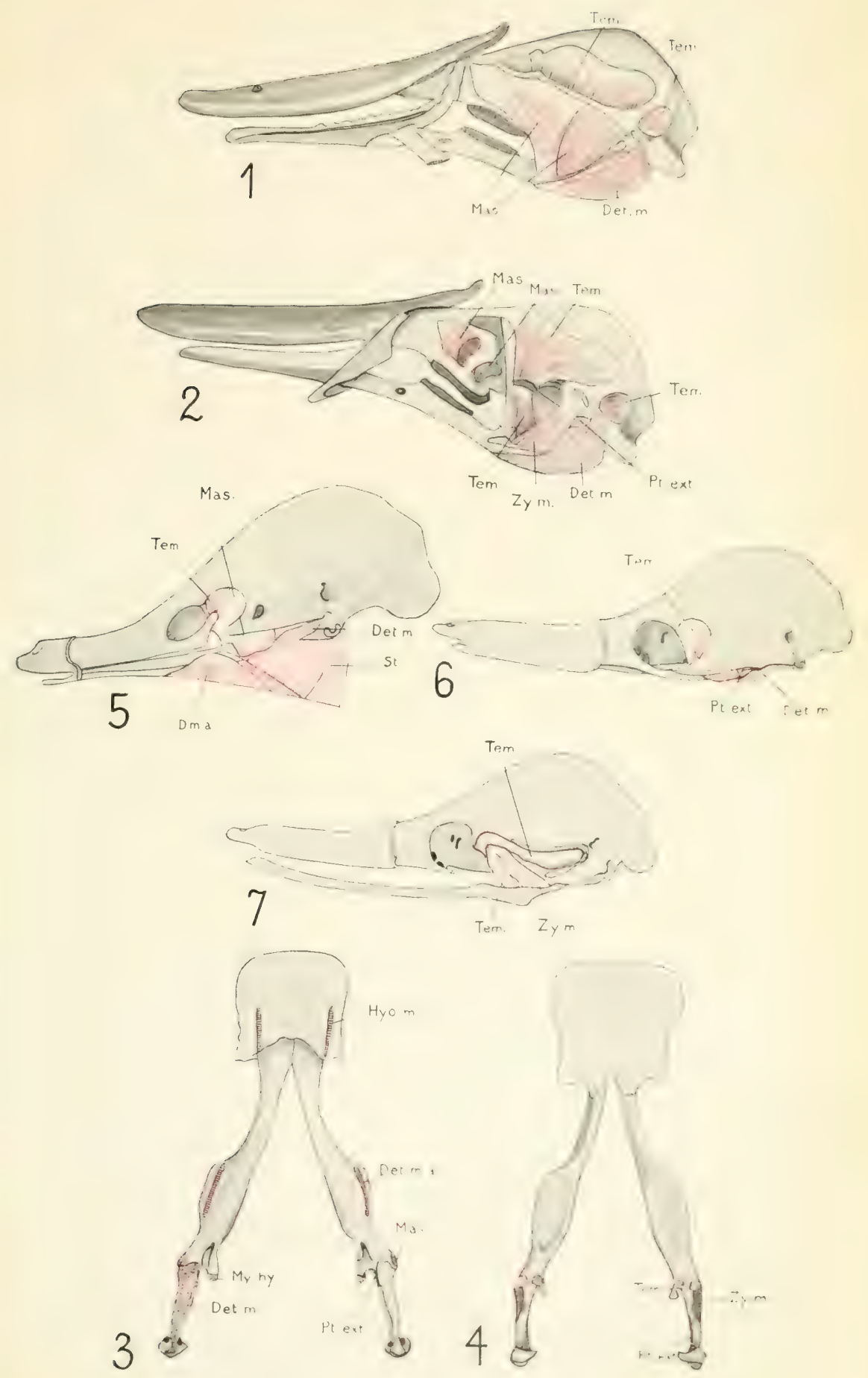

FXPLANATION OF PLATE $\mathbf{X}$

Jatw muscles of typical mammals: Didelphys, Solenodon, II

In mammals the jaw muscles in front of the auditory meatus are derived from the capiti-umdibularis of reptiles and are innervated by the nerve $V_{3}$. The depressor mandibula of the reptiles has disappeared and is functionally reIlacer by the digastric which is originally a compound muscle characteristic of marsupials and placentals. The posterior belly of the digastric (Dig. p.) probably represents a separate slip of the stylohyoideus, both museles being innervated by closely associated branches of the seventh nerve. The anterior belly (Dig. $($.) belongs with the rentral throat museles and is imervated by the mylohyoid branch of $\mathrm{V}_{3}$.

Fra. 1.-Didelphys. Superfieial muscles.

In correlation with the carnirorous habits and orthal jaw motion the tem poralis and masseter are both powerfully developed, while the external pterysoid (Fig. 2) is relatively small. The anterior and posterior bellies of the (ligastric (Dig. a., Dig.p.) are in the normal mammalian position.

FIG. 3.-Solcnodon. Superficial muscles.

The masseter is considerably enlarged and its principal attachment is not on the slender zygomatic arch, but on the masseteric tubercle of the maxillary beneath the orbit. This is often the case in animals with piereing front teeth. The jaw muscles as a whole are of the carnivorous type.

FIs. 4.-Solenodon.

Deep muscles, showing the weak external pterygoid ( $I^{\prime} t$. cxt.).

FIG. 5.-HILs. Superficial museles.

The masseter is extended forwar beneath the zygomatic arch in front of the orbit, crossing the temporalis nearly at a right angle.

Fig. 6.--Mus. Deep muscles.

Frg. 7.-Homo. Superficial muscles.

FIG. 8.-Homo. Deep muscles. 


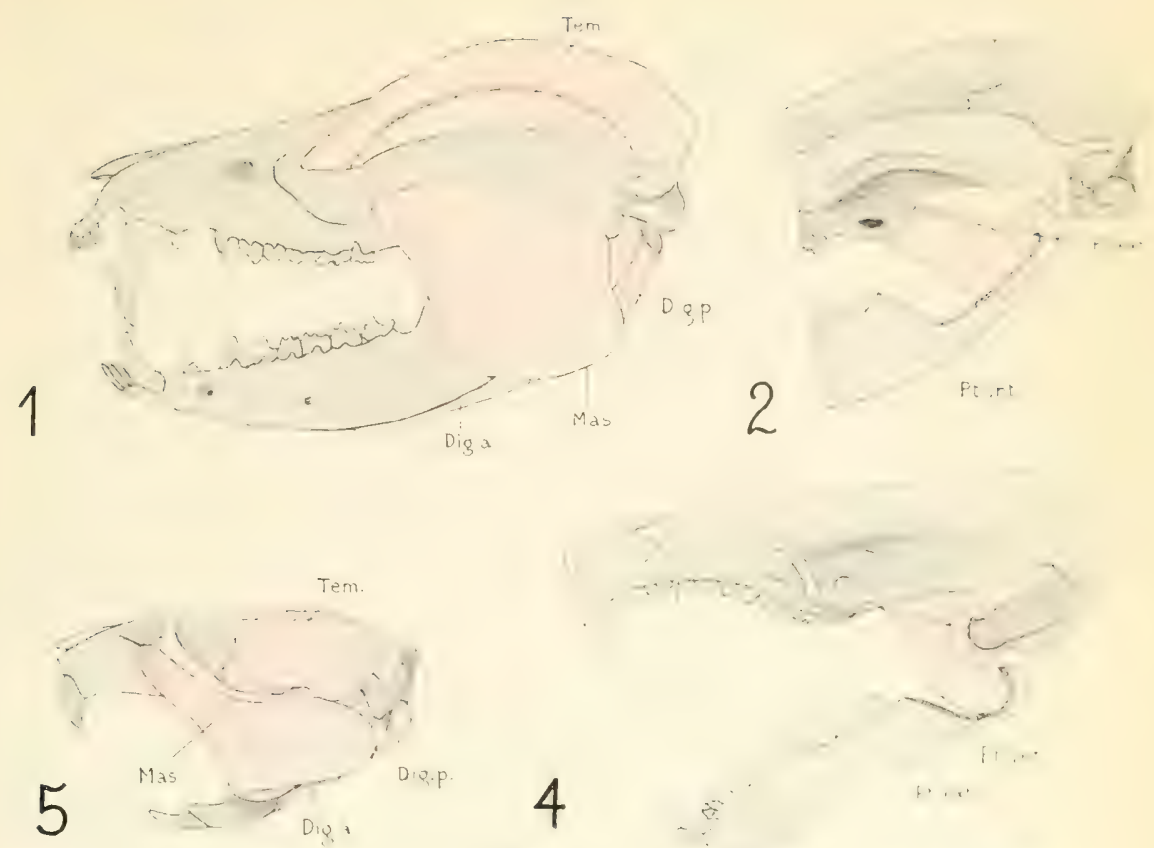

4

Pl ext.

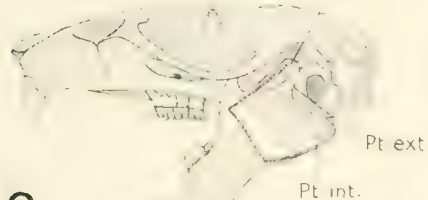

6

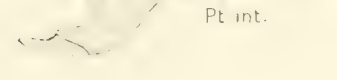

3
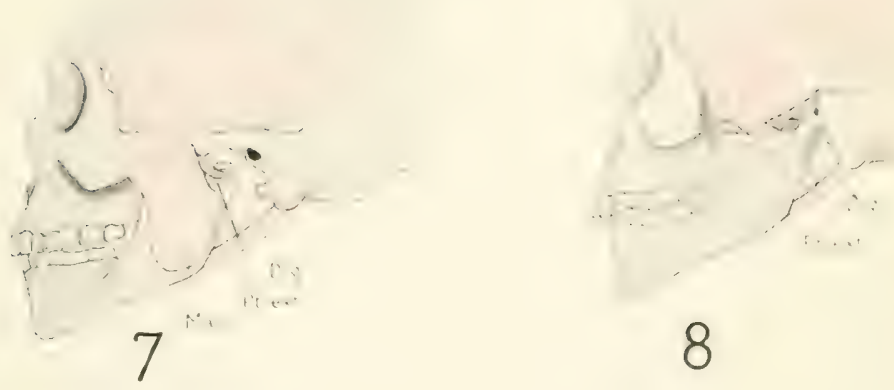

Gxplanation of Plate XI

I'artial reconstruction of the jaw muscles of Dinichthys, representing the Arthrodira

F1G. 1.-Dinichthys.

Jaws closed, depressor capitis ( D. $\left.C_{0}\right)$ contracted, levator capitis $\left(L . c_{0}\right)$ es. tended.

Fig. 2.-Dinichthys.

Jaws open, depressor capitis extended, levator capitis contrated. 



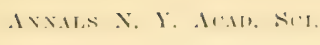

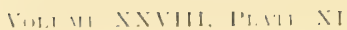

1
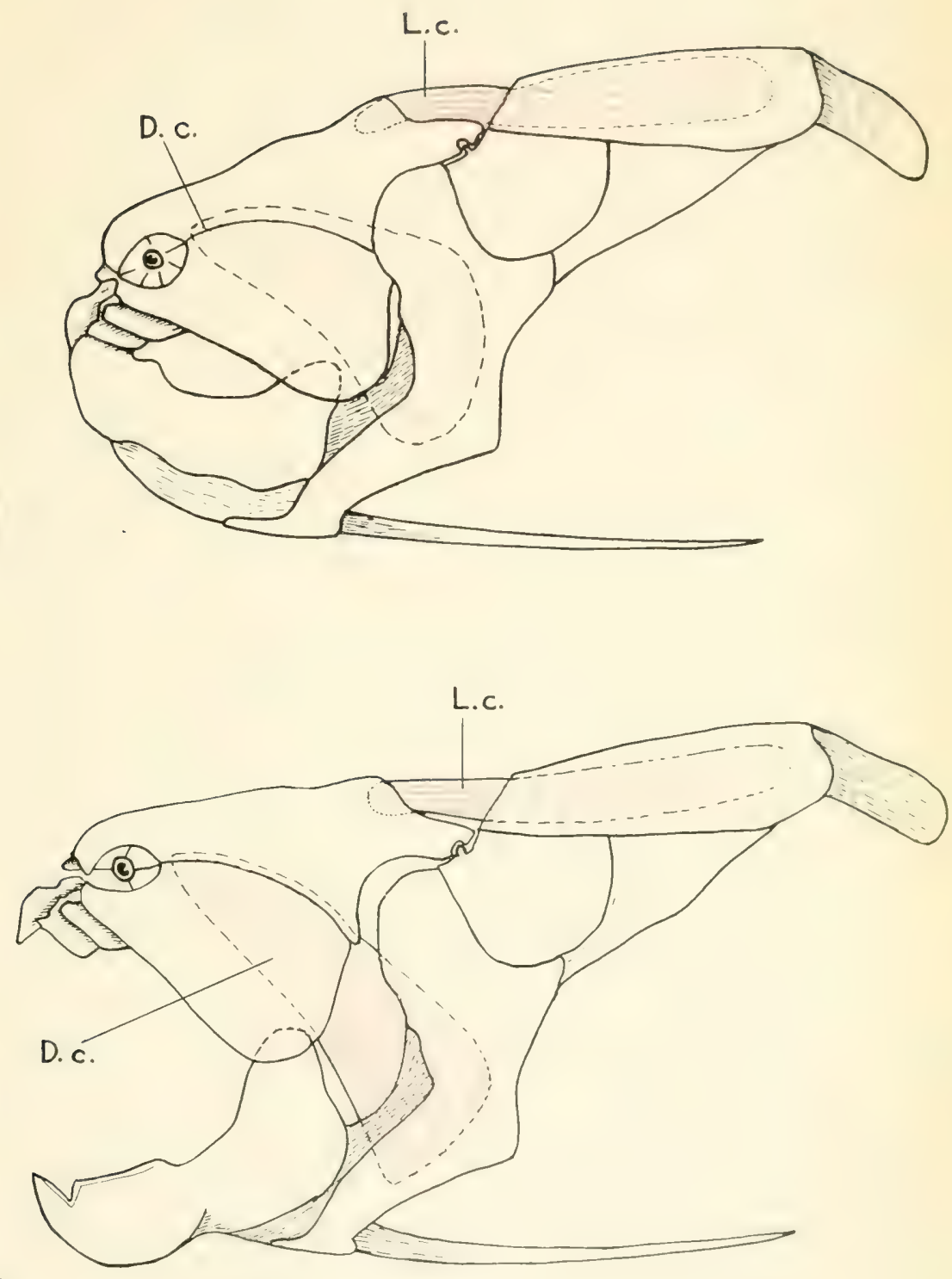

2 



\section{Explanation of Plate NII}

Restoration of the jaw muscles of bryop, representiug the 'Temnospondyli, and of Labidosaurus, representing the Cotylosamia

Fig. 1.-Lryops. Superficial muscles.

Very probably the jaw muscles of this form were fundamentally similar to those of modern amphibians and include suyerficial, middle and deep layer's of the capiti-mandibularis $(G, m$.$) . The pterygoidens anterior \left(P t_{0}\left(u t_{0}\right)\right.$ rery mobably had the normal comse and crossed the capiti-mandibularis on the imner side. The jaw was doubtless depressed by the depressor mandibula (D.m.) lying behind the quadrate.

Fis: 2-4.-Labidosaurus.

As in the Temnospondyli (Fig. 1) the jaw muscles were entirely beneath the dermal skull roof. The capiti-mandibularis was probably differentiated into three layers and was inserted into the Meckelian fossa of the mandible, and the pterggoideus anterior probably crossed heneath these, heing inserted on the hack of the mandible.

$$
\begin{aligned}
& \text { ang. = angular } \\
& \text { art. = articular } \\
& \text { cor. = coronoid }
\end{aligned}
$$

(I. $=$ dentary

pa. = prearticular

sp. = splenial 


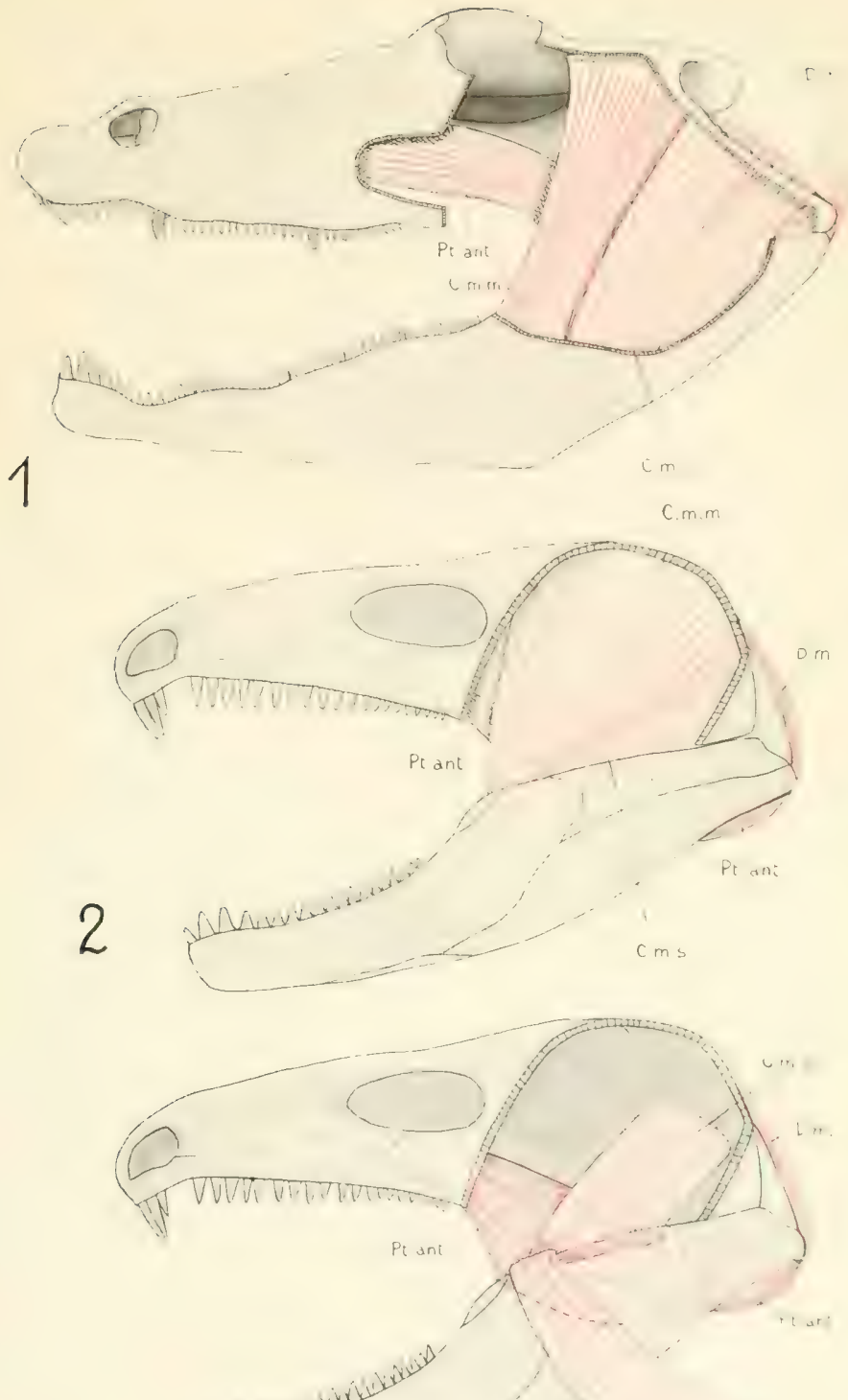

3

4

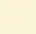





\section{Explaxation of P'LATE XIII}

Restoration of the jaw muscles of Tyramosumbs, representing the Dinosituria Theropoda, and of cynogmathus, representing the Therapsida

FIt. 1.-Tyramosum Superficial muscles.

As in many other reptiles, the capiti-mandibularis $\left(C, m . s_{0}\right)$ was probably differentiated into three layers, the more superficial layer of which $(c . m$. $)$ is allatogous with the masseter of higher types of mammals. 'The supratemporal fenestra was probably filled by the middle and deep layers. The ptergoideus anterior may have filled the space beneath the preorbital fenestra.

Fres. "--5.-Cynogmathus. Jaw museles.

A distant approach to mammalian conditions is seen in the reduction of the posterior jaw elements and in the enlargement of the ascending ramus of the dentary. Very probably the outer layer of the capiti-mandibularis was attached to the lower border of the zyromatic arch in the position of its homologne, the mammalian masseter. The middle and deep layers fill the temporal fossa as in mammals. Cynognathus probably still retained the reptilian pterygoideus anterior which does not appear to be homologous with either of the pterygoid muscles of mammals, but may possibly be represented by the tensor tympani. 'The capiti-mandibularis was in a better position to give rise to these muscles. A true depressor mandibula $(D, m$. $)$ was donbtless present and the general arlangement of the muscles was reptilian in type.
A. $=$ articular (inside)
D. = dentiry
Ang. = angular
P.art. = prearticular
Art. = articular (outside)
sur. a. = surangulat

('r. = coronoid 


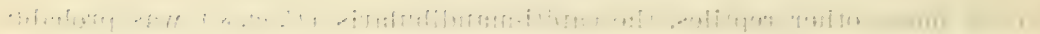

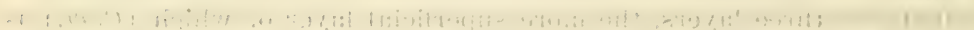

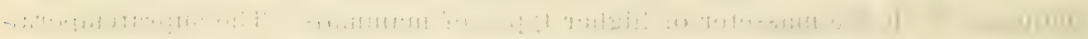

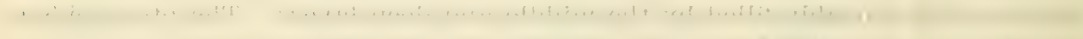

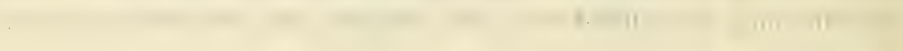

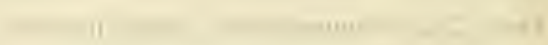

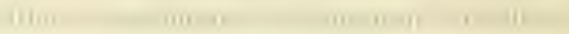

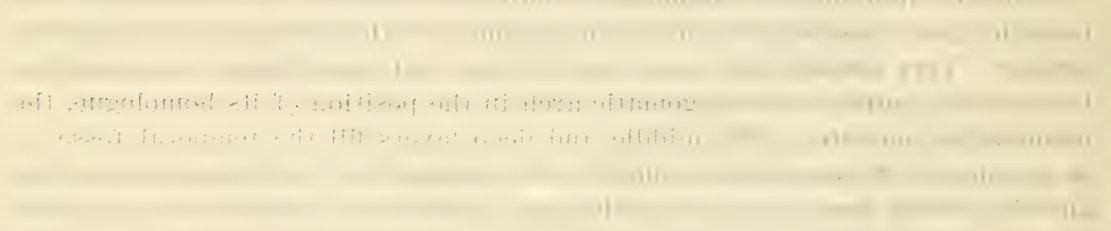

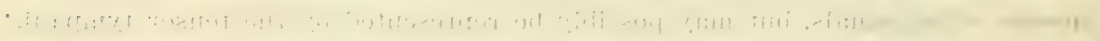

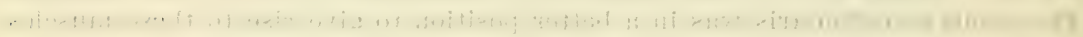

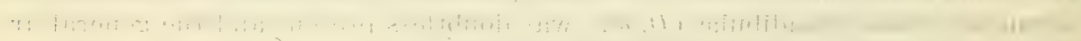
: $7,16, i 1 ;$ it $=.1 i$

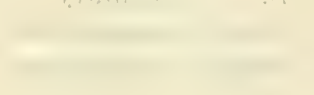



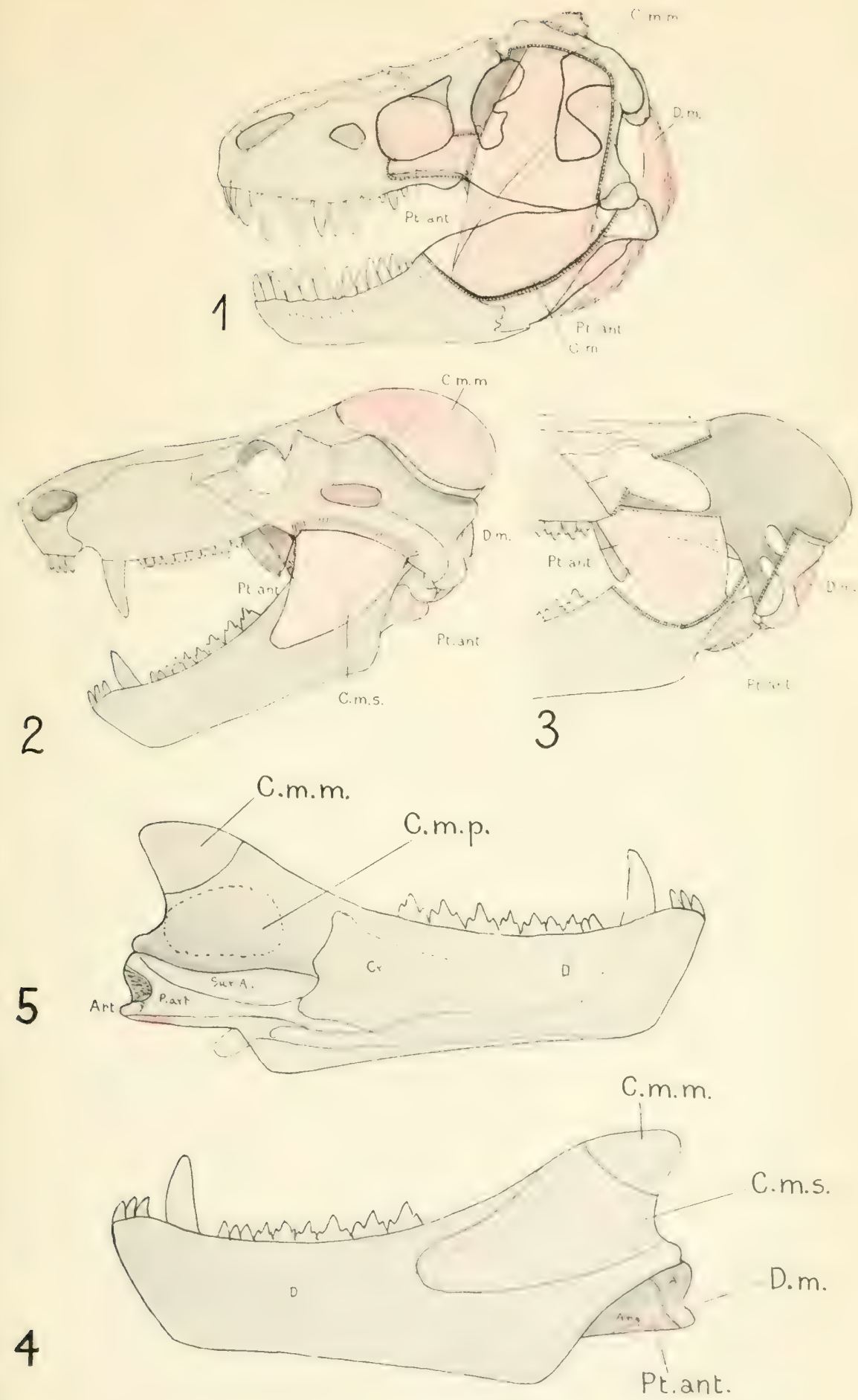



\title{
PUBLICATIONS
}

OF THE

\section{NEW YORK ACADEMY OF SCIENCES}

\author{
(Lyceuar of Natural History, 1817-1876)
}

(1) The Annals (octaro series), estalblished in 1823, contain the scientific contributions and reports of researehes, together with the records of meetings of the Acarlemy. The articles which comprise each rolume are printed separately, each in its orm cover, and are distributed immediately upon pulblication. The price of the separate articles depends upon their length and the number of illustrations, and may be learned upon application to the Librarian of the Academy.

(2) The Memoirs (quarto series), establisherl in 1895, are issued at irregnlar intervals. It is intended that each rolume shall be devoted to monographs relating to some particular department of Science. Tolume I is devoted to Astronomical Memoirs, Volume II to Zoülogical Memoirs, etc. The price is one dollar per part.

These pullications are sent free to Fellows and Active Members. The Amnals are sent to IIonorary and Corresponding Members desiring them.

Subscriptions and inquiries concerning current and back numbers of any of the prublications of the Academy should be addressed to

\section{The Librarian,}

New York Academy of Sciences, care of

American Museum of Natural History, New York, N. Y. 


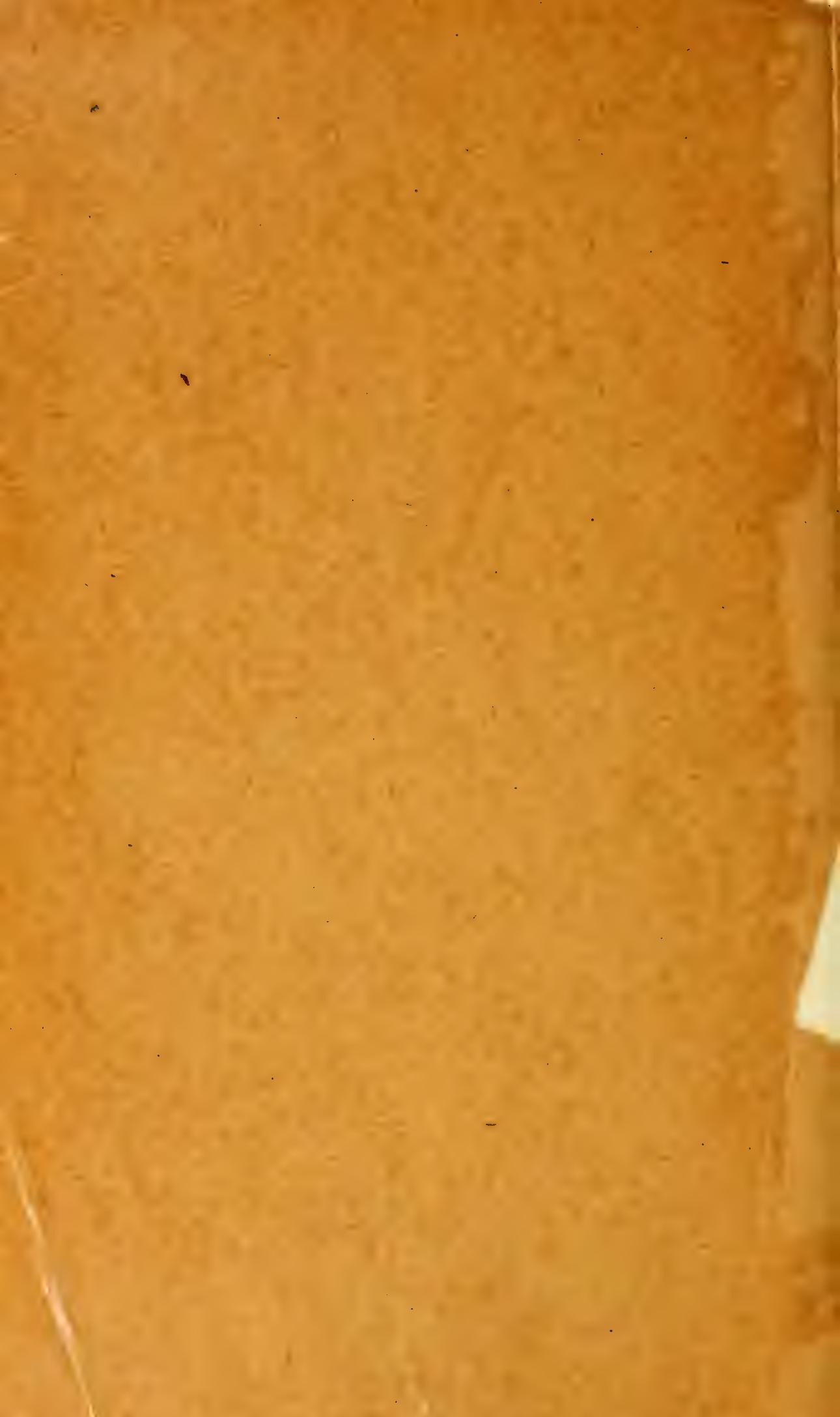





